Universidade de São Paulo Instituto de Física

\title{
Síntese e análise da sílica mesoporosa SBA-15 para incorporação de moléculas
}

\author{
Paulo Ricardo de Abreu Furtado Garcia
}

Orientadora: Prof ${ }^{\mathrm{a}}$. $\mathrm{Dr}^{\mathrm{a}}$. Márcia Carvalho de Abreu Fantini

Dissertação de mestrado apresentada ao Instituto de Física para a obtenção do título de Mestre em Ciências.

Banca Examinadora:

Prof $^{a}$. Dr ${ }^{a}$. Márcia Carvalho de Abreu Fantini (IFUSP)

Prof. Dr. Leandro Ramos Souza Barbosa(IFUSP)

Prof $^{a}$. Dr ${ }^{a}$ Leide Passos Cavalcanti (LNLS)

São Paulo

2015 


\section{FICHA CATALOGRÁFICA}

Preparada pelo Serviço de Biblioteca e Informação do Instituto de Física da Universidade de São Paulo

Garcia, Paulo Ricardo de Abreu Furtado

Síntese e análise da sílica mesoporosa SBA-15 para incorporação de moléculas. São Paulo, 2015.

Dissertação (Mestrado) - Universidade de São Paulo. Instituto de Física - Depto. de Física Aplicada

Orientador: Prof ${ }^{\mathrm{a}} \mathrm{Dr}^{\mathrm{a}}$ Márcia Carvalho de Abreu Fantini

Área de Concentração: Cristalografia

Unitermos: 1. Silício; 2. Proteínas; 3. Adsorção; 4. Adjuvantes Imunológicos.

USP/IF/SBI-027/2015 
À meus pais, Hélio e Luzia, e à minha tia, Elisa. 


\section{Agradecimentos}

Muitas são as pessoas que fizeram parte dessa jornada e que são responsáveis pela realização deste trabalho de forma direta ou indireta. Dentre as quais gostaria de destacar meus agradecimentos:

À meus pais, Luzia e Hélio, e à minha tia Elisa, por todo o incentivo, pela educação que me deram e pelo apoio e suporte incondicional, sobretudo nos momentos difíceis. À Isabella pela paciência, compreensão e por toda ajuda prestada na concepção dessa dissertação.

À minha orientadora, Profa. Márcia Fantini, pela oportunidade, orientação e empenho na elaboração deste trabalho. Ao Prof. Cristiano Oliveira pela incansável disposição em esclarecer dúvidas e auxiliar o nosso trabalho com as proteínas. Ao Dr. Osvaldo A. Sant'Anna pela coodernação do projeto IFUSP-Butantan. Aos Professores Gilberto Francisco de Lima e Marisa, pelas diversas vezes que me incentivaram e orientaram desde o início dessa caminhada.

Aos colegas de sala e à aluna Renata pelo auxílio nas disciplinas e atividades de laboratório e pelas contribuições prestadas a esse trabalho. Aos técnicos de laboratório pela assistência com os experimentos realizados.

À Cristália e UNIEMP pelo suporte financeiro concedido para a realização deste trabalho. 
"Três coisas não podem ser escondidas por muito tempo: o sol, a lua e a verdade." (Sidarta Gautama) 


\section{RESUMO}

GARCIA, P. R. A. F. Síntese e análise da sílica mesoporosa SBA-15 para incorporação de moléculas. 2015. 97 f. Dissertação (Mestrado) - Instituto de Física, Universidade de São Paulo, São Paulo, 2015.

Neste trabalho estudou-se a encapsulação de proteínas com diferentes pesos moleculares na sílica mesoporosa ordenada SBA-15 para avaliar sua aplicação como adjuvante imunológico. Para tanto, as proteínas IgG $(150 \mathrm{kDa})$ e BSA $(66,5 \mathrm{kDa})$ foram incorporadas à sílica mesoporosa com poros expandidos. Primeiramente estudou-se a dilatação dos poros utilizando-se um agente dilatador de estrutura no processo de síntese, através da preparação de amostras com diferentes quantidades de triisopropilbenzeno (TIPB). Resultados de isoterma de adsorção de nitrogênio (NAI) e espalhamento de raios $X$ a baixo ângulo (SAXS) revelaram um aumento no diâmetro médio de poros da ordem de $23 \%$ e uma rede de poros mais desordenada. Para se ter uma estimativa das dimensões das proteínas, medidas de SAXS foram feitas e indicaram que ambas têm dimensões que permitiriam sua incorporação nos poros da SBA-15. As amostras com poros dilatados foram então utilizadas para a incorporação das proteínas IgG e BSA em solução tampão fosfato salina (PBS). Os resultados indicaram o preenchimento dos microporos pela solução de PBS com valor superior a 95\%. Quanto ao preenchimento de mesoporos, observou-se maior variação no volume de poros e área superficial, para o material com maior diâmetro médio de poros, atingindo valores em torno de $80 \%$ e $90 \%$, respectivamente. Não houve diferença significativa nestas porcentagens entre a incorporação das duas proteínas, indicando que as proteínas devem estar encapsuladas na macroporosidade da sílica, obstruindo a entrada dos mesoporos. Um modelo teórico foi utilizado para analisar as medidas de SAXS e ele confirmou o preenchimento dos microporos e a presença da proteína nos mesoporos da sílica. Utilizando a técnica analítica de Particle Induced X-ray Emission (PIXE), o conteúdo de silício em fezes de camundongos isogênicos foi avaliado em função do tempo, com o intuito de analisar a liberação de sílica pelo organismo dos camundongos. Observou-se que após a primeira administração de sílica os camundongos inoculados por via oral liberaram uma quantidade de silício similar à liberada pelos camundongos controle, que receberam apenas a solução de PBS. Após a segunda administração os camundongos inoculados com sílica por via oral liberaram uma quantidade de silício superior à dos camundongos controle, devido à morte dos macrófagos e outras células que atuam na resposta imunológica, evidenciando a eliminação de silício pelo organismo. Um estudo paralelo de controle de qualidade foi realizado em amostras de SBA-15 preparadas pela Cristália Produtos Químicos Farmacêuticos Ltda. a fim de garantir a reprodutibilidade deste material, que será comercialmente utilizado para a formulação de vacina oral contra Hepatite B, produzida pelo Instituto Butantan. Os resultados mostraram propriedades texturais reprodutíveis das amostras produzidas pela Cristália indústria farmacêutica.

Palavras chave: SBA-15, proteínas, poros expandidos, adjuvante. 


\begin{abstract}
GARCIA, P. R. A. F. Synthesis and analysis of SBA-15 mesoporous silica for incorporation of molecules. 2015. $97 \mathrm{f}$. Master thesis - Instituto de Física, Universidade de São Paulo, São Paulo, 2015.

In this work we studied the encapsulation of proteins with different molecular weights into SBA15 ordered mesoporous silica to evaluate its application as immunological adjuvant. Hence, the $\operatorname{lgG}$ protein $(150 \mathrm{kDa})$ and $\mathrm{BSA}(66.5 \mathrm{kDa})$ were incorporated into the mesoporous silica with expanded pores. First we studied the expansion of the pores using a structure swelling agent in the synthesis process, by preparing samples with different amounts of triisopropylbenzene (TiPB). Results of Nitrogen Adsorption Isotherm (NAI) and Small Angle X-Ray Scattering (SAXS) showed an increase in average pore diameter of the order of $23 \%$ and a more disordered pore network. To provide an estimate of the size of proteins, SAXS measurements were performed and indicated that both have dimensions that allow its incorporation in the pores of SBA-15. These samples were used for the incorporation of $\lg G$ and BSA proteins in phosphate buffered saline (PBS) solution. The results indicated a filling of the micropores by PBS solution larger than $95 \%$. Concerning the filling of mesopores, we observed a larger variation in pore volume and surface area for the material with highest average pore diameter, reaching values around $80 \%$ and $90 \%$, respectively. There was no significant difference in these percentages between the incorporation of the two proteins, indicating that the proteins could be encapsulated in the silica macroporosity, blocking the entry of mesopores. A theoretical model was used to analyze the SAXS measurements and it confirmed the filling of micropores and the presence of protein in the silica mesopores. Using the analytical technique "Particle-Induced X-ray Emission"(PIXE), the silicon content in mice feces was evaluated as a function of time, in order to analyze the release of silica from the organism of the mice. We observed that after the first silica administration the isogenic mice inoculated by oral administration released a similar amount of silicon compared with the amount released by the isogenic control mice, which received only PBS solution. After the second oral administration, the mice inoculated with silica released a higher amount of silicon than the control mice, due to the death of macrophages and other cells that act on the immune response, indicating the elimination of silicon by the organism. A parallel study about quality control was performed on SBA-15 samples prepared by Cristália Produtos Químicos Farmacêuticos Ltda., to ensure the reproducibility of this material which will be used commercially for the formulation of an oral vaccine against hepatitis $B$, produced by the Butantan Institute. The results showed reproducible textural properties of the samples produced by the Cristália pharmaceutical industry.
\end{abstract}

Keywords: SBA-15, protein, expanded pores, adjuvant. 


\section{LISTA DE FIGURAS}

1.1 Imagens de microscopia eletrônica de varredura (SEM) e de transmissão (TEM) da sílica mesoporosa ordenada SBA-15 (ZHAO et al., 1998a). . . . . . . . . . . 2

1.2 Representação da sílica mesoporosa ordenada SBA-15. . . . . . . . . . . . . . 2

3.1 Diagrama esquemático da síntese da sílica mesoporosa ordenada SBA-15 com diferentes quantidades do agente dilatador de estrutura TIPB. Para a síntese da amostra P05 foi adicionado 0,5 g de TIPB e para a amostra P2 foi adicionado $2 \mathrm{~g}$. 7

3.2 Diagrama esquemático mostrando a síntese da sílica mesoporosa ordenada SBA-

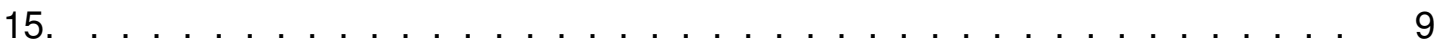

3.3 Molécula do copolímero tribloco Pluronic $\mathrm{P} 123 \ldots \ldots \ldots$

3.4 Ilustração das reações de hidrólise e condensação do TEOS (com $\mathrm{R}=\mathrm{C}_{2} \mathrm{H}_{5}$ ) em água $(H E N C H ;$ WEST, 1990). . . . . . . . . . . . . . . . . . . . 10

4.1 Diagrama esquemático de um experimento de difração de raios $X$ utilizando o método pó. . . . . . . . . . . . . . . . . . . . . . 12

4.2 Ilustração da Lei de Bragg. . . . . . . . . . . . . . . . . . . . . . . . . . . . 13

4.3 Difração em dois objetos com diferentes dimensões. . . . . . . . . . . . . . . . . . 14

4.4 Representação esquemática da seção transversal de um cilindro "core-shell". . . 17

4.5 Curvas de SAXS de uma amostra de SBA-15 e o porta amostras (2 micas). . . . 21

4.6 Os seis tipos de isotermas de adsorção e os quatro tipos de histere (SING, 1985). 24

4.7 Exemplo de um ajuste a pontos dados pela equação 4.23 . . . . . . . . . . . 26

4.8 Exemplo de um gráfico t-plot. . . . . . . . . . . . . . . . . . . . . . . . . 29

4.9 Diagrama de níveis de energia eletrônico com as principais transições $\mathrm{K}$ e L. . . 30

4.10 Figura mostrando uma região do espectro carcacterístico obtido por medidas de PIXE. . . . . . . . . . . . . . . . . . . 32

5.1 Curvas de SAXS de amostras de SBA-15 com poros de diferentes tamanhos. . . 34

5.2 Isotermas de adsorção e distribuição de tamanho de poros de amostras de SBA15 convencional e com poros expandidos. . . . . . . . . . . . . . . 35

5.3 Dados experimentais e curva de ajuste da BSA realizado considerando a amostra como um sistema monodispersa. Curva obtida através do programa Gnom. . . . 36

5.4 Função de distribuição de pares de distâncias da amostra de BSA obtida através do programa Gnom. . . . . . . . . . . . . . . . . . . . .

5.5 Dados experimentais e curva de ajuste da BSA realizado considerando a amostra como um sistema de monômeros e dímeros. Curva obtida através do programa Oligomer. $\chi^{2}=9,88 \ldots \ldots \ldots \ldots \ldots$. . . . . . . . . . . . . .

5.6 Dados experimentais e curva de ajuste da IgG realizado considerando a amostra como um sistema monodisperso. Curva obtida através do programa Gnom. . . . 39

5.7 Função de distribuição de pares de distâncias da amostra de lgG obtida através do programa Gnom. . . . . . . . . . . . . . . . . . . . . . . 
5.8 Representação gráfica do monômero e do dímero da proteína BSA. Realizado no programa Rasmol. . . . . . . . . . . . . . . . . . . . . . . . . 40

5.9 Curvas de SAXS de amostras de SBA-15 convencional, com proteínas e PBS. . 42

5.10 Picos de difração das amostras PO, POB e POH. . . . . . . . . . . . . . . . . 42

5.11 Curvas de SAXS de amostras de SBA-15 com razão P123/TIPB igual a 0,5 . . . 43

5.12 Picos de difração das amostras P05, P05B e P05H. . . . . . . . . . . . . . . 43

5.13 Curvas de SAXS de amostras de SBA-15 com razão TIPB/P123 igual a 2. . . . . 44

5.14 Picos de difração das amostras P2, P2B e P2H. . . . . . . . . . . . . . . . . . 44

5.15 Isotermas de adsorção e distribuição de tamanho de poros de amostras de SBA15 convencional, com proteínas e PBS. . . . . . . . . . . . . . . . . 46

5.16 Isoterma de adsorção e distribuição de tamanho de poros de amostras de SBA-15 com razão em massa P123/TIPB igual a $0,5 \ldots$. . . . . . . . . . . . . . . . . 47

5.17 Isoterma de adsorção e distribuição de tamanho de poros de amostras de SBA-15

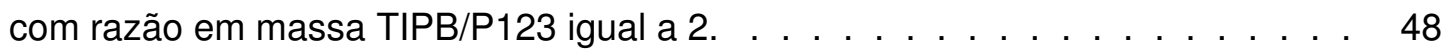

5.18 Dados experimentais e curva de ajuste da amostra P0. $\chi^{2}=4,1 . \quad \ldots$. . . . . 51

5.19 Dados experimentais e curva de ajuste da amostra P0B. $\chi^{2}=9,1 \ldots \ldots$. . . . . 52

5.20 Dados experimentais e curva de ajuste da amostra POH. $\chi^{2}=7,9 \ldots \ldots$. . . . . 52

5.21 Dados experimentais e curva de ajuste da amostra POP. $\chi^{2}=5,2 \ldots \ldots \ldots 3$

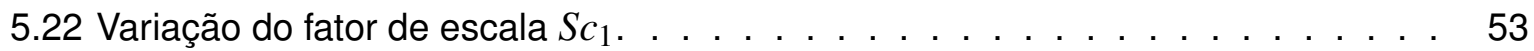

5.23 Variação do fator de escala $S c_{2} \ldots \ldots \ldots \ldots$. . . . . . . . . . . . . . . 54

5.24 Variação do parâmetro $R_{i n} . \ldots \ldots \ldots \ldots \ldots$. . . . . . . . . . . 54

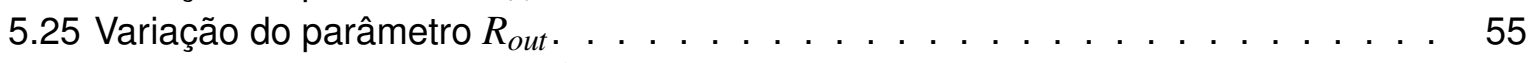

5.26 Variação do parâmetro $\rho_{\text {out }} / \rho_{\text {in }} \ldots \ldots \ldots \ldots \ldots \ldots \ldots$

5.27 Variação do parâmetro $c \ldots \ldots$. . . . . . . . . . . . . . . . . . 56

6.1 Concentração de sílicio em fezes de camundongo que receberam SBA-15. . . . 58

7.1 Curvas de SAXS de amostras de SBA-15 do controle de qualidade da Cristália. . 62

7.2 Gráficos de NAl da amostra de SBA-15 Lote 28/10 . . . . . . . . . . . . . . . . 63

7.3 Gráficos de NAI da amostra de SBA-15 Lote 30/10 . . . . . . . . . . . . . . . . 64

7.4 Gráficos de NAl da amostra de SBA-15 Lote 04/11 . . . . . . . . . . . . . . . . 65

7.5 Gráficos de NAl da amostra de SBA-15 Lote 0082/14. . . . . . . . . . . . . . . 66

7.6 Gráficos de NAl da amostra de SBA-15 Lote 0211/14 . . . . . . . . . . . . . . 67

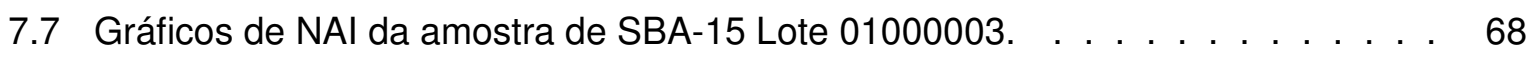

7.8 Gráficos de NAI da amostra de SBA-15 Lote 0244/14 . . . . . . . . . . . . . . 69

7.9 Gráficos de NAl da amostra de SBA-15 Lote 0281/12. . . . . . . . . . . . . . . 70

A.1 Vetor espalhamento $(\vec{q})$, vetor de onda do feixe incidente $\left(\overrightarrow{s_{0}}\right)$ e do feixe espaIhado $(\vec{s}) \ldots \ldots \ldots \ldots \ldots$

B.1 Ilustração do processo de adsorção multicamadas. . . . . . . . . . . . . . . . . 91

C.1 Diagrama esquemático do processo de dessorção em um poro (BARRETT; JOYNER; HALENDA, 1951). . . . . . . . . . . . . . . . . . . . . . . . . . 94

D.1 Diagrama esquemático de um experimento de PIXE. . . . . . . . . . . . . . . . . 95 


\section{LISTA DE TABELAS}

3.1 Preparação do PBS. . . . . . . . . . . . . . . . . . . . . . . .

3.2 Amostras de SBA-15 com poros expandidos e proteínas encapsuladas utilizadas nesse trabalho. Além das amostras ilustradas aqui há também a amostra com PBS (POP) . . . . . . . . . . . . . . . . . . . . . . .

4.1 Parâmetros integrantes do modelo teórico (equação 4.10) . . . . . . . . . . . . 19

5.1 Razões entre os as posições dos picos de difração no espaço recíproco. . . . . .

5.2 Dados de SAXS e NAI de amostras de SBA-15 convencional e com poros expandidos. Os erros no cálculo dos parâmetros de rede e das áreas específicas BET devidos aos ajustes foram iguais ou inferiores a $0,5 \%$. Aqui $V_{t}$ é o volume total de poros, $V_{m}$ é o volume de microporos, $A_{B E T}$ é a área superficial específica BET, $A_{m}$ é a área superficial específica de microporos, $D_{p}$ é o diâmetro médio de poros e $a$ é o parâmetro de rede. . . . . . . . . . . . . . . . . . . . . .

5.3 Massa molecular, fração de volume ocupado e dimensões dos monômeros e dímeros da amostra de BSA . . . . . . . . . . . . . . . . . . . . 38

5.4 Áreas integradas dos picos de difração. . . . . . . . . . . . . . . . . . . . . 45

5.5 Dados de SAXS e NAI de amostras de SBA-15 convencional e com poros expandidos com proteínas. Os erros nos cálculos dos parâmetros de rede e das áreas especíicas BET devidos aos ajustes foram iguais ou inferiores a 0,5\%.Aqui $V_{t}$ é o volume total de poros, $V_{m}$ é o volume de microporos, $A_{B E T}$ é a área superficial específica BET, $A_{m}$ é a área superficial específica de microporos, $D_{p}$ é o diâmetro médio de poros e $a$ é o parâmetro de rede. . . . . . . . . . . . . . .

5.6 Variação percentual do volume total de poros e área superficial específica BET devido à incorporação das proteínas.

5.7 Tabela com os valores dos parâmetros que variaram durante o ajuste realizado. O parâmetro $\chi^{2}$ é o qui quadrado reduzido e é uma estimativa da qualidade do ajuste.

5.8 Parâmetros que foram mantidos fixos durante o ajuste. . . . . . . . . . . . . 50

6.1 Grupos de camundongos utilizados . . . . . . . . . . . . . . . . . . . .

6.2 Concentração de sílicio das amostras de fezes de camundongo. As incertezas devidas aos ajustes da função Gaussiana para a determinação do número de contagens do elemento no espectro foram iguais ou menores que $1 \%$. . . . . .

7.1 Dados do controle de qualidade realizado em diferentes amostras de SBA-15. . . 61

7.2 Dados do controle de qualidade realizado em diferentes amostras de SBA-15. . . 61

A.1 Razões entre as posições dos picos de difração no espaço recíproco de uma rede hexagonal de acordo com equação A.10 . . . . . . . . . . . . . . . . . 89

A.2 Valores de $q$ referentes aos picos de difração das amostras P0, P05 e P2 em $\AA^{-1}$. 89 


\section{LISTA DE ABREVIATURAS E SIGLAS}

\begin{tabular}{|c|c|}
\hline Anvisa & Agência Nacional de Vigilância Sanitária \\
\hline BET & Brunauer-Emmett-Teller \\
\hline BJH & Barrett-Joyner-Halenda \\
\hline BSA & Bovine Serum Albumin \\
\hline $\mathrm{HCl}$ & Ácido Clorídrico \\
\hline HGG & Human Gamma Globulin \\
\hline IFA & Incomplete Freund's Adjuvant \\
\hline IFT & Indirect Fourier Transform \\
\hline IFUSP & Instituto de Física da Universidade de São Paulo \\
\hline $\lg G$ & Imunoglobulina G \\
\hline IUPAC & International Union of Pure and Applied Chemistry \\
\hline LAMFI-USP & Laboratótio de Materiais e Feixes lônicos da Universidade de São Paulo \\
\hline LCT & Liquid Crystal Tamplate \\
\hline MCM-41 & Mobil Composition of Matter-41 \\
\hline NAI & Nitrogen Adsorption Isotherms \\
\hline PBS & Phosphate-Buffered Saline \\
\hline PEO & Poly(Ethylene-Oxide) \\
\hline PIXE & Particle Induced X-Ray Emission \\
\hline PPO & Poly(Propylene-Oxide) \\
\hline PSD & Pore Size Distribution \\
\hline SAS & Small Angle Scattering \\
\hline SAXS & Small Angle X-ray Scattering \\
\hline SBA-15 & Santa Barbara Amorphous-15 \\
\hline SEM & Scanning Electron Microscopy \\
\hline
\end{tabular}


Thickness Plot

TEM

Transmission Electron Microscopy

TEOS Tetraetilortosilicato

TIPB 1,3,5-Triisopropilbenzeno

TMB 1,3,5-Trimetilbenzeno

TMOS Tetrametilortosilicato 


\section{SUMÁRIO}

1 INTRODUÇÃO

1.1 A sílica mesoporosa ordenada SBA-15 . . . . . . . . . . . . . . . . 1

1.2 SBA-15 como adjuvante imunológico . . . . . . . . . . . . . 4

2 OBJETIVOS 5

3 SÍNTESE DA SBA-15 7

3.1 Incorporação das proteínas . . . . . . . . . . . . . . . . . . 7

3.2 Mecanismo de formação da SBA-15 . . . . . . . . . . . . . . 9

4 TÉCNICAS EXPERIMENTAIS

4.1 Espalhamento e difração de raios $X \ldots \ldots \ldots$. . . . . . . . . . . . . 11

$4.1 .1 \quad$ A Lei de Bragg . . . . . . . . . . . . . . . . . . . . . . . . . . . . . 12

4.1.2 Espalhamento de raios $X$ a baixo ângulo (SAXS) . . . . . . . . . . . . 13

4.1.3 Vetor espalhamento e a determinação do parâmetro de rede . . . . . . . 14

4.1.4 Função de distibuição de pares de distância . . . . . . . . . . . . . . . . . 15

4.1.5 Modelagem de dados de SAXS de amostras de SBA-15 . . . . . . . . . 16

4.1.6 Arranjo experimental, tratamento dos dados e metodologia . . . . . . . . 19

4.2 Isotermas de Adsorção de Nitrogênio . . . . . . . . . . . . . . . . . . . . . 22

4.2.1 Área superfícial especifica BET . . . . . . . . . . . . . . . . . . . . 25

4.2.2 Volume específico e distribuição de diâmetro de poro . . . . . . . . . . . . 26

4.2.3 Volume específico e área superficial específica de microporos . . . . . . 28

4.2 .4 Aparato experimental . . . . . . . . . . . . . . . . . . . . . . . . . . . . . 29

4.3 Particle Induced X Ray Emission (PIXE) . . . . . . . . . . . . . . . . . . . . . 30

4.3.1 Aparato experimental e método . . . . . . . . . . . . . . 31

5 ESTUDO DA INCORPORAÇÃO DE PROTEÍNAS EM SBA-15 COM POROS EXPANDIDOS $\quad 33$

5.1 Adição de TIPB . . . . . . . . . . . . . . . . . . . . . . . . . . . . . . . 33

5.2 Caracterização das proteínas . . . . . . . . . . . . . . . . . . . 36

5.3 Incorporação de proteínas . . . . . . . . . . . . . . . . . . . . 41

5.3.1 Modelagem dos dados de SAXS . . . . . . . . . . . . . . . . . . . 49

6 Determinação do teor de silício em fezes de camundongos 57

6.1 Preparação das amostras de fezes de camundongo . . . . . . . . . . . . 57

6.2 Resultados e discussão . . . . . . . . . . . . . . . . . . . . . 58

7 Controle de qualidade de amostras de SBA-15 61

8 CONCLUSÕES E PERSPECTIVAS $\quad 71$ 
A Dedução do vetor espalhamento q $\quad 88$

A.1 Razões entre os valores de q para uma rede hexagonal $\ldots \ldots$. . . . . . . . . 89

$\begin{array}{ll}\text { B Método BET } & 90\end{array}$

$\begin{array}{ll}\text { C Método BJH } & 93\end{array}$

D Formulação do método PIXE $\quad 95$

D.1 Alvos finos . . . . . . . . . . . . . . . . . . . . . . . . . . . 96

D.2 Alvos Grossos . . . . . . . . . . . . . . . . . . . . . . . . . . . . . . . . . . . 97 


\section{INTRODUÇÃO}

\subsection{A sílica mesoporosa ordenada SBA-15}

Materiais com estrutura porosa ajustável sempre foram de grande interesse da indústria e da comunidade acadêmica. Entre suas propriedades desejáveis estão estreita distribuição de tamanho de poros, grande área superficial e volume de poros. Aluminossilicatos microporosos (materiais com poros com diâmetro menor ou igual a $20 \AA$ ), conhecidos como zeólitas, frequentemente satisfazem essas condições e assim encontram diversas aplicações em catálise e seleção de moléculas. No entanto, o uso das zeólitas é restrito ao tamanho de seus poros e havia uma crescente demanda por materiais mesoporosos ordenados devido a sua potencial aplicação envolvendo moléculas maiores (SAYARI; LIU, 1997; CIESLA; SCHÜTH, 1999).

A família de materiais mesoporosos ordenados M41S foi desenvolvida pela Mobil Corporation Laboratories no início da década de 90 e o primeiro material mesoporoso ordenado que apresentava características desejáveis foi a MCM-41 cuja o diâmetro médio de poros é de 40 $\AA^{1}$ (KRESGE et al., 1992; BECK et al., 1992). Este material é constituido por poros ordenados em simetria hexagonal em uma matriz de sílica amorfa. Segundo definição da IUPAC ${ }^{2}$ (SING, 1985), materiais mesoporos são materiais com poros de diâmetros de 20 a $500 \AA$.

Desde a descoberta de materiais mesoporosos ordenados pela Mobil Corporation em 1992 a composição dos surfactantes direcionadores de estrutura bem como as condições em que ocorre a formação de uma estrutura ordenada foram exploradas e surfactantes poliméricos e não iônicos começaram a ser utilizados. Bagshaw, Prouzet e Pinnavaia (1995) produziram uma "worm-like" sílica mesoporosa desordenada com tamanhos de poros entre $200 \AA$ e $580 \AA$ utilizando surfactantes não iônicos em meio aquoso neutro.

Empregando surfactantes não iônicos de grande peso molecular em meio aquoso ácido $(\mathrm{pH} \sim 2)$, Zhao et al. (1998a) produziram a sílica mesoporosa altamente ordenada SBA-153. Nela, as associações entre a espécie inorgânica (silicato) e orgânica (polímero) ocorrem através de ligações de hidrogênio (ZHAO et al., 1998b). Exemplos de sílicas mesoporosas obtidas com surfactantes neutros são a SBA-11 (cúbica), SBA -12 (hexagonal) e SBA-14 (cúbica). As figuras 1.1a e 1.1b mostram as características texturais da SBA-15. O método utilizado para produção de SBA-15 é o método sol-gel. Esse método é fundamentado na transição de um sistema composto por partículas dispersas (sol) para um precipitado gelatinoso (gel).

\footnotetext{
${ }^{1}$ MCM significa "Mobil Composition of Matter".

${ }^{2}$ International Union of Pure and Applied Chemistry.

${ }^{3}$ Santa Barbara Amorphous-15.
} 


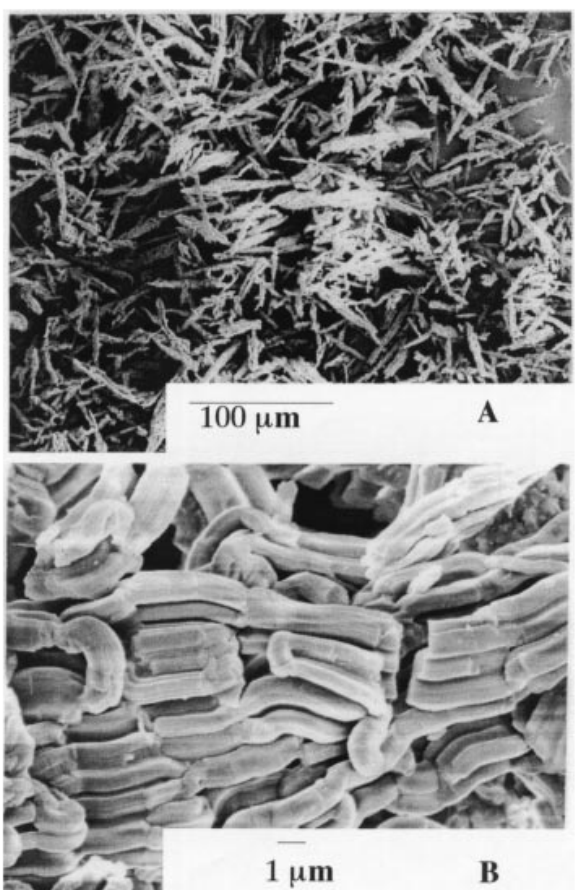

(a) SEM

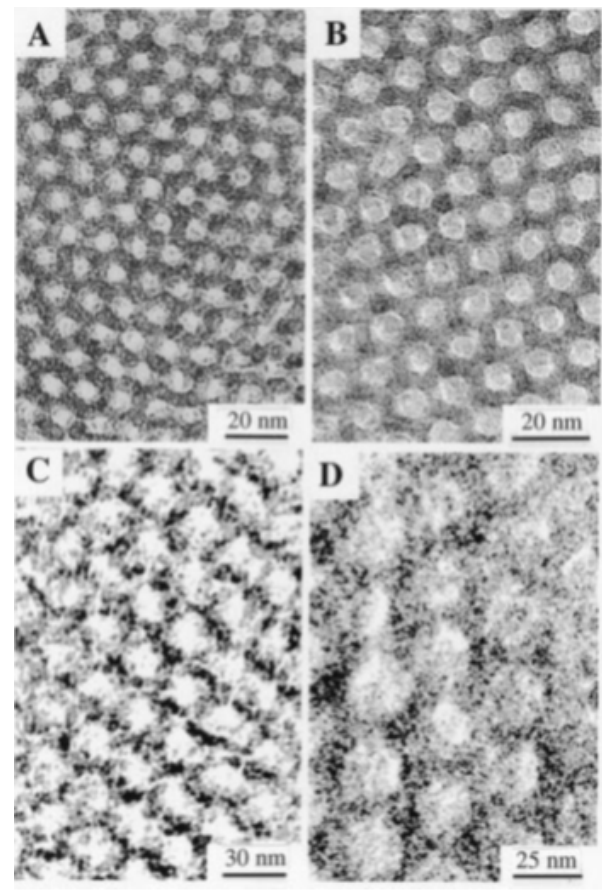

(b) TEM

Figura 1.1: Imagens de microscopia eletrônica de varredura (SEM) e de transmissão (TEM) da sílica mesoporosa ordenada SBA-15 (ZHAO et al., 1998a).

\section{SBA-15}

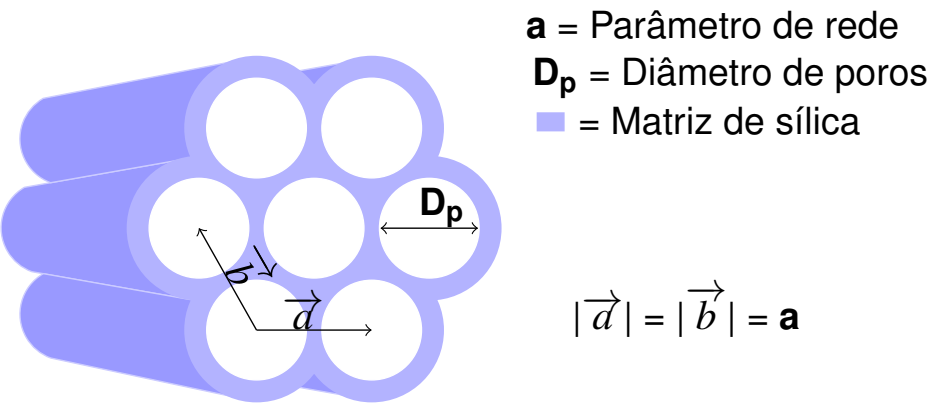

Figura 1.2: Representação da sílica mesoporosa ordenada SBA-15. 
Denomina-se sol um conjunto de partículas coloidais ${ }^{4}$ dispersas em um líquido. Gel é a rede rígida de partículas interligadas e cadeias poliméricas cujo comprimento médio é maior que um micrometro (HENCH; WEST, 1990). Os precursores podem ser orgânicos e os mais utilizados são alcóxidos de silício como tetrametilortosilicato (TMOS) e tetraetilortosilicato (TEOS). Esses percursores são populares porque reagem prontamente com a água.

As principais vantagens do processo sol-gel são o alto grau de pureza e homogeneidade da solução e as baixas temperaturas de preparação associadas à formação sol-gel quando comparadas às temperaturas de síntese de outros métodos (BRINKER; SCHERER, 1990) ${ }^{5}$.

A rota principal de síntese desses materiais utiliza três reagentes básicos: um direcionador de estrutura, um solvente e uma fonte de silicio. O processo de formação do agente responsável por promover o direcionamento da estrutura se fundamenta na ação de um surfactante que, quando em contato com um solvente, desencadeia um processo de auto-agregação levando à formação de micelas poliméricas em um mecanismo conhecido como Modelamento de Cristal Líquido (LCT) proposto por Kresge et al. (1992) e Beck et al. (1992).

As sílicas mesoporosas ordenadas têm vasta aplicação. Na indústria do petróleo, a atuação da SBA-15 como suporte catalítico na produção de biocombustíveis vem sendo investigada (ALBUQUERQUE, 2008). Outra aplicação da sílica ocorre na produção de nanotubos de carbono utilizados na construção de células combustíveis e dispositivos eletrônicos (WU; BEIN, 1994a); nanotubos de materiais nobres, como platina para potencial aplicação em microeletrônica e microrobótica (HAN; KIM; STUCKY, 2000); nanotubos de polianilina e de grafite no desenvolvimento de dispositivos eletrônicos baseados em moléculas de escala nanométricas com o objetivo de aumentar a capacidade de processamento e armazenamento de dados (WU; BEIN, 1994b; WU; BEIN, 1994c).

Partículas nanométricas de sílica funcionalizada foram utilizadas como marcadores celulares (LIN et al., 2005). A separação de moléculas biológicas, tais como vitaminas e proteínas, de substâncias com propriedades químicas e físicas parecidas e que contêm impurezas também foram investigadas (KISLER et al., 2001).

A capacidade de liberação e adsorção de substâncias nos poros desses materiais tem sido amplamente estudada. Para tal estudo, o encapsulamento de medicamentos como o antiinflamatório ibuprofen (CHARNAY et al., 2004) e camptotecina ${ }^{6}$, além de imobilização de enzimas globulares (DIAZ; JR, 1996) tem sido realizadas.

Desde a descoberta das sílicas mesoporosas ordenadas (SMO) o ajuste do tamanho de poro tem sido de grande interesse da comunidade acadêmica e da indústria. Uma grande vantagem de se utilizar copolímeros como agentes direcionadores de estrutura é a possibilidade do ajuste do diâmetro do poro através da alteração no tamanho das suas cadeias. Outra

\footnotetext{
${ }^{4}$ Partículas coloidais são partículas com tamanho de 10 a $1000 \AA$.

${ }^{5} \mathrm{O}$ processo sol-gel é um processo consideravelmente mais complicado do que as sistematizações propostas na literatura. A hidrólise da sílica e as reações de condensação ocorrem ao mesmo tempo e os fatores que influenciam no produto final são a temperatura, $\mathrm{pH}$, natureza dos percursores, etc.

${ }^{6}$ Droga que apresenta atividade anti-tumoral usada em terapia para câncer.
} 
possibilidade é a expansão das micelas através do uso de agentes dilatadores como 1,3,5trimetilbenzeno (TMB) ou 1,3,5-triisopropilbenzeno (TIPB) . Quando o dilatador de estrutura, que é um composto hidrofóbico, é adicionado à síntese ele solubiliza com a porção hidrofóbica das micelas e contribue para o aumento da porção hidrofóbica destas em solução, dando origem a sistemas com poros de maior diâmetro. Em particular a segunda abordagem é preferível já que o tamanho do poro poderia, em princípio, ser continuamente aumentado através do aumento da quantidade do agente dilatador de estrutura (CAO; MAN; KRUK, 2009; CAO; KRUK, 2010). Estudos mostraram que o TIPB é o dilatador de estrutura mais adequado para amostras com estrutura hexagonal (CAO; MAN; KRUK, 2009).

\subsection{SBA-15 como adjuvante imunológico}

No campo da imunologia, a SBA-15 mostrou maior eficiência como adjuvante imunológico do que adjuvantes tradicionais. Mercuri et al. (2006) e Carvalho et al. (2010) demonstraram que a SBA-15 age como um adjuvante ao constatar que camundongos de linhagens BALB/c e de linhagens geneticamente selecionadas que possuem resposta imunológica alta $(\mathrm{H})$ e baixa (L) imunizados com a proteína recombinante Int $1 \beta$ de $16,5 \mathrm{kDa}$ e proteínas do veneno da cobra Micrucurus Ibiboboca (20 proteínas com massas moleculares que variam de 7 a 87 kDa) apresentaram respostas similares ou superiores ao adjuvante incompleto de Freund (IFA) e hidróxido de alumínio $\left(\mathrm{AlOH}_{3}\right)$. Para tal aplicação o conhecimento sobre o processo de encapsulamento de proteínas é fundamental. Informações como área superficial ocupada e volume de poros preenchidos nesse processo são muito importantes para determinar condições de optimização do sistema tais como a concentração adequada proteína:sílica, tamanho adequado de poros da sílica a ser usada, além de outros.

A SBA-15 protege os antígenos de ambientes hostis do organismo, como o ambiente estomacal, e previne a atividade catabólica dos macrófagos permitindo assim que linfócitos e células dendríticas conduzam uma imunogenicidade mais eficiente (MERCURI et al., 2006). Outra vantangem do uso de SBA-15 é que ela não ocasiona nenhum tipo de lesão tecidual nem provoca necrose na área de aplicação da injeção e portanto não provoca certos efeitos indesejados apresentados por outros adjuvantes (MERCURI et al., 2006).

Estudos sobre a acumulação de síica em organismos de camundongos já foram realizados (MARIANO-NETO, 2008). Porém, a análise da maneira como o organismo elimina silica ainda não havia sido realizada. Esse conhecimento certamente é um complemento importante aos estudos sobre a interação da silica com o organismo.

Finalmente, é importante garantir que este material, quando preparado em escala industrial, preserva suas características texturais através do processo de síntese reprodutível. 


\section{OBJETIVOS}

Esse trabalho tem por objetivos:

- Investigar a dilatação dos poros da sílica mesoporosa ordenada SBA-15 através da adição do dilatador de estrutura 1,3,5-triisopropilbenzeno para produzir um material capaz de encapsular moléculas de maior dimensão.

- Analisar e comparar a incorporação da proteína Imunoglobulina G nos poros da SBA-15 com a incorporação do soro albumina bovina de $(66,5 \mathrm{kDa})$. Essa proteína foi escolhida devido a sua maior massa molecular $(150 \mathrm{kDa})$ do que as proteínas utilizadas em estudos anteriores.

- Analisar a liberação de sílica do organismo através das fezes de camundongos que receberam doses de SBA-15 utilizando o método de Particle Induced X-Ray Emission.

- Realizar um controle de qualidade de diversas amostras de SBA-15, produzidas pela Cristália Industria Química e Farmacêutica Ltda., para a produção de vacina oral comercial de Hepatite B. 



\section{SÍNTESE DA SBA-15}

Foram preparadas três amostras da sílica mesoporosa ordenada SBA-15 usando-se diferentes quantidades do dilatador de estrutura TIPB. São elas: P0, P05 e P2 onde o número indica a razão em massas TIPB/P123. ${ }^{1}$ A rota de síntese é aquela utilizada para a SBA-15 convencional (MATOS et al., 2001), porém, com a adição de TIPB.

Para a síntese dessas amostras, foi solubilizado o copolímero tribloco Pluronic P123 com ácido clorídrico à concentração de $2 \mathrm{~mol}^{-1}{ }^{-1}$. A solução foi mantida em agitação magnética por duas horas à temperatura de $40{ }^{\circ} \mathrm{C}$. Então, a fonte de silício, TEOS, e o agente dilatador de estrutura TIPB foram adicionados à solução e a mistura foi mantida em agitação magnética por 24 horas. Em seguida a solução foi colocada em uma auto-clave e submetida a tratamento hidrotérmico a $100{ }^{\circ} \mathrm{C}$ em uma estufa por 48 horas. Após esse processo foi realizada a lavagem da amostra com água deionizada e secagem na estufa a $100^{\circ} \mathrm{C}$ por 24 horas. Para remoção do polímero, o material resultante foi calcinado a $540{ }^{\circ} \mathrm{C}$ por duas horas em atmosfera de nitrogênio e por 4 horas em ar. Essa rota de síntese está esquematizada na figura 3.1 abaixo:

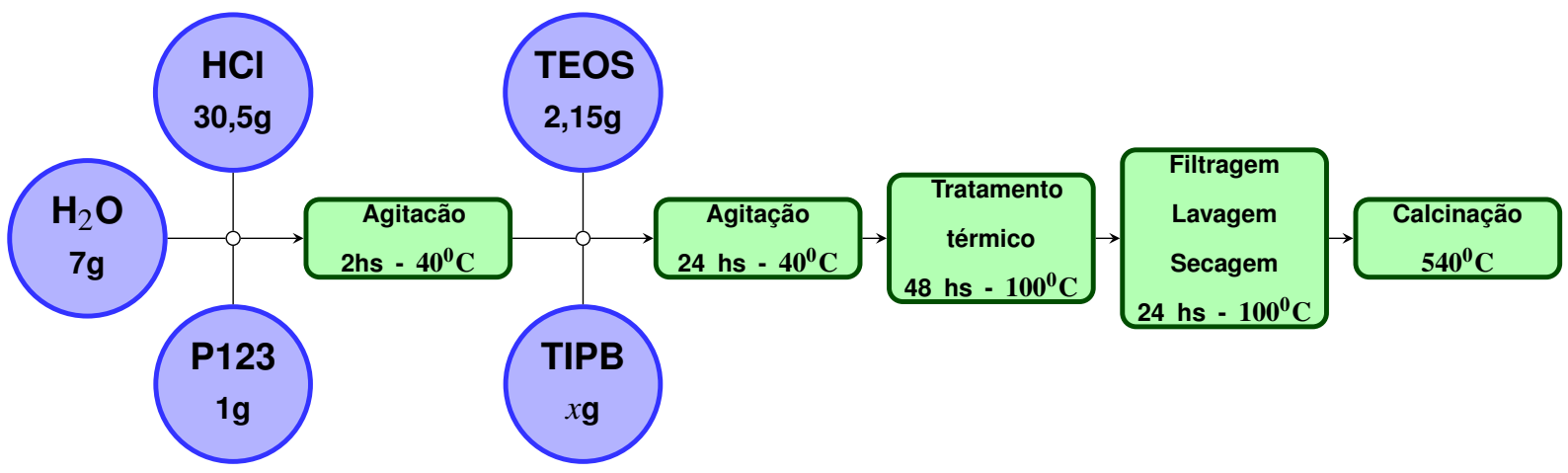

Figura 3.1: Diagrama esquemático da síntese da sílica mesoporosa ordenada SBA-15 com diferentes quantidades do agente dilatador de estrutura TIPB. Para a síntese da amostra P05 foi adicionado 0,5 g de TIPB e para a amostra P2 foi adicionado $2 \mathrm{~g}$.

\subsection{Incorporação das proteínas}

As proteínas foram recebidas do Instituto Butantan e suas especificações são:

- Gama globulina humana (HGG), classe IgG, de 150 kDa (Sigma-Aldrich Biotechnology Co., St. Louis, MO, EUA).

\footnotetext{
${ }^{1} \mathrm{~A}$ amostra P0 tem uma razão TIPB/P123 $=0$ e portanto é a amostra convencional de SBA-15.
} 
- Soro albumina bovina (BSA) de 66,5 kDa (Sigma-Alddrich Biotechnology Co., St. Louis, MO, EUA).

A incorporação do Soro Albumina Bovina e da Imunoglobulina humana $G$ foi realizada através da solubilização dessas proteínas e as amostras de sílica com a solução tampão fosfatosalino (PBS). A proporção proteína:sílica usada foi de 1:5. As quantidades dos reagentes utilizados na preparação do PBS estão listados na tabela 3.1.

\begin{tabular}{|c|c|}
\hline $\mathrm{H}_{2} \mathrm{O}$ & $500 \mathrm{~g}$ \\
\hline $\mathrm{NaCL}$ & $4 \mathrm{~g}$ \\
\hline $\mathrm{KCL}$ & $0,1 \mathrm{~g}$ \\
\hline $\mathrm{Na}_{2} \mathrm{HPO}_{4}$ & $0,575 \mathrm{~g}$ \\
\hline $\mathrm{KH}_{2} \mathrm{PO}_{4}$ & $0,1 \mathrm{~g}$ \\
\hline
\end{tabular}

Tabela 3.1: Preparação do PBS.

Para a incorporação, $20 \mathrm{mg}$ de proteína foram dissolvidas em $10 \mathrm{ml}$ de PBS e mantidos sob agitação magnética por 45 minutos. Em seguida, $100 \mathrm{mg}$ de sílica foram adicionadas e a solução foi mantida em agitação por mais meia hora. Após isso, elas foram levadas para estufa para secar à temperatura de $35^{\circ} \mathrm{C}$ por 96 horas.

As amostras com BSA foram nomeadas P0B, P05B e P2B, equanto que as amostras com IgG foram nomeadas $\mathrm{P} 0 \mathrm{H}, \mathrm{P} 05 \mathrm{H}$ e $\mathrm{P} 2 \mathrm{H}$.

Uma amostra convencional de SBA-15 foi preparada apenas com PBS. Essa amostra foi nomeada POP. A tabela 3.2 identifica as amostras estudadas neste trabalho.

\begin{tabular}{|c|c|c|}
\hline Amostra & TIPB/P123 & Proteína \\
\hline \hline $\mathrm{P} 0$ & 0 & - \\
\hline $\mathrm{P} 0 \mathrm{~B}$ & 0 & $\mathrm{BSA}$ \\
\hline $\mathrm{P} 0 \mathrm{H}$ & 0 & $\operatorname{lgG}$ \\
\hline \hline $\mathrm{P} 05$ & 0,5 & - \\
\hline $\mathrm{P} 05 \mathrm{~B}$ & 0,5 & $\mathrm{BSA}$ \\
\hline $\mathrm{P} 05 \mathrm{H}$ & 0,5 & $\operatorname{lgG}$ \\
\hline \hline $\mathrm{P} 2$ & 2 & - \\
\hline $\mathrm{P} 2 \mathrm{~B}$ & 2 & $\mathrm{BSA}$ \\
\hline $\mathrm{P} 2 \mathrm{H}$ & 2 & $\operatorname{lgG}$ \\
\hline
\end{tabular}

Tabela 3.2: Amostras de SBA-15 com poros expandidos e proteínas encapsuladas utilizadas nesse trabalho. Além das amostras ilustradas aqui há também a amostra com PBS (POP). 


\subsection{Mecanismo de formação da SBA-15}

A síntese da SBA-15 é caracterizada principalmente por utilizar o polímero Pluronic P123 como agente direcionador de estrutura e ocorrer em meio ácido. As moléculas do copolímerotribloco Pluronic P123 são compostas por um bloco hidrofóbico central de polioxipropileno (PPO) e por dois blocos hidrofílicos de polioxietileno (PEO) periféricos e atuam na síntese como direcionador de estrutura. A sua composição química é $(P E O)_{20}(P P O)_{70}(P E O)_{20}$. A fonte de silício mais utilizada na síntese da SBA-15 é o tetraetilortosilicato (TEOS) e a sua fórmula química é $\mathrm{Si}\left(\mathrm{OC}_{2} \mathrm{H}_{5}\right)_{4}$. A partir de uma determinada concentração ${ }^{2}$, o surfactante, ao ser solubilizado com o solvente, inicia um processo de auto-organização de modo a minimizar o contato entre as partes hidrofóbicas das moléculas e a água formando assim micelas esféricas, como mostrado na figura 3.2.

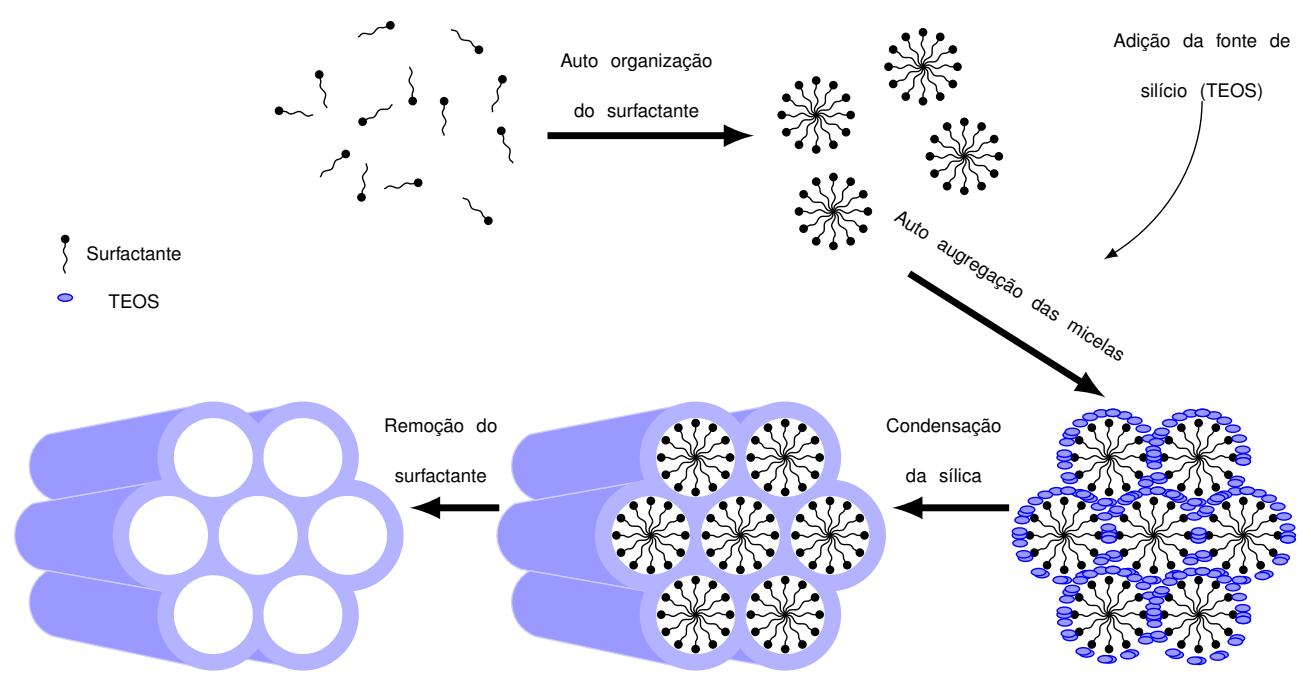

Figura 3.2: Diagrama esquemático mostrando a síntese da sílica mesoporosa ordenada SBA15.

Em seguida, a fonte de silício é adicionada e moléculas de TEOS migram para a parte hidrofóbica das micelas onde começam a sofrer a reação química de hidrólise. Essa reação tem como resultado a produção de etanol $\left(\mathrm{C}_{2} \mathrm{H}_{6} \mathrm{O}\right)$ e grupos silanóis $\mathrm{Si}-\mathrm{OH}$. Esses silanóis começam a interagir e se unir formando redes de Si-O-Si numa reação conhecida como condensação. Essas reações são mostradas na figura 3.4.

Conforme as reações de condensação e hidrólise vão ocorrendo as moléculas de sílica hidrolisadas vão migrando para a região externa da micela, para a interface entre a região hidrofílica da micela e o solvente especificamente (RUTHSTEIN; FRYDMAN; GOLDFARB, 2004), onde se associam ao polímero através de pontes de hidrogênio.

\footnotetext{
${ }^{2}$ Chamada de concentração micelar crítica (CMC).
} 


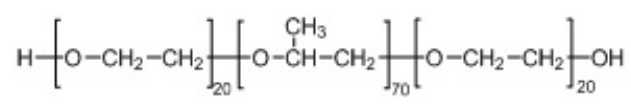

Figura 3.3: Molécula do copolímero tribloco Pluronic P123.

\section{Hidrólise}

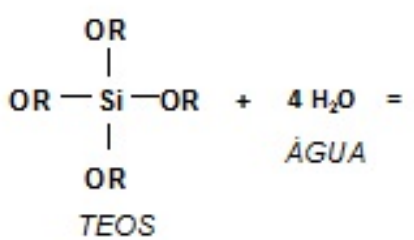

\section{Condensação \\ Condensação}

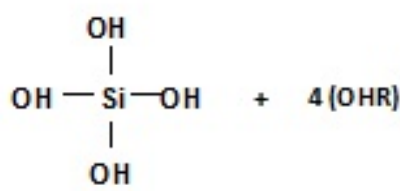<smiles>O[Si](O)(O)O</smiles>

Figura 3.4: Ilustração das reações de hidrólise e condensação do TEOS (com $R=\mathrm{C}_{2} \mathrm{H}_{5}$ ) em água (HENCH; WEST, 1990).

As micelas começam então a interagir formando mesoestruturas cilíndricas dispostas em formação hexagonal e a condensação do precursor prossegue formando as paredes inorgânicas do material. O tratamento térmico a $100{ }^{\circ} \mathrm{C}$ é então realizado e as reações de hidrólise e condensação continuam. Por fim, o material é calcinado para a remoção do polímero, originando os mesoporos e microporos.

A hipótese sobre a formação dos microporos mais aceita é que ocasionalmente após a associação das micelas com as moléculas de sílica hidrolisadas partes do polímero se estendem para dentro da matriz de sílica. Após a secagem e calcinação da sílica o polímero é queimado e retirado deixando microporos na sílica que se estendem dos mesoporos para a matriz (POLLOCK et al., 2011). 


\section{TÉCNICAS EXPERIMENTAIS}

São apresentadas nos textos a seguir as técnicas experimentais de caracterização utilizadas nesse trabalho.

Para obter informações sobre a estrutura de poros ordenados, como o parâmetro de rede, da SBA-15 e as dimensões das proteínas foi utilizada a técnica de espalhamento de raios $X$ a baixo ângulo (SAXS).

Para informações sobre as propriedades texturais dos poros, como diâmetro médio, volume e áreas superficiais, a técnica isotermas de adsorção de nitrogênio (NAl) foi utilizada.

A técnica particle induced $X$ ray emission (PIXE) foi utilizada para realizar uma análise multielementar das fezes de camundongos. Mais especificamente, para determinar a concentração de silício nas fezes.

\subsection{Espalhamento e difração de raios $X$}

O primeiro a utilizar raios $X$ para estudo da estrutura de materiais foi o físico alemão Max Theoder Felix von Laue. Ele descobriu que raios $X$ são difratados por cristais e recebeu 0 prêmio Nobel de Física em 1914 por seu trabalho.

A difração é um fenômeno caracterizado pelo espalhamento de uma onda por um objeto ou fenda. No presente caso as ondas são os raios $X$ e elétrons da amostra são responsáveis por seu espalhamento. Neste sentido, os elétrons são denominados centros espalhadores.

Ao serem submetidos ao feixe de raios $X$ os elétrons da amostra são induzidos pelo campo elétrico senoidal do feixe a oscilar periodicamente em torno de uma posição principal. Como estão sujeitos à acelerações, os elétrons emitem uma onda eletromagnética com o mesmo comprimento de onda da onda incidente no caso de espalhamento coerente.

Como o número de moléculas, e portanto o número de elétrons, é muito grande os raios espalhados tendem a interferir uns com os outros destrutivamente na maioria das direções. Porém, se os centros espalhadores estiverem organizados em uma rede ordenada, ocorrerá em algumas direções interferência construtiva e os feixes se reforçarão gerando máximos de intensidade.

Existem três métodos principais utilizados em experimentos de difração: O método Laue, o método de rotação de cristal e o método pó. Neste trabalho foi utilizado o método pó, onde cada partícula da amostra em forma de pó se comporta como um cristal orientado em direções aleatórias. Ao submeter a amostra a um feixe de raios $\mathrm{X}$, a maioria dessas partículas não 
estará orientada de forma a satisfazer a Lei de Bagg (descrita na próxima seção) de forma que não produzirão interferência construtiva, mas algumas terão seus planos orientados na direção correta para satisfazê-la de forma a produzir máximos de intensidade (CULLITY; STOCK, 2001).

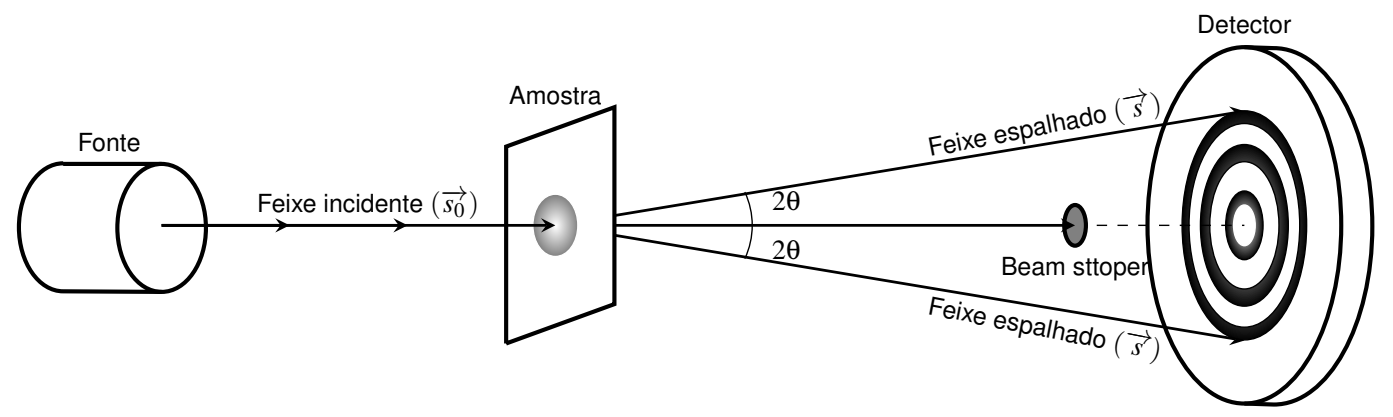

Figura 4.1: Diagrama esquemático de um experimento de difração de raios $\mathrm{X}$ utilizando o método pó.

A fonte de raios $X$ é composta por um cátodo e um ânodo. $O$ cátodo é responsável por gerar um feixe de elétrons que ao atingir o ânodo produz raios $X$. Molibdênio, cobre e tungstênio são exemplos de materiais usados como ânodo.

Em geral, como o número de elétrons em uma amostra é muito grande, faz sentido relacionar a intensidade de espalhamento à densidade eletrônica $\rho$, que expressa o número de elétrons por unidade de volume. Porém, se as partículas de densidade eletrônica $\rho_{1}$ de interesse estão em um meio de densidade eletrônica $\rho_{2}$ essa diferença, ou contraste de densidade eletrônica, deve ser considerada. Nesse caso a intensidade de espalhamento será uma função de $\left(\rho_{1}-\rho_{2}\right)^{2}$.

No caso da sílica mesoporosa SBA-15 esse contraste se dá entre os poros cilíndricos vazios $\left(\rho_{1} \sim 0\right)$ e a matriz de sílica amorfa $\left(\rho_{2}\right)$. Flutuações dessas densidades eletrônicas podem gerar informações sobre o preenchimento dos poros por substâncias de interesse. Já no caso das medidas realizadas nas proteínas o contraste de densidade eletrônica se dá entre as proteínas e o solvente utilizado, nesse caso o PBS.

\subsubsection{A Lei de Bragg}

A rede cristalina pode ser arranjada numa série de planos cristalinos paralelos (BRAGG, 1922). A figura 4.2 mostra duas frentes de onda em fase espalhadas por planos cristalinos separados por uma distância $d$. 


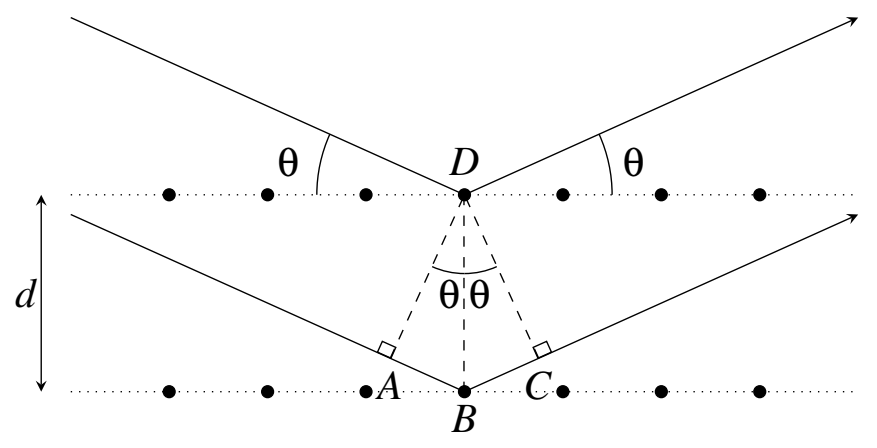

Figura 4.2: Ilustração da Lei de Bragg.

O feixe espalhado pelo plano inferior percorre uma distância adicional $\overline{A B C}$ em relação ao feixe espalhado pelo plano superior. Vemos pela figura 4.2 que a distância $\overline{A B}$ é igual a distância $\overline{B C}$ e a sua relação com ângulo $\theta$ e a distância $d$ é:

$$
\overline{A B}=\overline{B C}=d \operatorname{sen} \theta \quad \overline{A B C}=2 d \operatorname{sen} \theta
$$

Onde $d$ é a distância interplanar e $\theta$ é o ângulo de incidência.

Só haverá interferência construtiva entre essas duas frentes de onda se a diferença de caminho $\overline{A B C}$ for igual a um número inteiro de comprimento de onda do feixe incidente. Assim as ondas estarão em fase novamente após cruzar linha $\overline{C D}$ se a seguinte relação for satisfeita:

$$
n \lambda=2 d \operatorname{sen} \theta
$$

Onde $n$ é um número inteiro positivo. Esta equação é conhecida como Lei de Bragg.

\subsubsection{Espalhamento de raios $X$ a baixo ângulo (SAXS)}

A técnica de espalhamento de raios $X$ a baixo ângulo envolve a detecção de raio $X$ sob ângulos de incidência $\theta$ muito pequenos, próximos de zero. Essa técnica geralmente é empregada quando se quer caracterizar partículas com tamanho de dezenas a centenas de Angstrons ${ }^{1}$ (GLATTER; KRATKY, 1982).

Os dois pontos indicados na figura 4.3 difratam duas frentes de onda em fase. Quanto maior o número de pontos sobre o objeto considerado maior será a tendência de haver interferência destrutiva e consequentemente não havendo essencialmente espalhamento na direção $\theta$. Mas quando ângulos menores são considerados as diferenças de fase diminuirão e haverá

\footnotetext{
${ }^{1} \mathrm{Um}$ Angstrom equivale a $10^{-10} \mathrm{~m}$.
} 
uma maior ocorrência de interferência construtiva (GLATTER; KRATKY, 1982). Para o objeto maior vemos que a mesma diferença de fase $\lambda / 2$ irá ocorrer para ângulos muito menores. Isso porque a distância entre os dois pontos espalhadores da figura (equivalente à distância interplanar $d$ da equação 4.2) é maior para o objeto da direita, o que implica em ângulos de espalhamantento menores de acordo com a Lei de Bragg. Assim, para partículas que são muito grandes comparadas com o comprimento de onda dos raios $\mathrm{X}$ o espalhamento ocorre principalmente em ângulos de incidência muito pequenos.

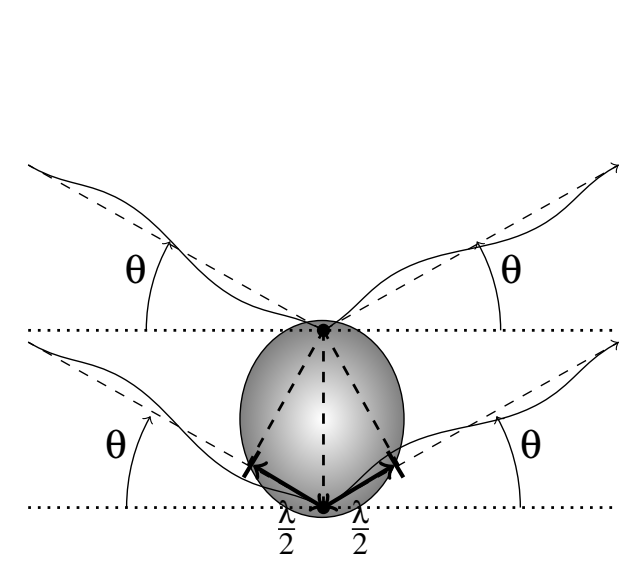

(a)

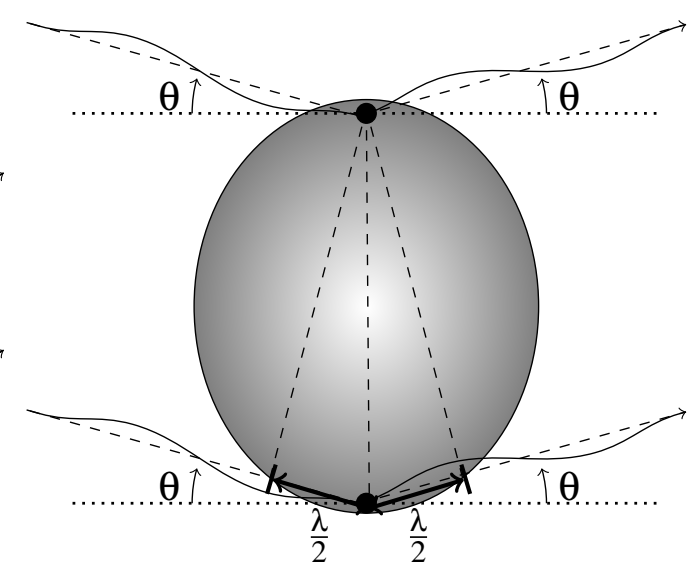

(b)

Figura 4.3: Difração em dois objetos com diferentes dimensões.

A técnica de SAXS foi utilizada nesse trabalho porque o diâmetro médio dos poros da SBA-15 e as dimensões das proteínas utilizadas são da ordem de $100 \AA$, ou seja, maiores que o comprimento de onda característico dos raios $X$ das câmaras de SAXS utilizadas que é cerca de $1,54 \AA$.

\subsubsection{Vetor espalhamento e a determinação do parâmetro de rede}

É conveniente expressar medidas de espalhamento a baixo ângulo (SAS) ${ }^{2}$ em termos da intensidade $I$ e do vetor $\vec{q}$, chamado de vetor de espalhamento. Esse vetor é definido como a diferença entre os vetores de onda do raio incidente $\left(\overrightarrow{s_{0}}\right)$ e o feixe espalhado $(\vec{s})$ e está relacionado ao ângulo $\theta$ e ao comprimento de onda $\lambda$ através da relação (GUINIER, 1994):

$$
q=\frac{4 \pi}{\lambda} \operatorname{sen} \theta
$$

Onde q é o módulo do vetor espalhamento $\vec{q}$ e sua unidade de medida pode $\operatorname{ser} \AA^{-1}$ ou 
$\mathrm{nm}^{-1} \cdot 3$

Combinando a Lei de Bragg com a equação 4.3 têm-se:

$$
q=\frac{2 \pi n}{d}
$$

A distância interplanar $d$ de um conjunto de planos responsáveis por uma dada reflexão é uma função dos índices de Miller $h k l$ dos planos e dos parâmetros de rede $a, b, c$, e dos ângulos $\alpha, \beta, \gamma$ da célula unitária. A relação exata depende do tipo de rede cristalina envolvida. A sílica mesoporosa ordenada utilizada nesse trabalho possui rede hexagonal bidimensional ${ }^{4}$ $(I=0)$ e a exata relação para esse tipo de rede é:

$$
\frac{1}{d_{h k l}^{2}}=\frac{4}{3}\left(\frac{h^{2}+h k+k^{2}}{a^{2}}\right)
$$

O processo de identificar os índices $h k l$ de um conjunto de planos correspondentes a uma reflexão chama-se indexação. No apêndice A.1 as relações entre os máximos de intensidade das diferentes reflexões estão mostradas.

\subsubsection{Função de distibuição de pares de distância}

Como citado anteriormente, é conveniente expressar dados de espalhamento a baixo ângulo em função do vetor $\vec{q}$. Assim, toda análise realizada quando feita em termos $\vec{q}$ é realizada no espaço recíproco, já que $\vec{q}$ tem dimensão de $\AA^{-1}$. A correspondência entre o espaço recíproco e o espaço real pode ser realizada através da Transformada de Fourier.

A Transformada de Fourier de I(q), que é definida no espaço recíproco, é a função $p(r)$, definida no espaço real, conhecida como função de distribuição de pares de distância. Isso permite a definição do par de Fourier:

$$
\begin{gathered}
I(q)=4 \pi \int_{0}^{\infty} p(r) \frac{\operatorname{sen}(q r)}{q r} d r \\
p(r)=\frac{r^{2}}{2 \pi^{2}} \int_{0}^{\infty} q^{2} I(q) \frac{\operatorname{sen}(q r)}{q r} d q
\end{gathered}
$$

Porém, esse método tem limitações intrínsecas já que a transformada de Fourier envolve integrais até o infinito (como descrito nas equações 4.6 e 4.7), o que não é possível de ser realizado pois os dados experimentais de espalhamento são coletados em uma região limitada do espaço recíproco. O método conhecido como Transformada de Fourier Indireta (IFT, Indirect

\footnotetext{
${ }^{3} \mathrm{~A}$ dedução da equação 4.3 é apresentada no apêndice $A$.

${ }^{4}$ Sobre os parâmetros de rede: $a=b$ e $c=0$.
} 
Fourier Transform), introduzido por Glatter, é uma alternativa a esse problema, ele parte de uma $p(r)$ que é descrita por uma série de funções ortogonais e então realiza a transformada de Fourier para obter essas funções no espaço recíproco buscando a curva que melhor descreve $\mathrm{I}(\mathrm{q})$.

A função $p(r)$ corresponde a um histograma de pares de distâncias do interior da partícula ponderada por $r^{2}$ e é definida como:

$$
p(r)=\gamma(r) \cdot r^{2} \quad \text { onde } \gamma(r)=\langle\rho(r) * \rho(-r)\rangle
$$

Onde $\gamma(r)$ é a função de auto correlação.

No métodod IFT, a integral da equação 4.7 é realizada até o tamanho máximo da partícula $D_{\max }$ pois a função de correlação $\gamma(r)$ se anula para os valores $r=0$ e $r>D_{\max }$.

\subsubsection{Modelagem de dados de SAXS de amostras de SBA-15}

Para obter informações quantitativas adicionais de dados experimentais de espalhamento de raios $\mathrm{X}$ a baixo ângulo para sílicas mesoporosas ordenadas hexagonais um modelo teórico foi desenvolvido e aplicado à amostras de SBA-15. Esse modelo se baseou no modelo desenvolvido por Förster et al. (2005) para materiais mesoscopicamente ordenados e considera a fatoração da intensidade em contribuições do fator de forma e do fator de estrutura.

Embora a SBA-15 tenha uma estrutura hexagonal de mesoporos, o modelo de Forster não ajusta adequadamente os seus dados experimentais já que não considera outros aspectos da SBA-15 como, por exemplo, a rede de microporos. No modelo descrito nos trabalhos dos autores Manet et al. (2011) e Sundblom et al. (2009), essa e outras particularidades são levadas em consideração. Ele utiliza como base um sistema de cilindros "core-shell" que são cilindros com uma interface externa difusa com densidade eletrônica descrita por uma função Gaussiana. A figura 4.4 mostra a seção transversal de um cilindro deste modelo.

Em termos gerais, a intensidade de espalhamento de uma amostra de SBA-15 convencional pode ser expressa como:

$$
I(q)=\left(\rho_{1}-\rho_{2}\right)^{2} n P(q) \cdot S(q)+I(q)_{\text {chain }}
$$

Onde $n$ é número de densidade de partículas ${ }^{5}$. O termo $\mathrm{P}(\mathrm{q})$ é chamado de fator de forma e contem informações sobre a forma, tamanho e estrutura interna das partículas que compõe o sistema. Já o fator de estrutura S(q) possui informações sobre a posição e interação entre as partículas. Quando o sistema é bastante diluído não há correlação entre as partículas

\footnotetext{
${ }^{5}$ No presente caso, os poros desempenham o papel de partículas do modelo.
} 


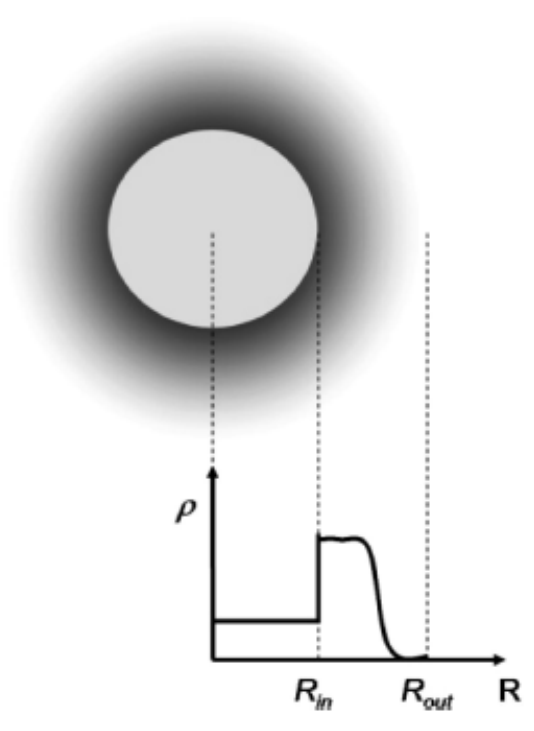

Figura 4.4: Representação esquemática da seção transversal de um cilindro "core-shell".

e o fator de estrutura $S(q)=1$.

Esse modelo se baseia no espalhamento de um sistema de partículas de densidade eletrônica $\rho_{1}$ em uma matriz de densidade eletrônica $\rho_{2}$. A equação principal desse modelo está descrita abaixo:

$$
I(q)=S c_{1} P(q)_{\text {rod }}\left\langle F_{C S}^{2}(q)\right\rangle(1+\beta(q)[\langle Z(q)\rangle-1] G(q))+S c_{2} I(q)_{\text {chain }}+S c_{\text {const }}
$$

Onde $P(q)=P(q)_{\text {rod }}\left\langle F(q)_{C S}^{2}\right\rangle$ é o fator de forma e $S(q)=(1+\beta(q)[\langle Z(q)\rangle-1] G(q))$ é o fator de estrutura.

Os termos $S c$ s são fatores de escalas e estão descritos na tabela 4.1 juntamente com os principais parâmetros do modelo. A seguir é feita uma breve explanação sobre os parâmetros dessa equação. ${ }^{6}$

$P(q)_{\text {rod }}$ é o fator de forma de uma haste infinitamente fina. Esse fator relaciona-se com o comprimento dos cilindros $(\mathrm{L})$ por:

$$
P(q)_{\text {rod }}=\frac{2 \operatorname{Si}(q L)}{q L}-\frac{\operatorname{sen}^{2}(q L / 2)}{(q L / 2)^{2}} \text { onde } \operatorname{Si}(x)=\int_{0}^{x} \frac{\operatorname{sen}(t)}{t} d t
$$

$F_{C S}$ é a amplitude de espalhamento de seção transversal do cilindro e está relacionado a vários fatores como os raios e o contraste de densidade eletrônica da região externa e interna do poro por:

$$
F_{C S}=\frac{\Delta \rho_{\text {out }}}{\Delta \rho_{\text {in }}} R_{\text {out }}^{2} \frac{2 J_{1}\left(q R_{\text {out }}\right)}{q R_{\text {out }}} \exp \left[-\frac{1}{2} q^{2} \sigma_{\text {int }}\right]-\left(\frac{\Delta \rho_{\text {out }}}{\Delta \rho_{\text {in }}}-1\right) R_{\text {in }}^{2} \frac{2 J_{2}\left(q R_{\text {in }}\right)}{q R_{\text {in }}}
$$

${ }^{6}$ Para informações mais detalhadas sobre esse modelo vide as referências Manet et al. (2011) e Sundblom et al. (2009). 
Onde $\Delta \rho_{\text {out }}$ e $\Delta \rho_{\text {in }}$ são os contrastes de densidade eletrônica da matriz de sílica e do interior dos poros respectivamente, $R_{\text {out }}$ e $R_{\text {in }}$ são os raios interno e externo dos poros respectivamente, $J_{1}$ e $J_{2}$ são as funções de Bessel de primeira e segunda ordem respectivamente, $\sigma_{i n t}$ é a largura da interface Gaussiana (figura 4.4).

O parâmetro $\beta(q)$ expressa a polidispersividade em diâmetro dos cilindros:

$$
\beta=\frac{\left\langle F_{C S}(q)\right\rangle^{2}}{\left\langle F_{C S}(q)^{2}\right\rangle}
$$

As médias dessa equação são calculadas através da distribuição de Schulz-Zimm $(D(r))$, que é usada para caracterizar a distribuição de tamanho:

$$
\left\langle F_{C S}\right\rangle=\frac{\int_{0}^{\infty} D(r) F_{C S}(q, r) d r}{\int_{0}^{\infty} D(r) d r} e\left\langle F_{C S}^{2}\right\rangle=\frac{\int_{0}^{\infty} D(r) F_{C S}^{2}(q, r) d r}{\int_{0}^{\infty} D(r) d r}
$$

Onde:

$$
D(x)=\left(\frac{z+1}{x_{0}}\right)^{z+1} \frac{x^{z}}{\Gamma(z+1)} \exp \left(-(z+1) \frac{x}{x_{0}}\right)
$$

Nessa equação a variável z está relacionado à polidispersividade $\left(\sigma_{R}\right)$ do raio por $z=$ $1 /\left(\sigma_{R} / R\right)^{2}-1$.

$Z(q)$ é o fator de rede para uma rede hexagonal e sua definição é:

$$
Z_{0}(q)=c \frac{2}{\sqrt{3} a^{2} q} \sum_{h k} m_{h k} L_{h k}(q)
$$

Onde $c$ é uma constante que assegura que o fator de forma satisfaça o invariante de Porod $(Q)$, $a$ é o parâmetro de rede, $m_{h k}$ é a multiplicidade da reflexão.

O termo $L_{h k}$ é uma função que determina a forma do pico centrado em $q_{h k}$. Essa função normalizada é definida como:

$$
L_{h k}(q)=\frac{2}{\pi \delta}\left|\frac{\Gamma\left[v / 2+i \gamma_{v} 2\left(q-q_{h k}\right) /(\pi \delta)\right]}{\Gamma[v / 2]}\right|^{2}
$$

Onde $\delta$ é a largura dos picos de difração e é relacionada ao tamanho de domínio $D$ por $D=2 \pi / \delta^{7}$. A função $\Gamma[x]$ é a função gama complexa.

$O$ parâmetro $v$ define a forma do pico; no limite $v \rightarrow 0$ o formato do pico é Lorentziano, no limite $v \rightarrow \infty$ o formato do pico é Gaussiano.

O parâmetro $G(q)$ leva em conta distorções na rede cristalina em função do deslocamento médio quadrático relativo $\sigma_{a}$ de cada cilindro em torno de sua posição média. Esse parâmetro é definido como:

$$
G(q)=\exp \left(-\sigma_{a} a^{2} q^{2}\right)
$$

\footnotetext{
${ }^{7}$ Essa equação é conhecida como equação de Debye-Scherrer.
} 
O espalhamento devido aos microporos é expressado pelo termo $I(q)_{\text {chain. }}$. Esse termo é o espalhamento do tipo cadeia polimérica e é descrito por um fator de forma de cadeia Gaussiana:

$$
I(q)_{\text {chain }}=\frac{2\left|\exp \left(-q^{2} R_{g}^{2}\right)-1+\left(q^{2} R_{g}^{2}\right)\right|}{\left(q^{2} R_{g}^{2}\right)^{2}}
$$

Onde $R_{g}$ é o raio de Guinier. O valor desse parâmetro é definido durante o ajuste.

\begin{tabular}{|c|l|}
\hline Parâmetro & Descrição \\
\hline$S c_{1}$ & Fator de escala de contribuição dos cilindros \\
\hline$S c_{2}$ & Fator de escala de contribuição dos microporos \\
\hline$S c_{\text {const }}$ & Fator de escala do background \\
\hline$c$ & $\begin{array}{l}\text { Constante de correção para a conservação do } \\
\text { invariante de Porod }\end{array}$ \\
\hline$a$ & Parâmetro de rede \\
\hline$D$ & Tamanho de domínio \\
\hline$v$ & Parâmetro que determina a forma do pico \\
\hline$\sigma_{a}$ & Parâmetro de desordem \\
\hline$R_{\text {in }}$ & Raio interno dos cilindros \\
\hline$R_{\text {out }}$ & Raio externo dos cilindros \\
\hline$L$ & Tamanho dos cilindros \\
\hline$\Delta \rho_{\text {out }} / \Delta \rho_{\text {in }}$ & $\begin{array}{l}\text { Razão entre os contrastes de densidade eletrônica } \\
\text { da região interna e externa dos poros }\end{array}$ \\
\hline$\sigma_{\text {int }}$ & Largura da interface Gaussiana \\
\hline$\sigma_{R} / R$ & Polidispersividade relativa do raio \\
\hline$R_{g}$ & Raio de Guinier dos microporos \\
\hline
\end{tabular}

Tabela 4.1: Parâmetros integrantes do modelo teórico (equação 4.10).

Todos os fatores $S c$ da equação 4.10 são fatores de escala e seus valores são definidos durante $o$ ajuste.

\subsubsection{Arranjo experimental, tratamento dos dados e metodologia}

As amostras P2, P2B, P2H e as proteínas foram caracterizadas em experimento realizado no laboratório do Grupo de Fluidos Complexos do Instituto de Física da Universidade de São Paulo (IFUSP) numa câmara de SAXS Xenocs modelo Xeuss. Esse instrumento possui algumas modificações se comparado ao equipamento comercial da Xenocs. Ele possui fonte de raios $\mathrm{X}$ microfoco (CuK $\alpha$ ), espelhos, 2 colimadores de baixo espalhamento e detector Pilatus. A distância amostra detector para esses experimentos foi $72,5 \mathrm{~cm}$. 
Todas as outras amostras de SBA-15 foram caracterizadas num equipamento Bruker AXS Nanostar (sistema Genix 3D com fendas scatterless slits) com um detector VANTEC-2000 e uma fonte microfoco de raios X XENOCS. A distância amostra detector nesse caso foi 66,7 $\mathrm{cm}$.

No caso dos dois difratômetros o comprimento de onda dos raios $\mathrm{X}$ foi $\lambda=1,54 \AA$ e a seção transversal do feixe tinha $0,8 \times 0,8 \mathrm{~mm}^{2}$ de dimensão.

As amostras de SBA-15, em forma de pó, foram colocadas entre duas folhas de mica e as medidas foram realizadas à temperatura ambiente por um tempo de 600 segundos de exposição cada uma.

As amostras de proteína foram preparadas em solução de PBS na concentração de 3 $\mathrm{mg} / \mathrm{mL}$ e foram seladas em capilares de quartzo de $2 \mathrm{~mm}$ de diâmetro. Após cada medida esses capilares eram lavados e utilizados novamente. As medidas da amostra de lgG foram realizadas na temperatura de $38{ }^{0} \mathrm{C}$ pois a proteína se mostrou mais estável nessa temperatura. As medidas da amostra de BSA foram realizadas em temperatura ambiente $\left(T \approx 21{ }^{\circ} \mathrm{C}\right)$. Foram realizados 30 frames com 1800 segundos de exposição para cada umas das amostras de proteínas.

Os dados de SAXS obtidos foram corrigidos pela eficiência do detector, distorções espaciais e a média azimutal (realizada pelo programa FIT2D) foi realizada. Uma medida de duas micas foi usada como fundo e foi subtraída dos dados das amostras no caso da SBA-15. Já para as medidas das proteínas uma medida de PBS no capilar utilizado foi empregada como fundo. Essas correções foram realizadas através da equação (LINDNER; ZEMB, 2002):

$$
I_{\text {Tratada }}(q)=\left(\frac{I_{a}(q)}{\Phi_{a} \cdot T_{a} \cdot t_{a}}-\frac{I_{b}(q)}{\Phi_{b} \cdot T_{b} \cdot t_{b}}-\frac{I_{n}(q)}{t_{n}\left(\Phi_{a} T_{a}-\Phi_{b} T_{b}\right)}\right) \cdot \frac{1}{I_{\text {shadow }}(q)} \cdot \frac{d \Sigma / d \Omega_{\mathrm{H}_{2} O, 20^{\circ} \mathrm{C}}}{I(0)_{\mathrm{H}_{2} O, 20^{\circ} \mathrm{C}}}
$$

Onde $I(q)$ é a medida (integrada) das intensidades de espalhamento, $\Phi$ é a intensidade do feixe incidente, $T$ é a transmissão da amostra, $t$ é o tempo de exposição, $I_{\text {shadow }}(q)$ é intensidade normalizada para a correção da sombra do beam stopper e $\left(\Sigma / d \Omega_{\mathrm{H}_{2} \mathrm{O}, 20^{\circ} \mathrm{C}}\right)=0,01632$ $\mathrm{cm}^{-1}$ é o espalhamento teórico de seção transversal da água a $20^{0} \mathrm{C}$. O subscrito $a$ refere-se à amostra, $b$ ao fundo e $n$ ao ruído.

Ao realizar esse procedimento de tratamento dos dados através da equação 4.20 a curva obtida está em escala absoluta se a amostra a ser medida e o padrão (nesse caso, água a 20 ${ }^{0} \mathrm{C}$ ) tiverem a mesma espessura. Em escala absoluta, a unidade de medida da intensidade de espalhamento $\mathrm{I}(\mathrm{q})$ é $\mathrm{cm}^{-1}$. Como o mesmo capilar foi utilizado para a medida das proteínas em solução e do padrão, as curvas de SAXS das amostras de proteínas estão em escala absoluta.

Porém, se as espessuras forem diferentes a equação 4.20 deverá ser multiplicada pela razão da espessura do padrão pela espessura da amostra. É difícil determinar um valor confiável para a espessura de amostras em pó visto a pequena quantidade de amostra utilizada entre outros motivos. Assim, como não houve necessidade de expressar os dados de SAXS 
das amostras de SBA-15 em escala absoluta, esses dados foram expressos em unidades arbitrárias.

A figura 4.5 mostra curvas da intensidade em função do vetor $q$ do fundo (2 micas) e de uma amostra de SBA-15.

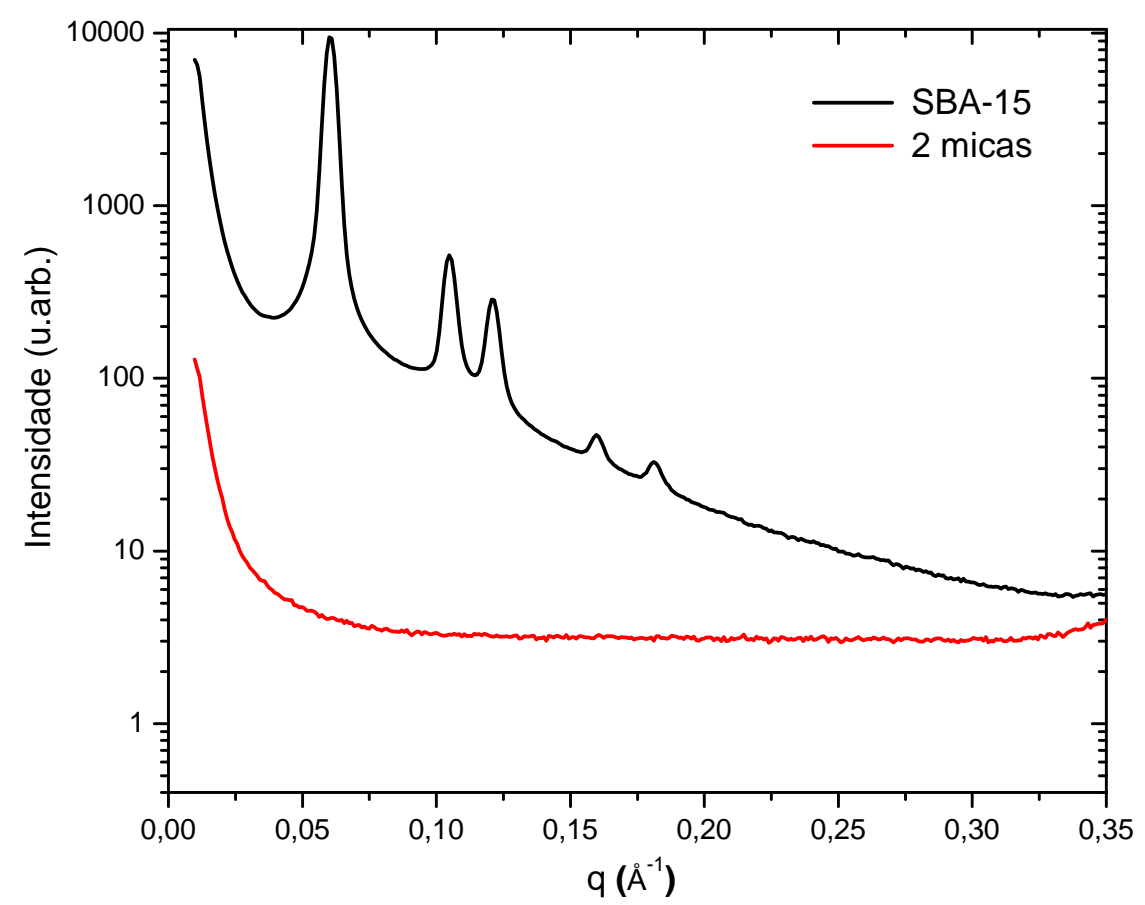

Figura 4.5: Curvas de SAXS de uma amostra de SBA-15 e o porta amostras (2 micas).

Uma curva Gaussiana foi ajustada aos picos de difração identificáveis e o parâmetro de rede foi calculado utilizando as equações 4.4 e 4.5 a partir do valor central fornecido pelo ajuste da Gaussiana.

O método IFT foi aplicado aos dados experimentais das proteínas afim de realizar uma estimativa da maior dimensão das partículas que compõe a amostra através do diâmetro máximo apontado pela $p(r)$. Para isso o programa Gnom (SEMENYUK; SVERGUN, 1991) foi utilizado.

No caso da BSA foi possível determinar a concentração de monômeros e dímeros e suas respectivas massas moleculares através do programa Oligomer (KONAREV et al., 2003) graças à quantidade de informação disponível sobre essa proteína. Foi utilizado o arquivo pdb dessa proteína disponível no site Protein data bank ${ }^{8}$ para aquisição dos fatores de forma dos componentes da amostra. Esse programa permite ajustar curvas a dados de espalhamento de amostras de proteínas compostas por dois ou mais sistemas de partículas(componentes). A intensidade de espalhamento de uma amostra composta por $\mathrm{K}$ componentes é escrita como:

\footnotetext{
${ }^{8}$ PROTEIN DATA BANK <http://www.rcsb.org/pdb/explore/explore.do?structureld=4F5S >. Acesso em: $19 \mathrm{de}$ Novembro de 2014.
} 


$$
I(q)=\sum_{i=1}^{K}\left(w_{i} \times I_{i}\right)
$$

Onde $w_{i}$ e $I_{i}$ são a fração de volume e a intensidade espalhada da i-ésima componente. A massa molecular média foi determinada através do raio de giro e da densidade média da proteína.

Os arquivos dos fatores de forma das componentes da BSA foram aplicados aos programas Massha (KONAREV; PETOUKHOV; SVERGUN, 2001), para realizar uma estimativa sobre as dimensões da proteína, e Rasmol (SAYLE; MILNER-WHITE, 1995), para geração das representações gráficas utilizadas nesse trabalho.

\subsection{Isotermas de Adsorção de Nitrogênio}

Denomina-se adsorção o processo no qual moléculas de um gás aderem à superfície de um sólido. Durante o processo as moléculas são atraídas por interação elétrica para a superfície do sólido onde formam camadas condensadas. Nesse processo, o sólido é chamado de adsorvente e as moléculas do gás de adsorbato.

Existem duas modalidades de adsorção: a adsorção química, também chamada de quimissorção, e a física, também chamada de fisissorção. A quimissorção é caracterizada pelo compartilhamento de elétrons entre o adsorvente e o adsorbato, alterando desta forma significativamente a estrutura eletrônica deste último.

$\mathrm{Na}$ fisissorção as moléculas do adsorbato são atraídas para a superfície por forças de Van der Waals. Por não haver compartilhamento de elétrons a estrutura eletrônica do adsorbato é perturbada em uma escala muito menor. A fisissorção envolve energias de 2-10 kcal/mole para moléculas simples e a quimissorção envolve energias da ordem de 15-100 kcal/mole (MASEL, 1996). Neste trabalho a modalidade utilizada é a fisissorção, sobre o qual trata o texto a seguir.

Ao interagir com o sólido, as moléculas do adsorbato são sujeitas a forças de dispersão ${ }^{9}$ atrativas e repulsivas de curto alcance. Ao se aproximarem do sólido, os átomos do adsorbato induzem um momento de dipolo temporário na superfície do sólido. London (1930) sugeriu que dois átomos neutros poderiam se atrair eletricamente através da perturbação na densidade eletrônica gerando assim um momento de dipolo induzido. A energia potencial total de um par de átomos desse sistema é:

\footnotetext{
${ }^{9}$ Forças de dispersão ou Forças de London são forças que surgem devido à interação entre duas moléculas apolares.
} 


$$
\varepsilon(r)=B / r^{m}-C / r^{6}
$$

Onde $C$ é uma constante relacionada a vários parâmetros do substrato e do adsorbato como polarizabilidade, potencial de ionização entre outros. $B$ é uma constante determinada empiricamente e $m$ é uma constante onde geralmente atribui-se o valor 12 (ROUQUEROL; ROUQUEROL; SING, 1998).

O primeiro termo da equação 4.22 está relacionado à força de repulsão e o termo da direita à força de atração. Essa equação é conhecida como potencial de Lennard-Jones e é uma aproximação que não é válida para substratos condutores.

Ao interagir com a superfície de um material poroso o adsorbato se deposita na forma de camadas condensadas ou filmes sobre as paredes dos poros do adsorvente. Após a formação de algumas camadas de filme o adsorbato começa a preencher o volume do poro. Esse fenômeno é conhecido como condensação capilar ${ }^{10}$. Nos filmes, as forças intermoleculares do adsorbato são menos intensas que as forças de atração devidas às paredes dos poros, por isso o filme tem densidade próxima à densidade de um gás. Já na formação do condensado capilar, as forças intermoleculares são mais intensas que as forças de atração para as parede dos poros, de modo que a densidade do volume interno capilar é próxima à densidade da fase líquida.

Características de interesse de um dado substrato, tais como área superficial e volume de poro são determinados com base em curvas que relacionam a quantidade de gás adsorvido à pressão relativa num sistema mantido à temperatura constante. Os gráficos dessa curvas são chamados de isotermas. Brunauer et al. (1940) propuseram a existência de cinco tipos de isotermas. Essas isotermas são mostradas na figura 4.6a juntamente com o sexto tipo que foi proposta posteriormente.

Os textos a seguir, sobre os seis tipos de isoterma e sobre os quatro tipos de histerese, foram realizados de acordo com o estabelecido pela IUPAC (SING, 1985).

Tipo I : É característica de sólidos microporosos com área superficial externa relativamente pequena. Esse tipo de isoterma é reversível e côncava em relação ao eixo $p / p_{0}$ e a quantidade de gás adsorvida tende a um valor limite quando $p / p_{0} \rightarrow 0$.

Tipo II : Forma comumente obtida de sólidos não porosos ou macroporosos. É reversível e representa o processo de adsorção irrestrita e o ponto $B$ (início da parte intermediária quase linear) é geralmente considerado como o estágio onde a monocamada está completa e a formação de multicamadas está iniciando.

Tipo III : Este tipo de isoterma é reversível e não possui ponto B já que apresenta curvatura convexa em relação ao eixo $p / p_{0}$. Nesse tipo incomum de isoterma a interação adsorbato-

\footnotetext{
${ }^{10} \mathrm{~A}$ condensação capilar só ocorre para amostras macro e mesoporosas. No caso de amostras microporosas há apenas a formação de camadas de filme condensado.
} 


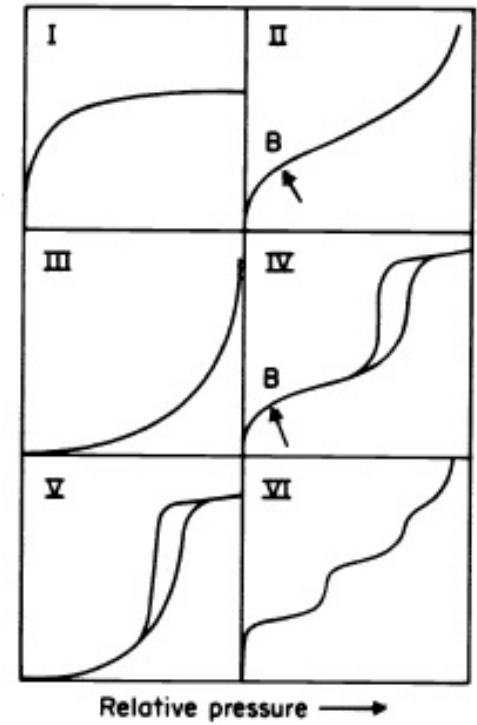

(a) Isotermas de adsorção.

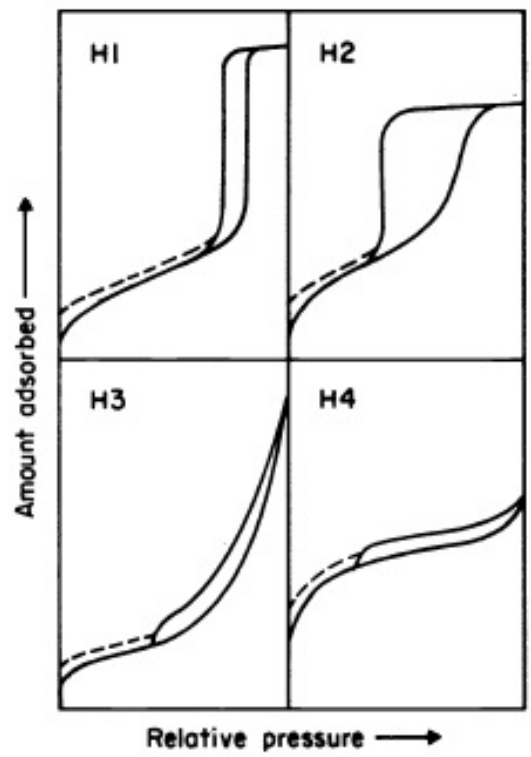

(b) Histereses

Figura 4.6: Os seis tipos de isotermas de adsorção e os quatro tipos de histere (SING, 1985).

adsorbato desempenha papel fundamental.

Tipo IV : Esse tipo de isoterma possui uma histere relacionada à condensação capilar nos mesoporos. A parte inicial é associada com a adsorção monocamadas e multicamadas já que ela tem a mesma forma da parte correspondente do Tipo 2. A quantidade de gá adsorvida tende a um valor alto e são características de adsorventes mesoporosos industriais.

Tipo V : Esse tipo de isoterma é incomum e está relacionada ao Tipo 3 de isoterma quando a interação adsorbato-adsorbato é fraca.

Tipo VI : Característica de processos de adsorção gradual multicamadas em superfícies não porosas e uniformes. O formato dos degrais depende do sistema e da temperatura e a sua altura representa a capacidade da monocamada para cada camada adsorvida. Argônio à temperatura do nitrogênio liquído é um exemplo de sólido que gera esse tipo de isoterma.

A histerese está geralmente associada com a condensação capilar. Embora muitas características do processo de adsorção ainda não sejam bem conhecidas, as histereses têm sido classificadas em quatro tipos:

H1 Associada a materiais porosos, aglomerados de esferas uniformes dispostas em arranjo regular e materiais com estreita distribuição de tamanho de poros.

H2 Característica de sólidos porosos com distribuição de tamanho de poros não muito bem definida. 
H3 Associada geralmente a agregados de partículas em forma de lâmina que possuem poros em forma de fenda. Não apresenta limite de quantidade adsorvida mesmo a altos valores $p / p_{0}$.

H4 Geralmente atribuída a sólidos com poros estreitos em forma de fenda. No caso de isoterma Tipo 1 é um indicativo de microporosidade.

\subsection{1 Área superfícial especifica BET}

Langmuir desenvolveu um modelo teórico para isotermas em processos de adsorção monocamadas. Esse modelo tem como base a teoria cinética dos gases e a superfície do adsorvente é encarada como um conjunto de sítios independentes e equivalentes disponíveis para adsorção (uma molécula por sítio). O modelo de Langmir é uma aproximação válida apenas para processos de adsorção em monocamadas e portanto não é uma representação precisa do processo de adsorção principalmente porque geralmente mais de uma molécula pode adsorver em cada sítio do adsorvente.

Através de uma série de simplificações Brunauer, Emmett e Teller estenderam o modelo de Langmuir para a adsorção em multicamadas (BRUNAUER; EMMETT; TELLER, 1938). Esse modelo, conhecido como BET, considera que as moléculas adsorvidas em cada camada podem se comportar como sítios de adsorção para moléculas da próxima camada. Uma vez formadas, as camadas de filme não são uniformes, mas pilhas aleatórias de moléculas.

A equação principal do método BET é:

$$
\frac{p / p_{0}}{V\left(1-p / p_{0}\right)}=\frac{c-1}{V_{m} c}\left(\frac{p}{p_{0}}\right)+\frac{1}{V_{m} c}
$$

Onde $V_{m}$ e $V$ são o volume do gás adsorvido em uma monocamada e o volume total adsorvido respectivamente ambos em $\mathrm{cm}^{3} / g$. O parâmetro $c$ é uma constante. ${ }^{11}$

De acordo com a equação 4.23, o fator $\left(p / p_{0}\right) /\left[V\left(1-p / p_{0}\right)\right]$ é uma função linear da variável $p / p_{0}$, onde $(c-1) /\left(V_{m} c\right)$ é o coeficiente angular e $1 /\left(V_{m} c\right)$ o coeficiente linear. Assim o volume $V_{m}$ e a constante $c$ podem ser determinados através do cálculo da inclinação dessa reta e da sua intersecção com o eixo $p / p_{0}$.

Uma vez que $V_{m}$ é calculado a partir de um ajuste linear realizado nos dados da equação 4.23 (figura 4.7), a área BET pode ser determinada por:

$$
A_{B E T}=\frac{V_{m} \cdot N_{A} \cdot s}{M_{V}}
$$

\footnotetext{
${ }^{11}$ Para informações mais detalhadas sobre o método BET e a equação 4.23 vide apêndice $B$.
} 
Onde $M_{V}$ é volume específico ocupado por um mol de moléculas do adsorbato em $\mathrm{cm}^{3} / \mathrm{mol}, N_{A}$ é o número de Avogrado em $\mathrm{mol}^{-1}$, s é a área de seção transversal média da molécula de Nitrogênio em $\mathrm{nm}^{2}$ (os valores desses parâmetros são $M_{V}=22414 \mathrm{~cm}^{3} / \mathrm{mol}, N_{A}=$ $6,022 \cdot 10^{23} \mathrm{~mol}^{-1}$ e $s=0,1620 \mathrm{~nm}^{2}$ ).

Um exemplo do ajuste da equação 4.23 é mostrado na figura 4.7.

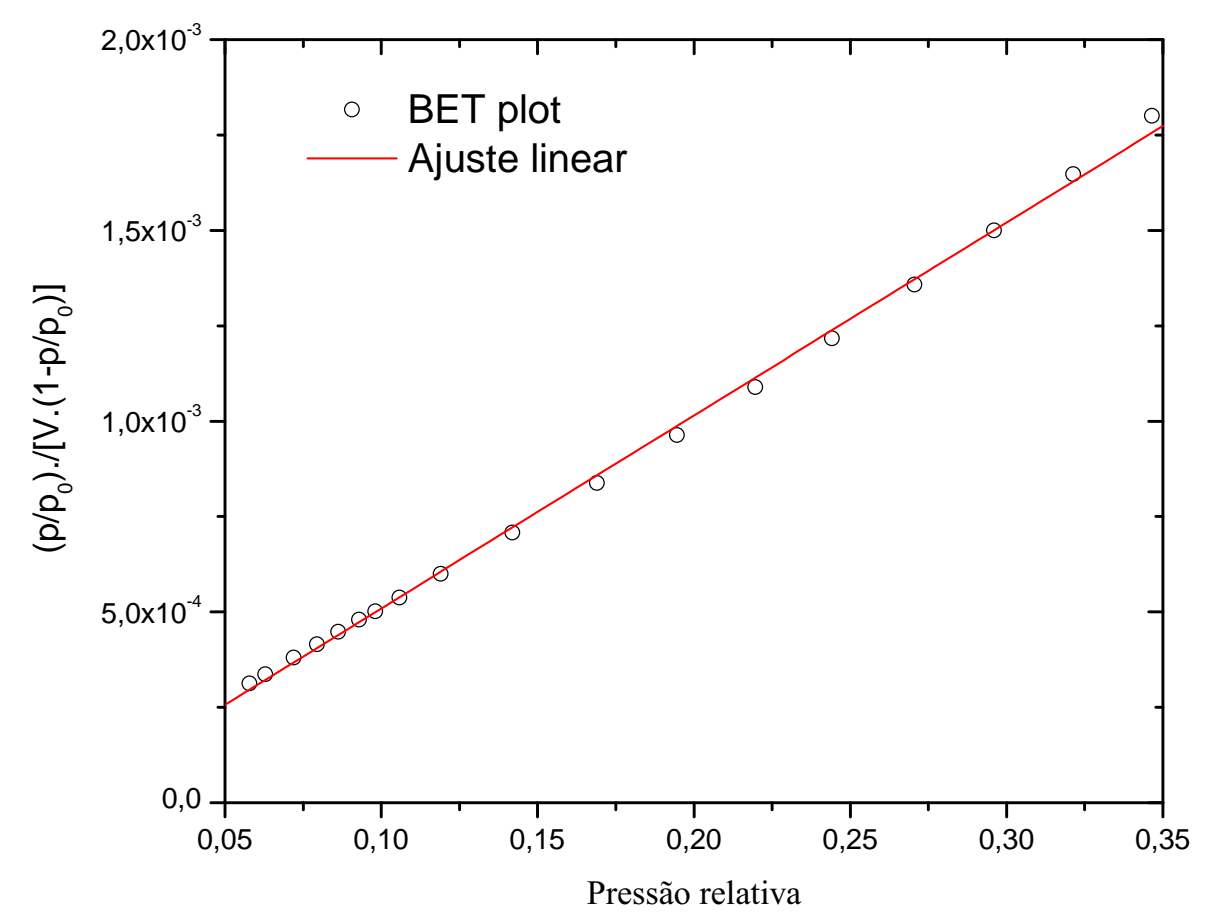

Figura 4.7: Exemplo de um ajuste a pontos dados pela equação 4.23.

\subsubsection{Volume específico e distribuição de diâmetro de poro}

O volume e a distribuição de diâmetro de poros foram determinados através do método desenvolvido por Barrett, Joyner e Halenda (1951) (BJH) com a correção posteriormente introduzida por Jaroniec e Solovyov $(2006)^{12}$. Esse método se baseia na equação de Kelvin e assume o esvaziamento gradual dos poros de acordo com a diminuição da pressão relativa. O raio do poro é igual a soma do raio do condensado capilar com a espessura das camadas

\footnotetext{
${ }^{12}$ Utilizando técnica de SAXS, esse artigo avalia a distribuição de diâmetro de poros do método BJH e chegou à conclusão que essa grandeza estava subestimada. Assim a constante $c$ foi introduzida na equação 4.27 como parte da correção proposta pelos autores.
} 
condensadas nas paredes internas do poro. O raio do condensado capilar, em nanometros, é calculado através da equação de Kelvin:

$$
r_{k}=\frac{-2 \gamma V_{M}}{R T \ln \left(p / p_{0}\right)}
$$

Onde $\gamma$ é a tensão superficial, $V_{M}$ é o volume molar do adsorbato em fase líquida, $R$ é a constante universal dos gases e $T$ a temperatura. Nesse trabalho os valores das constantes constam no artigo de Kruk, Jaroniec e Sayari (1997) $\left(\gamma=8,88 \cdot 10^{-3} \mathrm{~N} / \mathrm{m}, V_{M}=34,68 \mathrm{~cm}^{3} / \mathrm{mol}, R=\right.$ $8,314 \mathrm{~J} /(\mathrm{mol} \cdot \mathrm{K})$ e $T=77 \mathrm{~K})$.

A espessura da camada estatística de filme condensado nas paredes dos poros foi calculada através da equação Harkins-Jura (JARONIEC; SOLOVYOV, 2006):

$$
t=0,1 \cdot\left(\frac{60,65}{0,03071-\ln \left(p / p_{0}\right)}\right)^{0,3968}
$$

Com $t$ em nanometros. Uma vez que $r_{k}$ e $t$ são determinados, o diâmetro de poros pode ser calculado pela seguinte relação:

$$
D_{p}=2 \cdot r_{p}=2 \cdot\left(r_{k}+t+c\right)
$$

Na qual $c=0,3 n m$.

O volume específico total de poros foi determinado através da expressão abaixo com $p / p_{0}=0,98^{13}$ :

$$
V_{p n}=\frac{r_{p n}^{2}}{\left(r_{k n}+\Delta t_{n}\right)^{2}}\left(\Delta V_{n}-\Delta t_{n} \cdot \sum_{j=1}^{n-1} A_{p j} c_{j}\right)
$$

Onde $\Delta V_{n}$ e $\Delta t_{n}$ são a variação de volume e espessura da camada de filme entre os passos n e n-1 de adsorção respectivamente. $A_{p j}$ é a área superficial de poro de índice $j$ e $c_{j}=\left(\bar{r}_{p j}-t_{\bar{r} j}\right) / r_{p j}$ onde $\bar{r}_{p j}$ e $t_{\bar{r} j}$ são o raio médio e a espessura estatística média de filme dos poros de índice $j$ respectivamente.

A distribuição de diâmetro de poros $\left(\mathrm{PSD}^{14}\right)$ é determinada através da razão entre o volume de poro e o diâmetro:

$$
\frac{d V_{n}}{d D_{n}}=\frac{V_{p n}}{D_{p n}-D_{p(n-1)}}
$$

Os cálculos de volume e diâmetro dessa seção foram realizados utilizando-se o ramo de adsorção da isoterma. O motivo é que, de acordo com Jaroniec e Solovyov (2006), o ramo de desorção é mais suscetível a erros por ser mais sensível a qualidade da amostra. Além disso, o diâmetro médio de poros da SBA-15 convencional obtido a partir do ramo de adsorção está

\footnotetext{
${ }^{13}$ Para mais detalhes sobre o método BJH e a equação 4.28 vide o apêndice C.

${ }^{14}$ Pore Size Distribution.
} 
mais próximo daquele obtido pelo trabalho desses autores através de técnicas de difração de raios $X$.

\subsubsection{Volume específico e área superficial específica de microporos}

O volume e a área superficial específica de microporos foram determinados através do método t-plot que se baseia em um gráfico do volume adsorvido em função da espessura estatística das camadas de filme.

Esse método foi desenvolvido por DeBoer e co-autores em uma série de sete artigos (um deles é (LIPPENS; LINSEN; BOER, 1964)) nos quais a rede de poros do sólido é considerada como duas redes distintas de poros: os "poros estreitos" e os "poros largos". Assim, de acordo com essa abordagem, pode-se calcular o volume e a área devido aos microporos e devido aos mesoporos independentemente.

Em um processo de adsorção em sólidos não porosos, a espessura da camada de filme estatístico que se forma na superfície livre é proporcional ao volume de gás adsorvido. Esse fato também deve ser válido para materiais porosos submetidos a baixas pressões e cujo diâmetro de poro seja bem maior que o tamanho da molécula do adsorbato (MIKHAIL; BRUNAUER; BODOR, 1968). Assim a espessura das camadas de filme estatístico varia linearmente com a quantidade de gás adsorvido se essa condição for satisfeita. Porém, esse fato é válido na região da curva correspondente ao processo de adsorção intermediário que se desenvolve após o preenchimento dos microporos e anterior à formação do condensado capilar. Nessa região do gráfico o volume adsorvido pode ser descrito pela equação:

$$
V\left(p / p_{0}\right)=V_{m}+k A_{\text {ext }} \cdot t\left(p / p_{0}\right)
$$

Onde $V$ é o volume adsorvido em $\mathrm{cm}^{3} / \mathrm{g}, V_{m}{ }^{15}$ é o volume de microporos em $\mathrm{cm}^{3} / \mathrm{g}$, $k$ é uma constante experimental, $A_{\text {ext }}$ é a área superficial específica dos poros maiores que os microporos em $\mathrm{m}^{2} / \mathrm{g}$ e $t$ é a espessura estatística das camadas de filme adsorvidas em nanometros.

De acordo com a equação 4.30, o volume de microporos está relacionado à intersecção da reta com o eixo das ordenadas. A área superficial de microporos pode ser calculada pela subtração da área BET pela área superficial $A_{\text {ext }}$ (determinada através da equação 4.30):

$$
A_{m}=A_{B E T}-A_{e x t}
$$

Com $A_{m}$ em $\mathrm{m}^{2} / g$. A região de ajuste da reta variou para cada amostra, sendo que, em

\footnotetext{
${ }^{15} \mathrm{Não}$ confundir com $\mathrm{V}_{\mathrm{m}}$ da seção 4.2.1 que é o volume específico de uma monocamada de filme estatístico.
} 
geral os ajustes foram realizados entre os valores $0,5 \mathrm{~nm}$ e $0,7 \mathrm{~nm}$ de $t$, como no exemplificado na figura 4.8 .

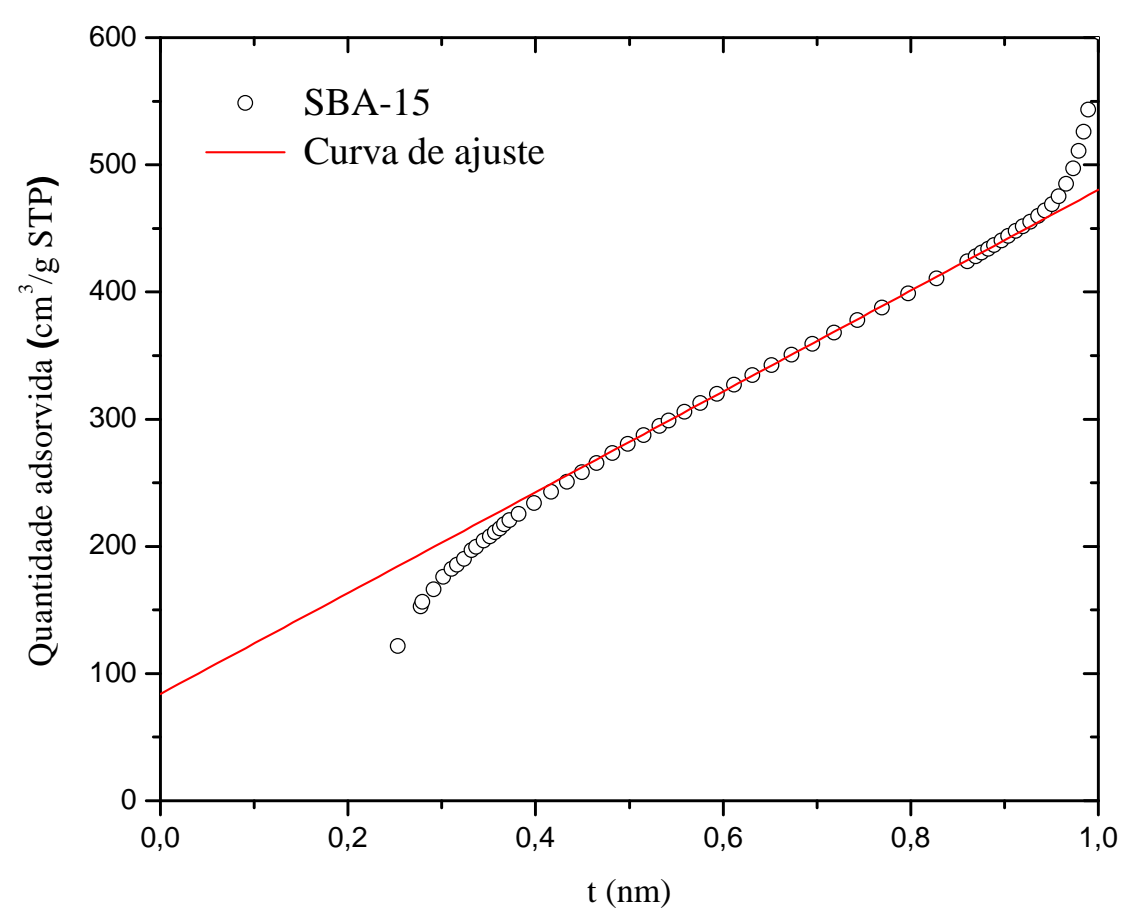

Figura 4.8: Exemplo de um gráfico t-plot.

\subsubsection{Aparato experimental}

As medidas de adsorção foram realizadas em um equipamento Micromeritics ASAP 2020. Este equipamento possui duas estações de degaseificação (degas) e uma de análise. As medidas foram realizadas na temperatura de $77 \mathrm{~K}$ com as amostras em banho de nitrogênio.

Antes de realizar as medidas as amostras foram submetidas a um tratamento térmico na estação de degas por períodos que variaram de 24 a 48 hs. As amostras sem proteínas foram submetidas a um tratamento térmico de $200{ }^{\circ} \mathrm{C}$, enquanto que as amostras com proteínas foram submetidas à temperatura de $40{ }^{\circ} \mathrm{C}$ para evitar a degradação das proteínas.

Depois da etapa de degaseificação a etapa de análise é iniciada onde a amostra é submetida a uma dada pressão mantida até que a pressão no interior da câmara onde se encontra a amostra se estabilize. Após a estabilização do sistema o valor da pressão é registrado e então prossegue-se para um novo valor de pressão. Esse processo se repete sucessivamente até que 
a pressão relativa quase atinja o valor da pressão de saturação. Após isso o sistema começa a seguir o caminho inverso, decrescendo a pressão e registrando seu valor após a estabilização sucessivamente. Durante o processo, a quantidade adsorvida é determinada com base na lei dos gases ideais, já que a quantidade de gás que entra e sai da câmara e o volume do sistema são conhecidos.

\subsection{Particle Induced X Ray Emission (PIXE)}

PIXE é um método baseado em técnicas de física nuclear que utiliza a emissão de radiação característica de elementos químicos induzida pelo bombardeamento por feixe de íons para análise da composição elementar de materiais. Os primórdios da técnica são atribuídos a Moseley em seu estudo precursor sobre a energia característica de linhas de raios $X$ de elementos da tabela periódica em 1914.

Nesta técnica, a amostra é bombardeada por um feixe de íons de alta energia, geralmente prótons ou partículas alfa. Existe então uma grande possibilidade de que elétrons de camadas interiores dos átomos da amostra sejam ejetados devido a colisões com os íons do feixe. Então, elétrons de camadas externas aos elétrons ejetados realizam uma transição para preencher a vacância deixada pelo elétron ejetado, emitindo desta maneira um fóton. ${ }^{16}$

As transições eletrônicas da camada $\mathrm{L}$ para a camada $\mathrm{K}$ são chamadas de $K \alpha$, as transições da camada $\mathrm{M}$ para a camada $\mathrm{K}$ são chamadas de transições $K \beta$, já as transições da camada $M$ para a camada $L_{3}$ são chamadas de $L \alpha$ e assim por diante. A figura 4.9 mostra algumas das possíveis linhas de transição.

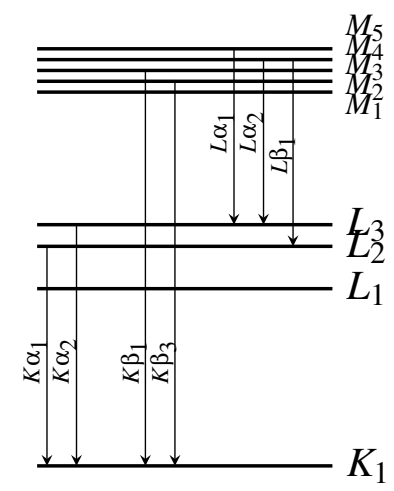

Figura 4.9: Diagrama de níveis de energia eletrônico com as principais transições $\mathrm{K}$ e L.

O espectro de raios $X$ é composto pela emissão característica dos elementos que compõem a amostra e por um fundo contínuo. O fundo contínuo determina o limite de detecção do

\footnotetext{
${ }^{16}$ Existe também a possibilidade da emissão de elétrons Auger. Elementos com Z menor que 11 têm maior probabilidade de emissão de elétrons Auger que fluorescência.
} 
método e é constituído por basicamente dois processos: o bremsstrahlung e a radiação gama.

O fundo devido a raios gama ocorre quando os íons do feixe atravessam a barreira de potencial Coulombiano do núcleo provocando uma reação nuclear com a emissão de radiação gama como resultado. A produção de radiação gama tem maior ocorrência em elementos leves e para feixes mais energéticos (a energia do feixe utilizado nesse experimento é 2,4 MeV) e é bastante atenuada através do arranjo experimental com escolha adequada dos materiais constituintes da câmara de amostra e o detector. Portanto, sua contribuição é desprezível.

O bremsstrahlung ocorre quando uma partícula carregada emite radiação ao ser desacelerada por uma campo eletromagnético. Existem o bremsstrahlung devido à desaceleração dos íons incidentes e de elétrons secundários ejetados da amostra. O bremsstrahlung devido aos prótons do feixe é muito menos intenso que o emitido por elétrons secundários já que, embora ambos estejam sujeitos à forças de Coulomb, a massa do elétron é cerca de 1836 vezes menor que a massa do próton.

Assim, a maior contribuição ao fundo é dada pela radiação proveniente de elétrons secundários da amostra. Para reduzir os efeitos do bremsstrahlung os detectores são geralmente posicionados em ângulos maiores que $90^{\circ}$ em relação à direção do feixe pois a radiação emitida devido à desaceleração de elétrons secundários é máxima na direção do feixe.

\subsubsection{Aparato experimental e método}

As medidas foram realizadas no Laboratório de Materiais e Feixes lônicos da Universidade de São Paulo (LAMFI-USP) que possui um acelerador de partículas Tandem de $2 M V$.

Para realizar as medidas as amostras foram transformadas em pastilhas. Essas pastiIhas foram feitas em um pastilhador de $15 \mathrm{~mm}$ no Laboratório de Alvos do Laboratório Pelletron, do Instituto de Física da Universidade de São Paulo. As amostras foram depositadas sobre uma matriz de ácido bórico onde foram submetidas à uma pressão de cerca de $4 \cdot 10^{7} \mathrm{~Pa}$.

Em análise de PIXE é necessário um modelamento do espectro para adquirir informações dos elementos da amostra. Para identificação dos picos, uma calibração (ou padronização) em energia foi realizada. O espectro adquirido foi graficado e, com o auxílio do programa QXAS $^{17}$, um polinômio foi ajustado ao fundo para a sua subtração. Em seguida, uma função gaussiana foi ajustada a cada pico a fim de determinar o total de contagens (que é igual a área do pico) referente a cada elemento.

O número de contagens referente ao elemento silício do espectro é substituído na equa-

\footnotetext{
${ }^{17}$ IAEA LABORATORIES WINQXAS <http://www.iaea.org/OurWork/ST/NA/NAAL/pci/ins/xrf/pci.XRFdown.php>. Acesso em: 15 de janeiro de 2015.
} 


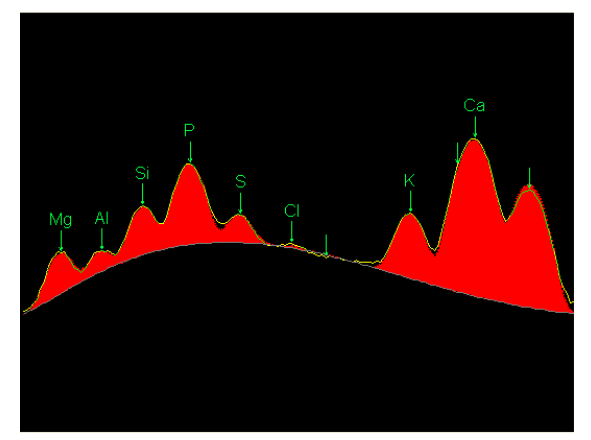

Figura 4.10: Figura mostrando uma região do espectro carcacterístico obtido por medidas de PIXE.

ção ${ }^{18}$ abaixo:

$$
Y=K \cdot r_{Z} \cdot C_{Z} \cdot Q
$$

Onde $\mathrm{Y}$ é o número de contagens, $\mathrm{K}$ é o fator de correção para alvos espessos em $\mathrm{g} / \mathrm{cm}^{2}, r_{z}$ é o fator de resposta para alvos finos em $\mathrm{cm}^{2} /(\mu \mathrm{C} \cdot \mu \mathrm{g}), C_{Z}$ é a concentração em massa do elemento de número atômico $Z$ em partes por milhão (ppm) e $Q$ é a carga integrada do feixe em $\mu \mathrm{C}$.

O fator de resposta $r_{Z}$ foi adquirido de tabela disponível no site do LAMFI ${ }^{19}$ e o seu valor é $r_{Z}=1,203 \cdot 10^{4} \mathrm{~cm}^{2} /(\mu \mathrm{C} \cdot \mu \mathrm{g})$.

O fator de correção para alvos grossos $\mathrm{K}$ é a razão entre os fatores de resposta para alvos grossos $\left(R_{Z}\right)$ e para alvos finos $\left(r_{Z}\right)^{20}$. Mariano-Neto (2008), em sua dissertação de mestrado, utilizou-se de amostras de órgãos de camundongos, e em nosso estudo utilizamos fezes desses animais. A partir do estudo elaborado por Mariano-Neto (2008) foi possível identificar o fator $\mathrm{K}$, valor este utilizado como referência em nosso estudo visto que, após a calcinação e eliminação dos produtos carbonáceos, consideramos que a composição da amostra de fezes é aproximadamente a mesma das amostras de órgãos utilizadas por Mariano-Neto. O valor desse fator é $\mathrm{K}=14,207 \cdot 10^{-4} \mathrm{~g} / \mathrm{cm}^{2}$.

A concentração de sílicio $C_{Z}$ de cada amostra foi então calculada utilizando a equação 4.32 já que os outros fatores são conhecidos.

\footnotetext{
${ }^{18}$ Para mais informaçãoes sobre o método PIXE vide apêndice D.

${ }^{19}$ LAMFI-USP <ftp://hidrogenio.if.usp.br/Espectros>. Acessado em: 15 de janeiro de 2014.

${ }^{20}$ Vide anexo D.2.
} 


\section{ESTUDO DA INCORPORAÇÃO DE PROTEÍNAS EM SBA-15 COM POROS EXPANDIDOS}

\subsection{Adição de TIPB}

Os dados de SAXS revelaram que a adição de TIPB deu origem a uma sílica com poros maiores e com estrutura de poros mais desordenada, como já observado em outros trabalhos da literatura (CAO; MAN; KRUK, 2009). Esse fato é evidenciado pela diminuição da intensidade integrada dos picos de difração e pela ausência dos picos (210) e (300) nas curvas das amostras com TIPB (figura 5.1). Os picos referentes à reflexão (100) estão deslocados para menores valores de $q$, fato relacionado ao maior parâmetro de rede dessas amostras.

Se a rede de poros for ordenada as posições dos picos de difração no espaço recíproco terão uma relação bem definida entre si. Para o caso da rede hexagonal as razões entre os valores de $q$ das reflexões pelo valor de $q$ da reflexão (100) são $\sqrt{1}, \sqrt{3}, \sqrt{4}, \sqrt{7}$ e $\sqrt{9}$ (FREIBERGER; GLATTER, 2006) ${ }^{1}$.

A tabela 5.1 mostra o valor dessas razões calculados para todas as amostras. As razões estão muito próximas dos valores esperados para uma rede hexagonal, o que inidica que, em média, a rede de poros não deixou de ser hexagonal com a adição de TIPB.

\begin{tabular}{|c|c|c|c|c|}
\hline & $\mathbf{q}_{(\mathbf{1 1 0})} / \mathbf{q}_{(\mathbf{1 0 0})}$ & $\mathbf{q}_{(\mathbf{2 0 0})} / \mathbf{q}_{(\mathbf{1 0 0})}$ & $\mathbf{q}_{(\mathbf{2 1 0})} / \mathbf{q}_{(\mathbf{1 0 0})}$ & $\mathbf{q}_{(\mathbf{3 0 0})} / \mathbf{q}_{(\mathbf{1 0 0})}$ \\
\hline P0 & 1,734 & 1,995 & 2,646 & 2,998 \\
\hline P05 & 1,727 & 1,992 & - & - \\
\hline P2 & 1,741 & 2,020 & - & - \\
\hline
\end{tabular}

Tabela 5.1: Razões entre os as posições dos picos de difração no espaço recíproco.

\begin{tabular}{|c|c|c|c|c|c|c|}
\hline & $\begin{array}{c}\mathbf{V}_{\mathbf{t}} \\
\left(\mathbf{c m}^{\mathbf{3}} / \mathbf{g}\right)\end{array}$ & $\begin{array}{c}\mathbf{V}_{\mathbf{m}} \\
\left(\mathbf{c m}^{\mathbf{3}} / \mathbf{g}\right) \cdot 10^{-2}\end{array}$ & $\begin{array}{c}\mathbf{A}_{\text {BET }} \\
\left(\mathbf{m}^{2} / \mathbf{g}\right)\end{array}$ & $\begin{array}{c}\mathbf{A}_{\mathbf{m}} \\
\left(\mathbf{m}^{2} / \mathbf{g}\right)\end{array}$ & $\begin{array}{l}D_{p} \\
(\AA)\end{array}$ & $\begin{array}{c}a \\
(\AA)\end{array}$ \\
\hline P0 & 1,33 & $12,99(25)$ & 910 & $297(4)$ & 109 & 121 \\
\hline P05 & 1,33 & $13,80(25)$ & 765 & $304(5)$ & 117 & 125 \\
\hline P2 & 1,34 & $13,74(22)$ & 698 & $303(4)$ & 135 & 146 \\
\hline
\end{tabular}

Tabela 5.2: Dados de SAXS e NAI de amostras de SBA-15 convencional e com poros expandidos. Os erros no cálculo dos parâmetros de rede e das áreas específicas BET devidos aos ajustes foram iguais ou inferiores a $0,5 \%$. Aqui $V_{t}$ é o volume total de poros, $V_{m}$ é o volume de microporos, $A_{B E T}$ é a área superficial específica BET, $A_{m}$ é a área superficial específica de microporos, $D_{p}$ é o diâmetro médio de poros e $a$ é o parâmetro de rede.

\footnotetext{
${ }^{1}$ Para mais detalhes vide o apêndice A.1.
} 


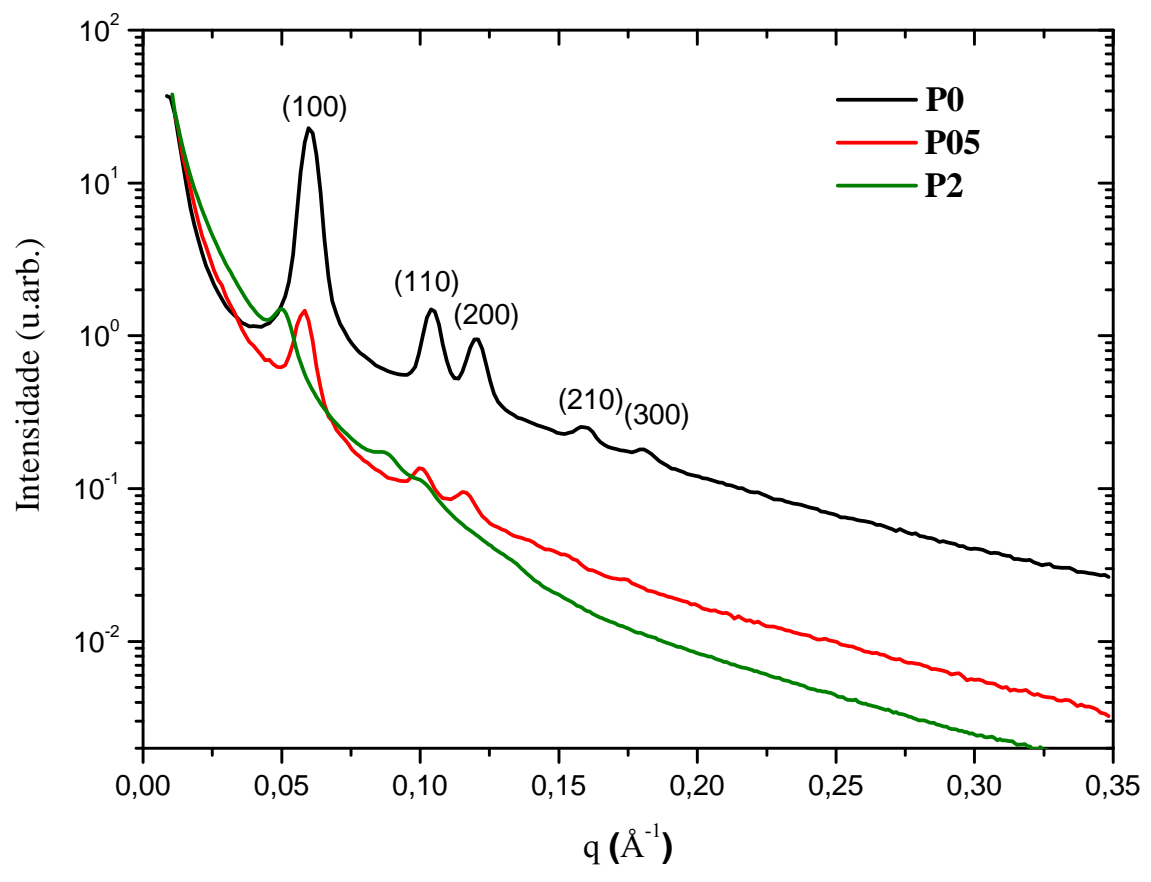

Figura 5.1: Curvas de SAXS de amostras de SBA-15 com poros de diferentes tamanhos.

Os dados de NAI, apresentados na tabela 5.2, mostram que a adição de TIPB provocou diminuição nas áreas superficiais específicas BET. As isotermas estão apresentadas na figura 5.2a.

As áreas específicas BET das amostras com poros expandidos apresentaram uma redução de $16 \%$ e $23 \%$. O diâmetro médio de poros aumentou com a razão em massa TIPB/P123 obtendo-se um valor $23 \%$ superior ao valor da amostra convencional P0 para amostra com maior quantidade de dilatador de estrutura. O volume e área superficial específica de microporos não foram alterados significativamente com a expansão dos poros.

Como esperado, a curva de PSD (figura 5.2b) da amostra P0 revela uma estreita distribuição de diâmetro de poros enquanto que as amostras com TIPB mostraram uma distribuição mais esparsa, característica de uma rede de poros mais polidispersa em diâmetro.

A isoterma da amostra P05 sugere uma porosidade secundária. Essa porosidade secundária é também evidenciada na curva de distribuição de tamanho de poros bi-modal dessa amostra, que revela um pequeno pico situado em $D \approx 104 \AA$. Assim, pode-se inferir a existência de uma rede de poros secundária com diâmetro médio de aproximadamente $104 \AA$ na amostra P05, provavelmente devido ao fato de que a quantidade de TIPB não foi suficiente para o alargamento de todos os poros da matriz.

A adição de TIPB não resultou em um aumento significativo de diâmetro de poros e de parâmetro de rede. Resultados na literatura mostram que é possível até mesmo dobrar o diâmetro por meio da adição de dilatadores de estrutura e alterações de outros parâmetros ex- 
Capítulo 5. ESTUDO DA INCORPORAÇÃO DE PROTEÍNAS EM SBA-15 COM POROS EXPANDIDOS

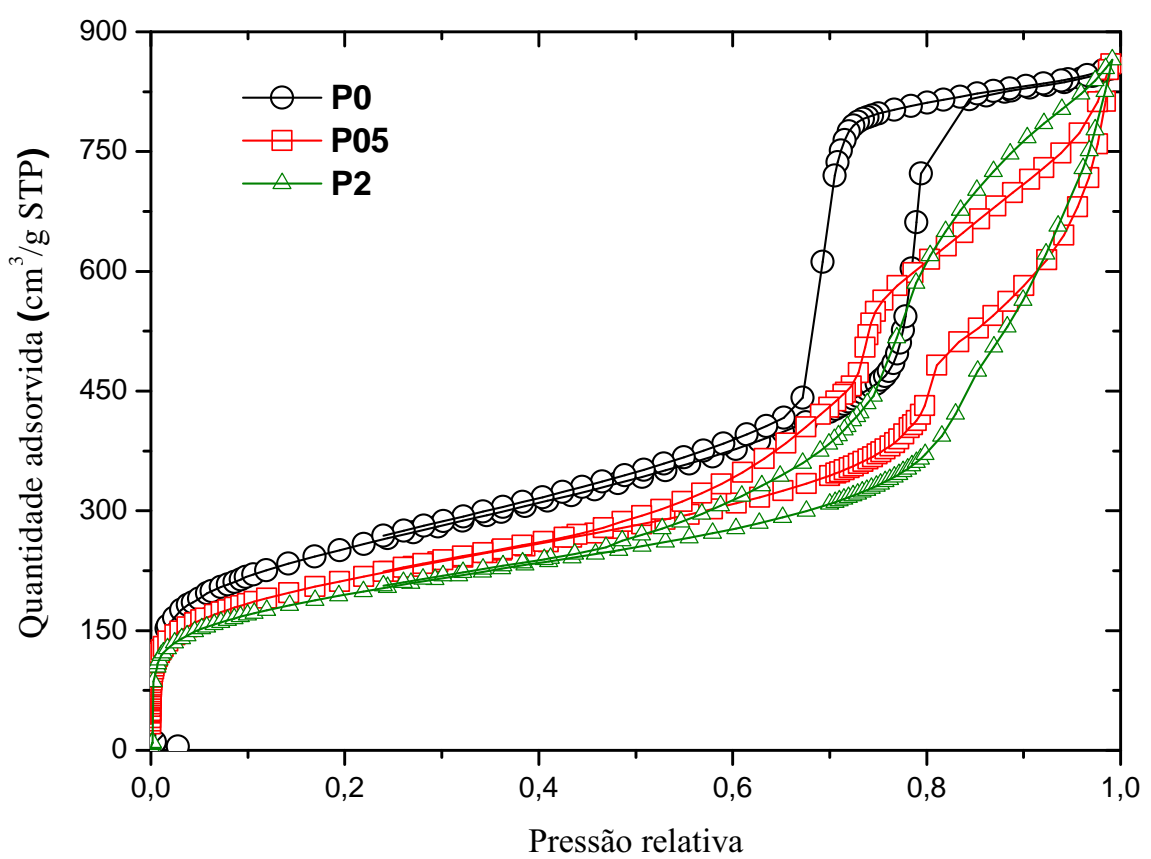

(a) Isotermas

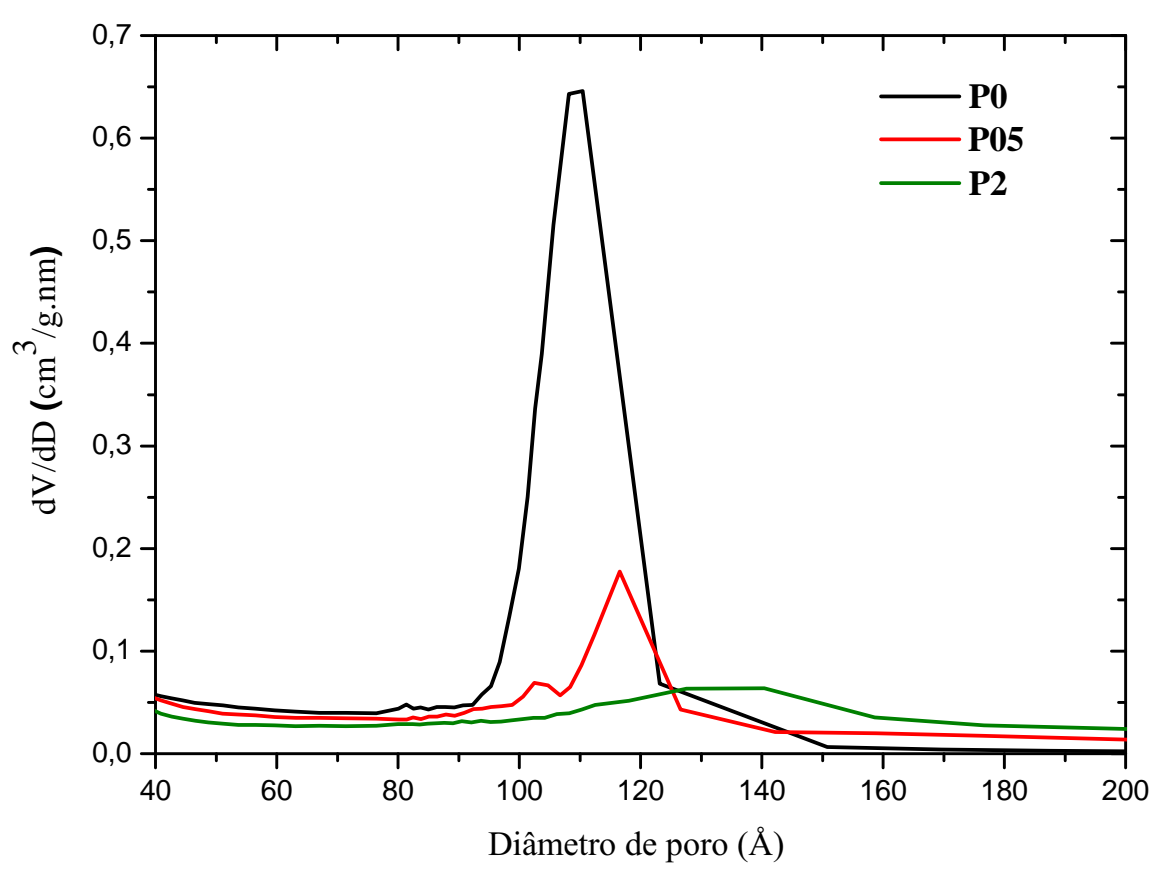

(b) Distribuição de tamanho de poros

Figura 5.2: Isotermas de adsorção e distribuição de tamanho de poros de amostras de SBA-15 convencional e com poros expandidos. 
perimentais como a temperatura de síntese (CAO; MAN; KRUK, 2009; CAO; KRUK, 2010). Por outro lado o grau de ordenamento das amostras foi satisfatório quando considerada a grande quantidade utilizada de dilatador de estrutra já que a curva de SAXS da amostra com maior quantidade (figura 5.1) ainda mostra os picos de difração (100), (110) e (200), o que tornou possível uma avaliação preliminar sobre a hexagonalidade da rede poros.

\subsection{Caracterização das proteínas}

Para realizar uma estimativa sobre as dimensões das proteínas utilizadas medidas de SAXS foram realizadas em amostras de BSA e IgG diluídas em PBS. Em uma primeira tentativa o programa Gnom foi utilizado para tentar ajustar os dados experimentais da BSA considerandose um sistema monodisperso. O diâmetro máximo da partícula para esse ajuste foi de $D_{\max }=$ $142 \AA$.

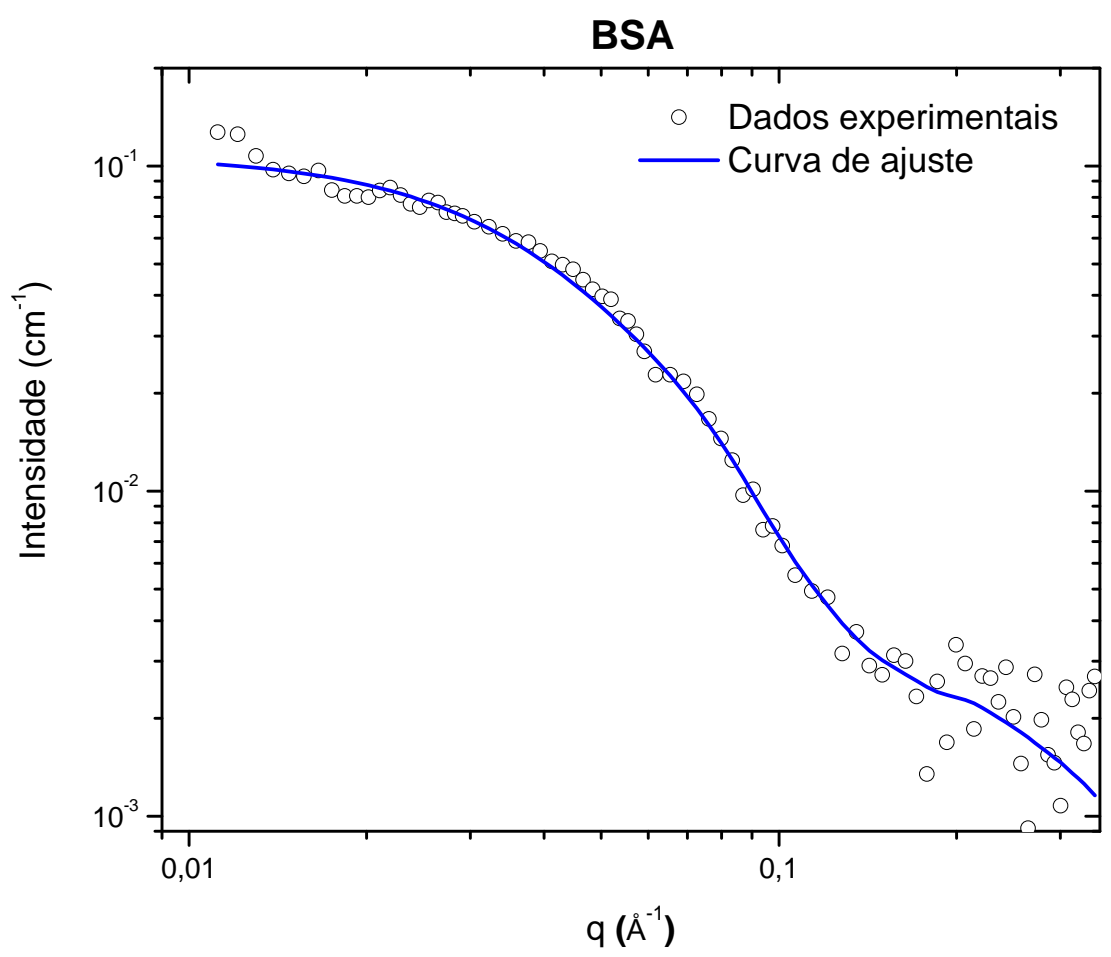

Figura 5.3: Dados experimentais e curva de ajuste da BSA realizado considerando a amostra como um sistema monodispersa. Curva obtida através do programa Gnom.

A figura 5.3 mostra o gráfico obtido e pode-se observar que a curva de ajuste não contempla os três primeiros pontos. Além disso, o ajuste não é satisfatório para pontos situados em q > 0,17 $\AA$. O fato da curva não se ajustar aos primeiros pontos de forma satisfatória pode 


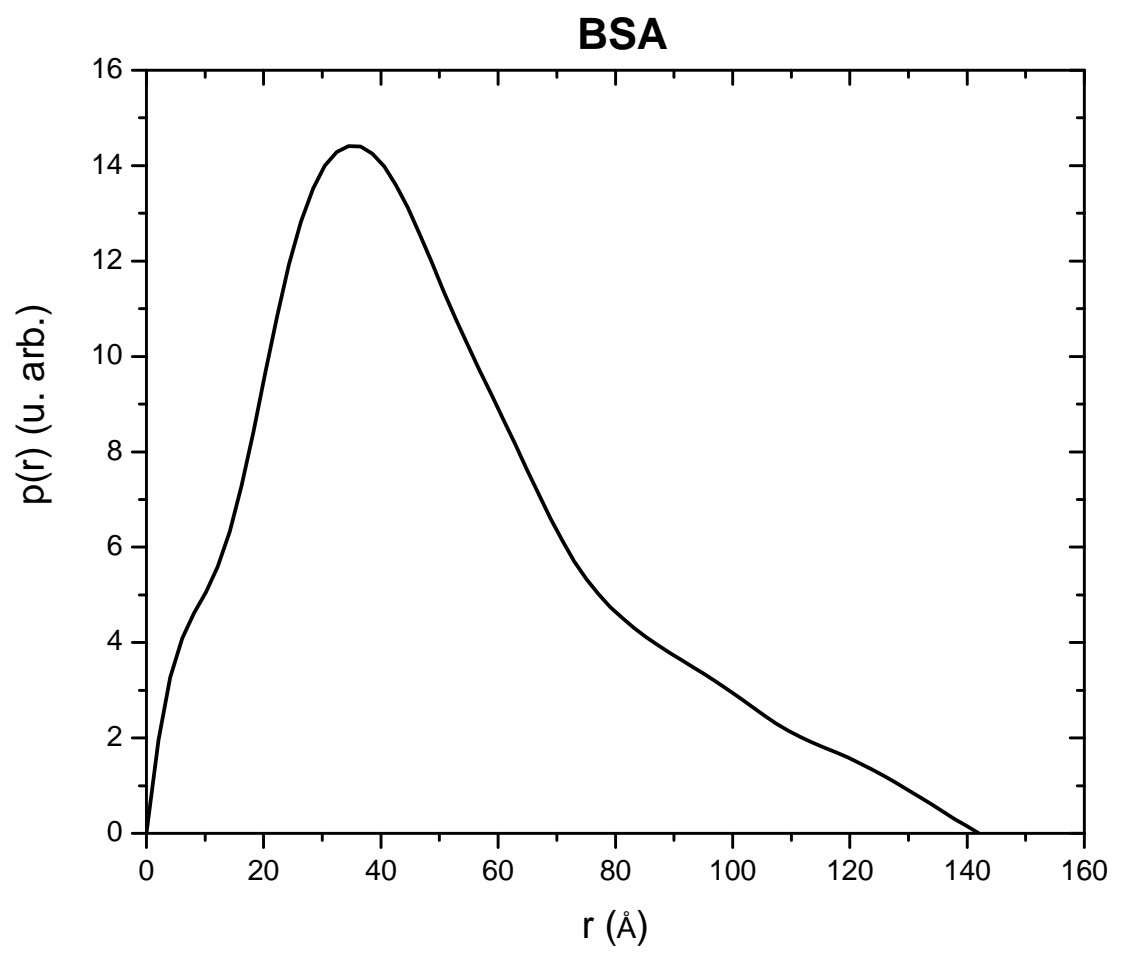

Figura 5.4: Função de distribuição de pares de distâncias da amostra de BSA obtida através do programa Gnom.

indicar que a amostra possui aglomerados de partículas ou partículas com diâmetro superior ao diâmetro considerado. Porém, ao realizar o ajuste com diâmetro maior a curva se ajusta aos primeiros pontos mas se distancia dos pontos restantes. Na verdade, a amostra de BSA é constituída de um sistema composto por monômeros e dímeros e portanto, como o sistema não foi considerado corretamente, a curva de ajuste não descreve corretamente os dados experimentais em algumas regiões do gráfico. A figura 5.4 mostra a $p(r)$ obtida a partir desse ajuste e a sua análise será realizada adiante.

Como não foi possível ajustar os dados satisfatóriamente considerando um sistema monodisperso o programa Oligomer foi utilizado. Como explicado na seção 4.1.6, esse programa permite ajustar curvas a dados de espalhamento de amostras de proteínas compostas por dois ou mais sistemas de partículas. O gráfico é mostrado na figura 5.5 (na legenda da figura também é mostrado $\chi^{2}$ reduzido que é uma estimativa da qualidade do ajuste) e observa-se que ao considerar o sistema como sendo composto de monômeros e dímeros a curva teórica descreve os dados de forma mais adequada. Utilizando esse ajuste foi possível determinar a massa molecular e a concentração de monômeros e dímeros, além de ter sido possível criar uma representação gráfica das proteínas nos programas Massha e Rasmol (figuras 5.8a e 5.8b) e assim determinar de forma aproximada as suas dimensões (tabela 5.3).

Observe-se que o diâmetro máximo obtido pela curva da $p(r)$ da BSA (figura 5.4) concorda com a maior dimensão do dímero $(\approx 140 \AA$ ) determinada através do programa Massha. 


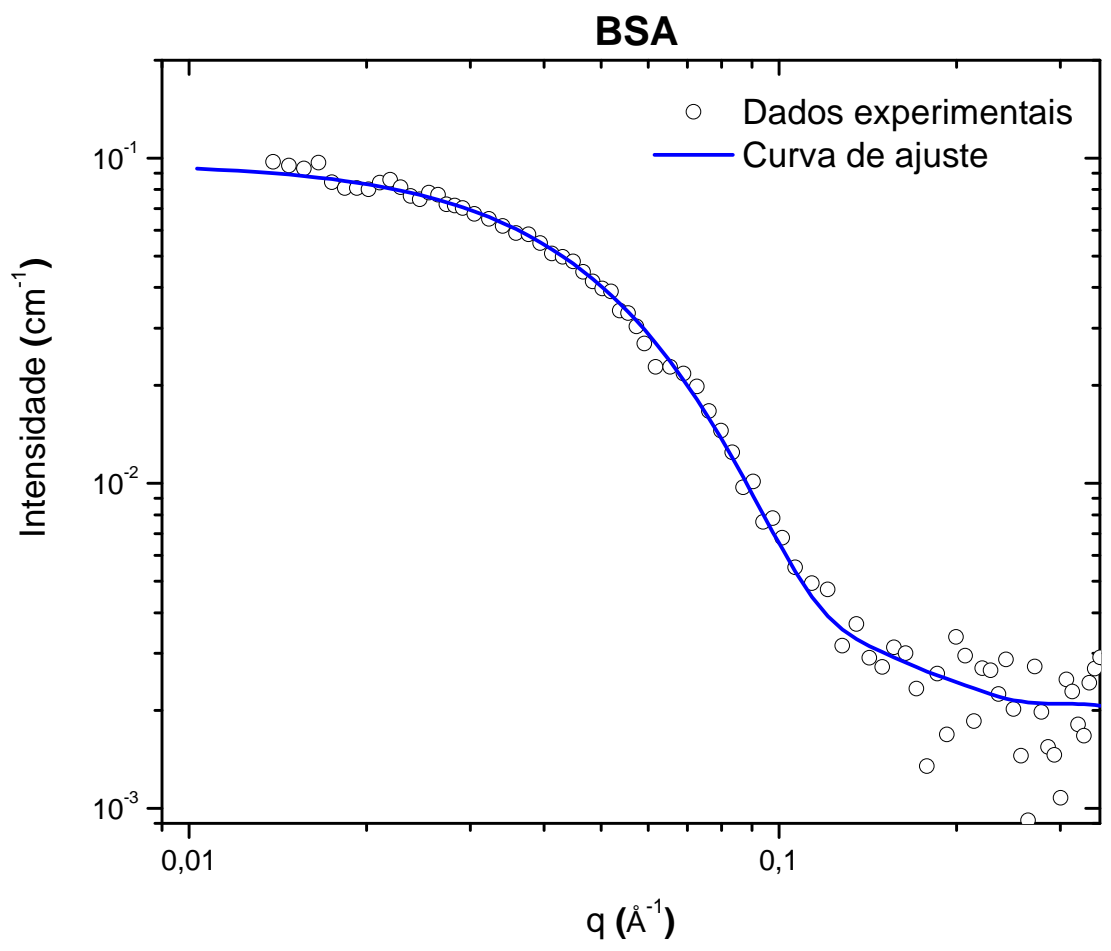

Figura 5.5: Dados experimentais e curva de ajuste da BSA realizado considerando a amostra como um sistema de monômeros e dímeros. Curva obtida através do programa Oligomer. $\chi^{2}=$ 9,88 .

\begin{tabular}{ccc}
\hline & Monômero & Dímero \\
\hline Massa molecular (kDa) & 66,4 & 133,0 \\
Fração de volume (\%) & $66,3(4)$ & $33,7(3)$ \\
Dimensões $(\AA)$ & $28 \times 70 \times 41$ & $30 \times 140 \times 40$ \\
\hline
\end{tabular}

Tabela 5.3: Massa molecular, fração de volume ocupado e dimensões dos monômeros e dímeros da amostra de BSA.

Isso ocorre porque, mesmo considerando um sistema monodisperso, a curva da $p(r)$ ainda denota a partícula de maior tamanho, nesse caso o dímero. Também, a $p(r)$ da amostra de BSA é característica de partículas alongadas e o pico em $r \approx 35 \AA$ corresponde ao valor médio das outras duas dimensões do monômero e do dímero, que são aproximadamente $30 \AA$ e $40 \AA$.

As figuras 5.6 e 5.7 mostram a curva e a função de distribuição de pares de distância calculadas para a amostra de IgG. Como no caso do ajuste realizado para a amostra de BSA considerando um sistema monodisperso, a curva de ajuste da amostra de IgG não descreve de forma satisfatória os dados experimentais nas partes inicial e final do gráfico.

Como não há informação suficiente (como, por exemplo, o(s) subtipo(s) de anticorpo(s) presente(s) na amostra) não foi possível realizar um ajuste utilizando o Oligomer. A curva da $\mathrm{p}(\mathrm{r})$ (figura 5.7) dessa proteína também dá indícios de que se trata de uma amostra polidispersa já que existe um pequeno "ombro" em $r \approx 10 \AA$. 


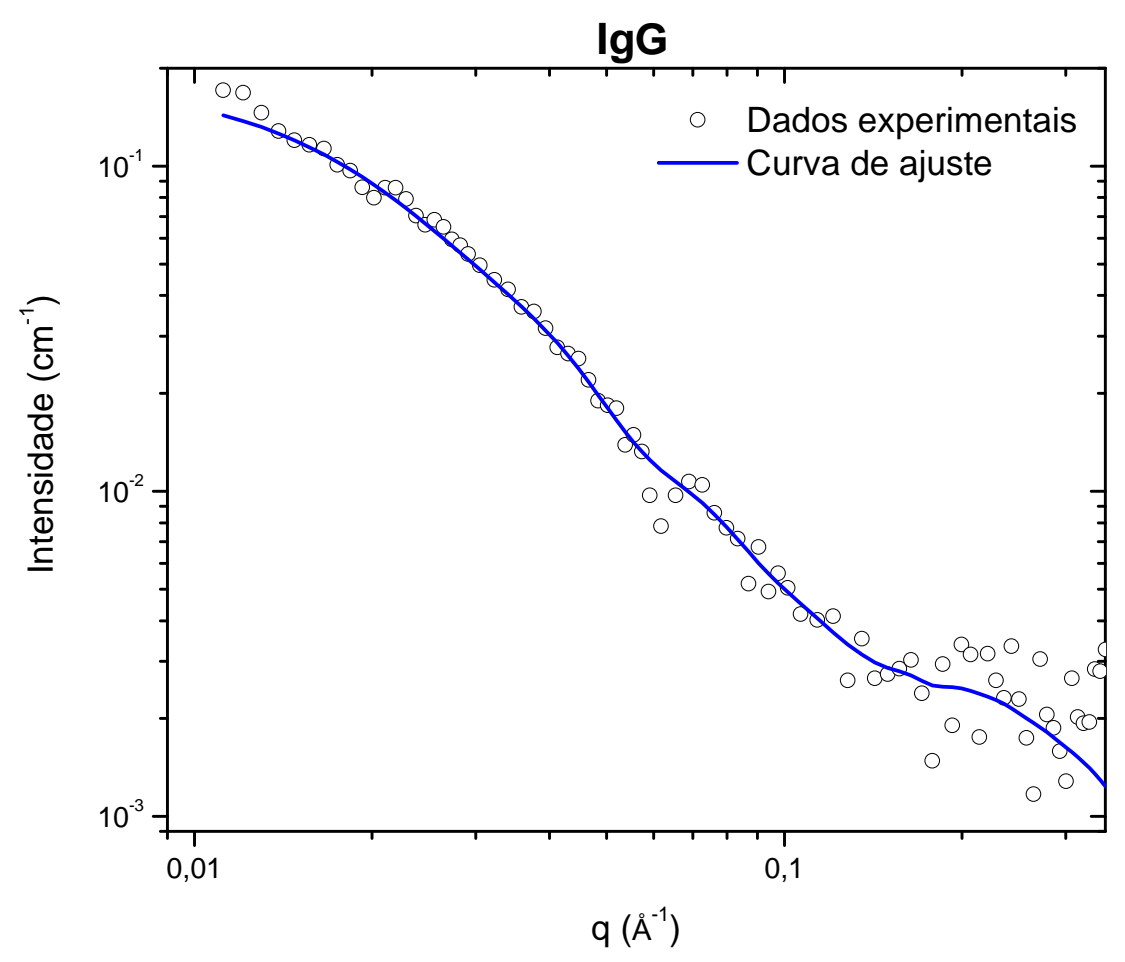

Figura 5.6: Dados experimentais e curva de ajuste da IgG realizado considerando a amostra como um sistema monodisperso. Curva obtida através do programa Gnom.

Apesar das discrepâncias entre a curva de ajuste e os dados experimentais, pode-se considerar que, de acordo com $\mathrm{p}(\mathrm{r})$, a lgG possui partículas de dimensão máxima de aproximadamente $270 \AA$ A pois, como dito anteriormente, a dimensão máxima obtida pela $p(r)$ está relacionada às partículas maiores que compõem a amostra. Essa $p(r)$ também é semelhante à $\mathrm{p}(\mathrm{r})$ de partículas alongadas (GLATTER; KRATKY, 1982).

Os resultados mostram que a BSA tem dimensões que permitiriam um eventual encapsulamento nos poros das amostras de SBA-15 já que, como demonstrado na seção 5.1, o diâmetro médio de poros das amostras utilizadas são $109 \AA$ Å, $117 \AA$ e $135 \AA$ para P0, P05 e P2 respectivamente. $A \mathrm{p}(\mathrm{r})$ da $\mathrm{lgG}$ apresenta um pico disforme em $r \approx 70 \AA$, o que pode caracterizar que, como no caso da BSA, as partículas que compõem a lgG têm diâmetro máximo de $270 \AA$ com valor médio de $70 \AA$ para as outras duas dimensões.

Sendo assim, é provável que ao menos parte das partículas que compõem IgG também tenham dimensões suficientes para serem encapsuladas nos poros das amostras de SBA-15. 
Capítulo 5. ESTUDO DA INCORPORAÇÃO DE PROTEÍNAS EM SBA-15 COM POROS EXPANDIDOS

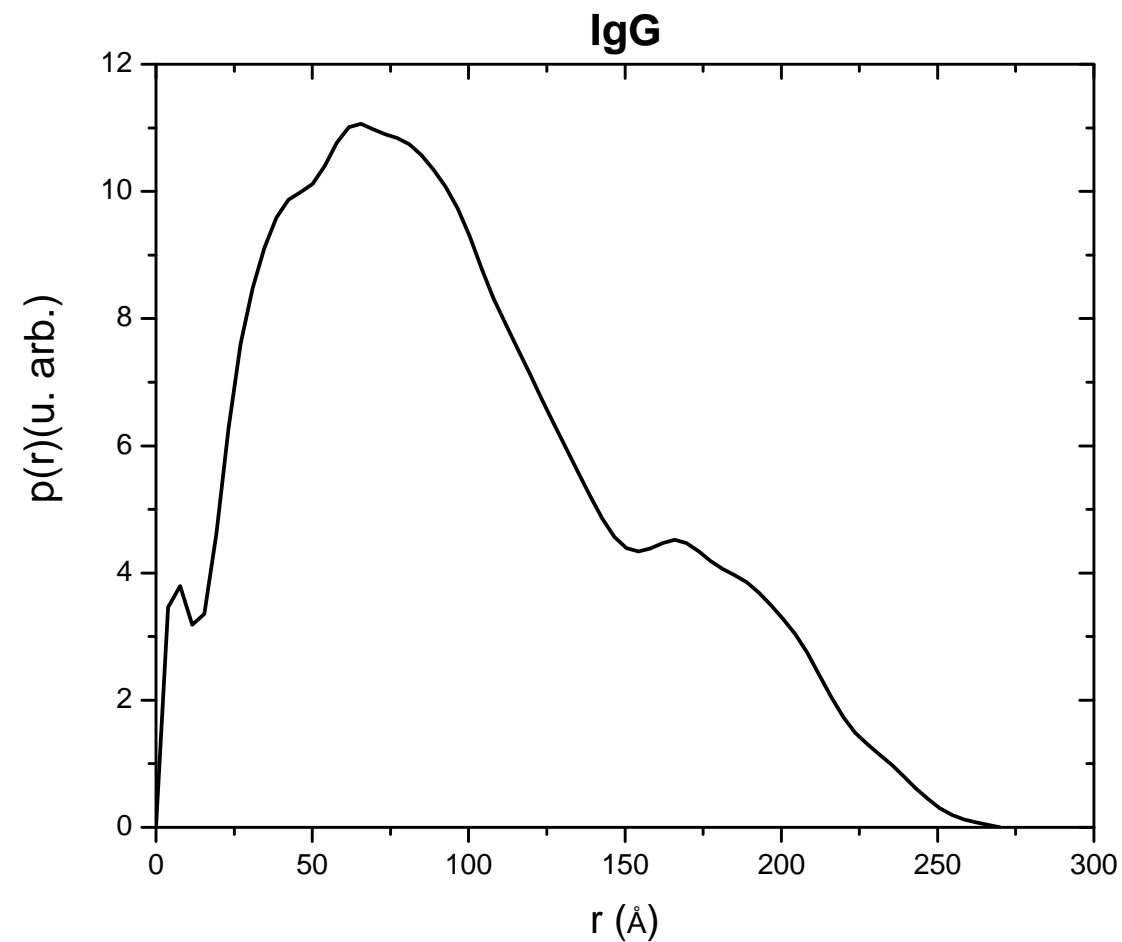

Figura 5.7: Função de distribuição de pares de distâncias da amostra de IgG obtida através do programa Gnom.

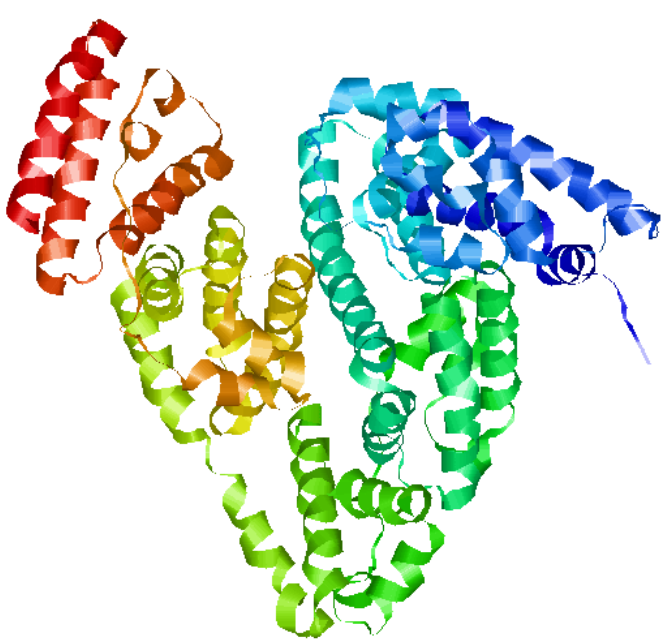

(a) Monômero

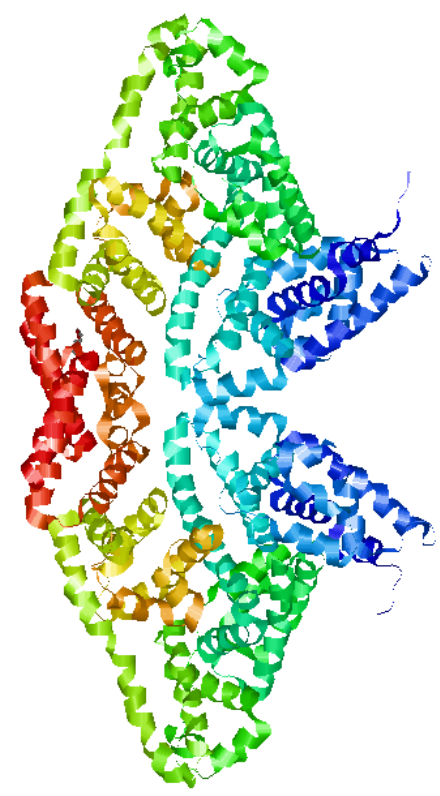

(b) Dímero

Figura 5.8: Representação gráfica do monômero e do dímero da proteína BSA. Realizado no programa Rasmol. 


\subsection{Incorporação de proteínas}

As curvas de SAXS (figuras 5.9, 5.11 e 5.13) das amostras com proteínas estão deslocadas para menores valores da intensidade no eixo das ordenadas. Esse fato se deve à absorção da proteína presente na amostra e também ao preenchimento dos microporos. O parâmetro de rede não foi alterado com a incorporação, resultado já esperado considerando a estabilidade hidromecânica da SBA-15.

Foram calculadas as áreas integradas dos picos de difração (100), (110) e (200) ${ }^{2}$ das amostras com proteínas (figuras 5.10, 5.12 e 5.14). Os valores estão listados na tabela 5.1 e mostram que as amostras com proteínas apresentaram intensidades integradas menores que as amostras sem proteínas. Essa é uma indicação da presença das proteínas e do PBS nos poros do material, já que a redução da intensidade de espalhamento dos picos de reflexão indica uma diminuição do contraste de densidade eletrônica entre os poros e a matriz de sílica. Não houve diferença significativa entre as amostras com BSA e IgG, com exceção da amostra com razão 2 de TIPB/P123. A maior área integrada dos picos de difração referentes à amostra com PBS (POP) revela que a incorporação isolada do PBS pode estar relacionada a um maior contrataste de densidade eletrônica entre os poros e a matriz do que nas amostras com PBS e proteína. Outra possibilidade é que a amostra com PBS pode ter uma menor absorção que as outras amostras, o que explicaria a maior intensidade integrada dos picos de difração.

A figura 5.11 mostra que o pico de difração (210) das amostras com razão em massa TIPB/P123 de 0,5 se tornou evidente após a incorporação das proteínas. Esse fato provavelmente está relacionado à redução de contraste de densidade eletrônica de mesoporos menores e microporos devido ao seu preenchimento. Esses poros menores contribuem significativamente para a intensidade da curva de espalhamento para grandes valores de $q$ (SUNDBLOM et al., 2009). Assim, como a influência ou o espalhamento devido a eles diminui, o espalhamento devido a rede hexagonal de mesoporos se torna mais evidente provocando a aparição da reflexão (210).

Os resultados de NAl estão apresentados nas figuras 5.15, 5.16 e 5.17. A diminuição no volume e área superficial de microporos foi igual ou superior a $95 \%{ }^{3}$. Os resultados da amostra POP sugerem que os microporos foram preenchidos apenas pelo PBS pois o volume e área superficial específica de microporos da amostra com PBS foram os mesmos das amostras com BSA e lgG. Além disso, as dimensões das proteínas, que foram calculadas de forma aproximada na seção 5.2, não permitem a sua entrada nos microporos. Deste modo, podemos atribuir o

\footnotetext{
${ }^{2}$ Não foram calculadas as áreas integradas dos picos (210) e (300) porque esses picos apresentam intensidades muito pequenas e são muito indefinidos.

${ }^{3}$ Ao realizar o ajuste linear para o cálculo da área e o volume específico de microporos (descritos na seção 4.2.3) da amostra P2B o coeficientes linear da reta resultou negativo. Isso é comum quando o método t-plot é aplicado à amostras que tem um volume muito baixo de microporos ou não são microporosas. Assim, $V_{m}$ e $A_{m}$ têm valores muito pequenos e foram assumidos como 0 .
} 
preenchimento dos microporos de todas as amostras à presença do PBS.

A curva de distribuição de diâmetro de poros também assinala um preenchimento de poros maiores já que o diâmetro médio de poros foi deslocado para menores valores. Essa diminuição é mais evidente para as amostras com poros expandidos (figuras 5.16b e 5.17b).

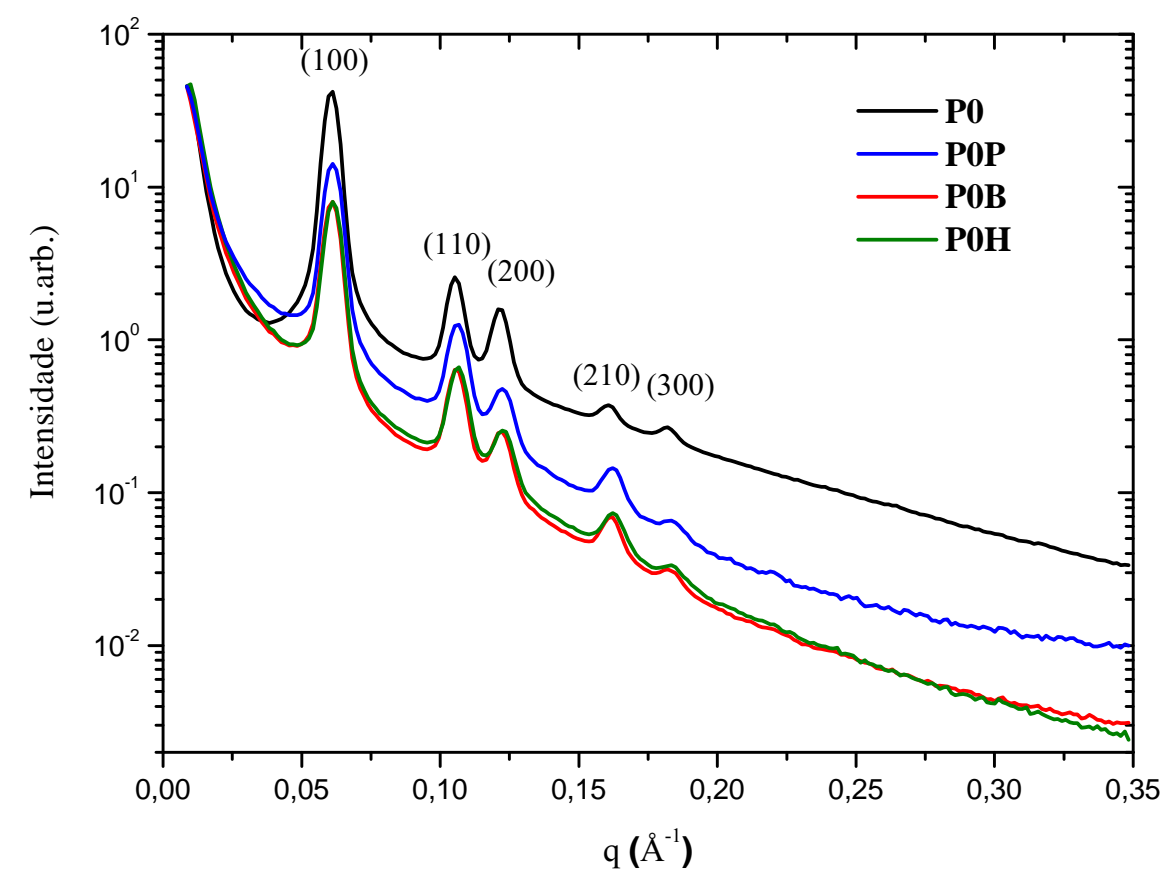

Figura 5.9: Curvas de SAXS de amostras de SBA-15 convencional, com proteínas e PBS.

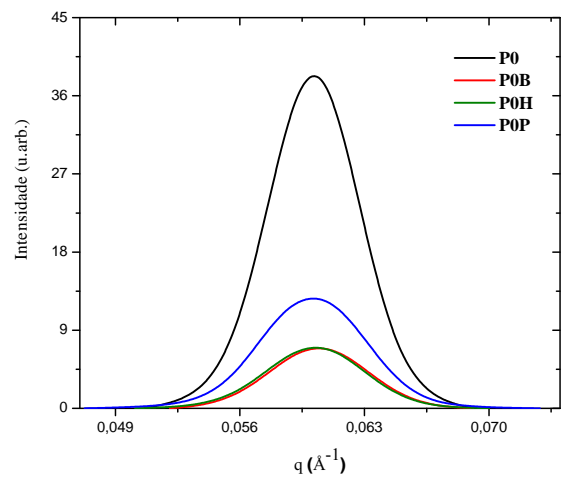

(a) (100)

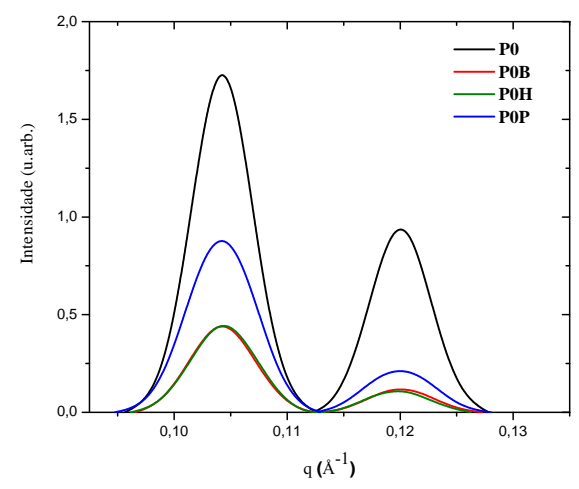

(b) (110) e (200)

Figura 5.10: Picos de difração das amostras P0, P0B e P0H. 
Capítulo 5. ESTUDO DA INCORPORAÇÃO DE PROTEÍNAS EM SBA-15 COM POROS EXPANDIDOS

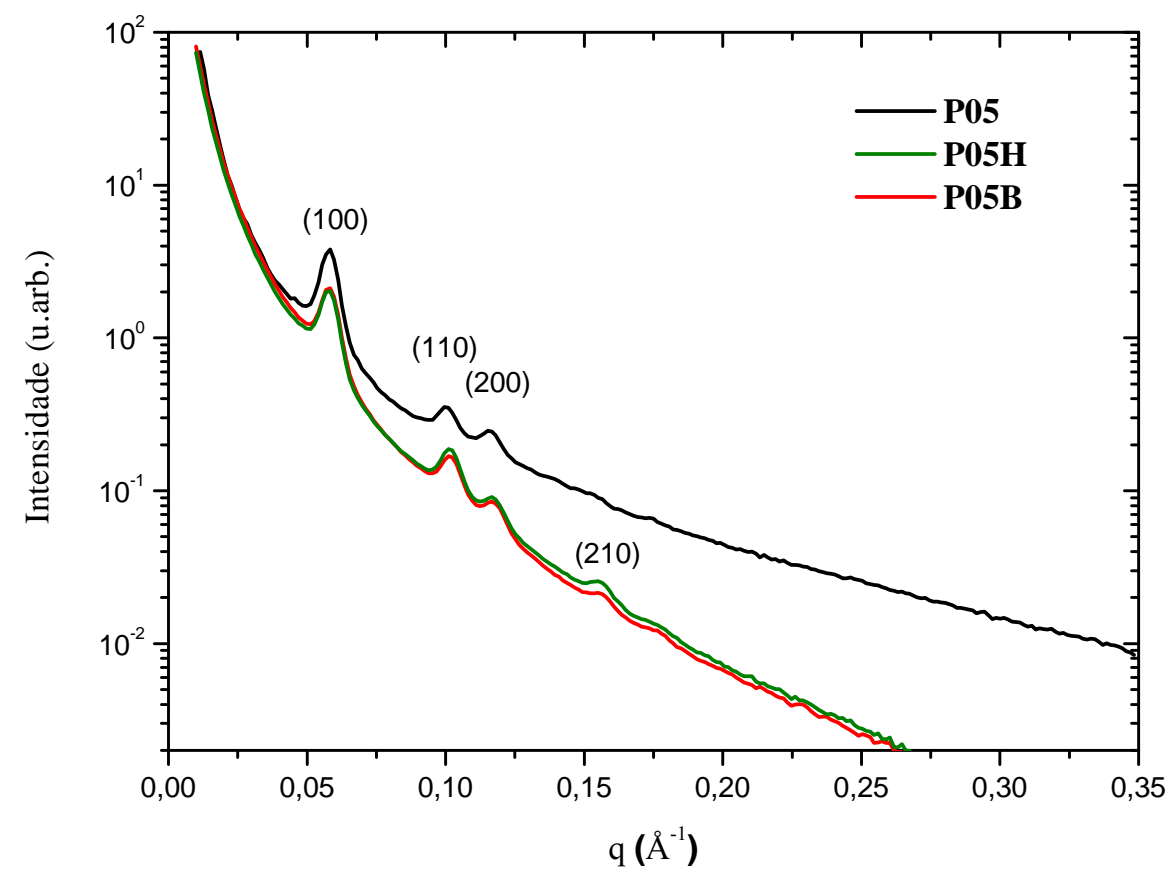

Figura 5.11: Curvas de SAXS de amostras de SBA-15 com razão P123/TIPB igual a 0,5.

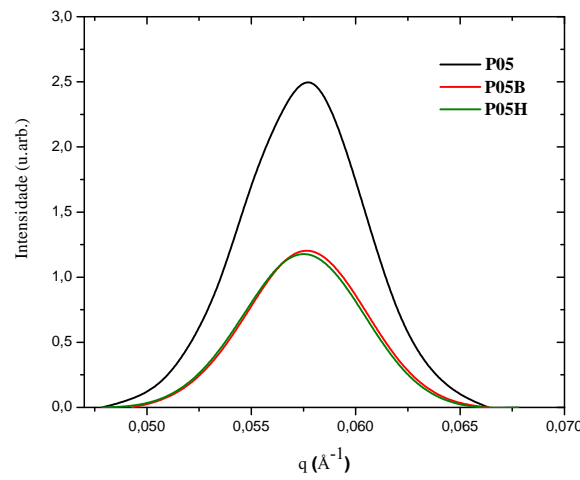

(a) (100)

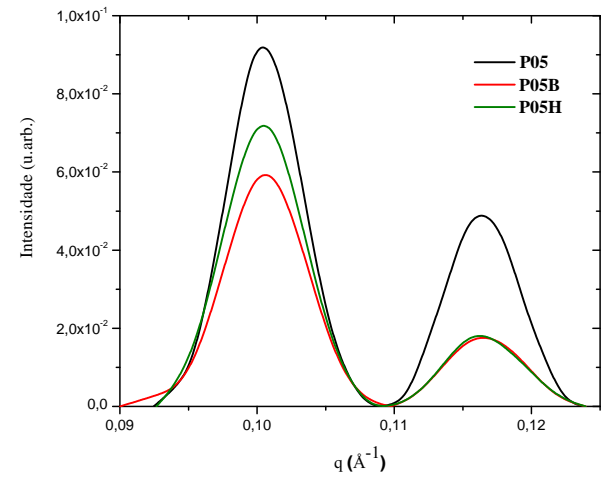

(b) (110) e (200)

Figura 5.12: Picos de difração das amostras P05, P05B e P05H. 
Capítulo 5. ESTUDO DA INCORPORAÇÃO DE PROTEÍNAS EM SBA-15 COM POROS EXPANDIDOS

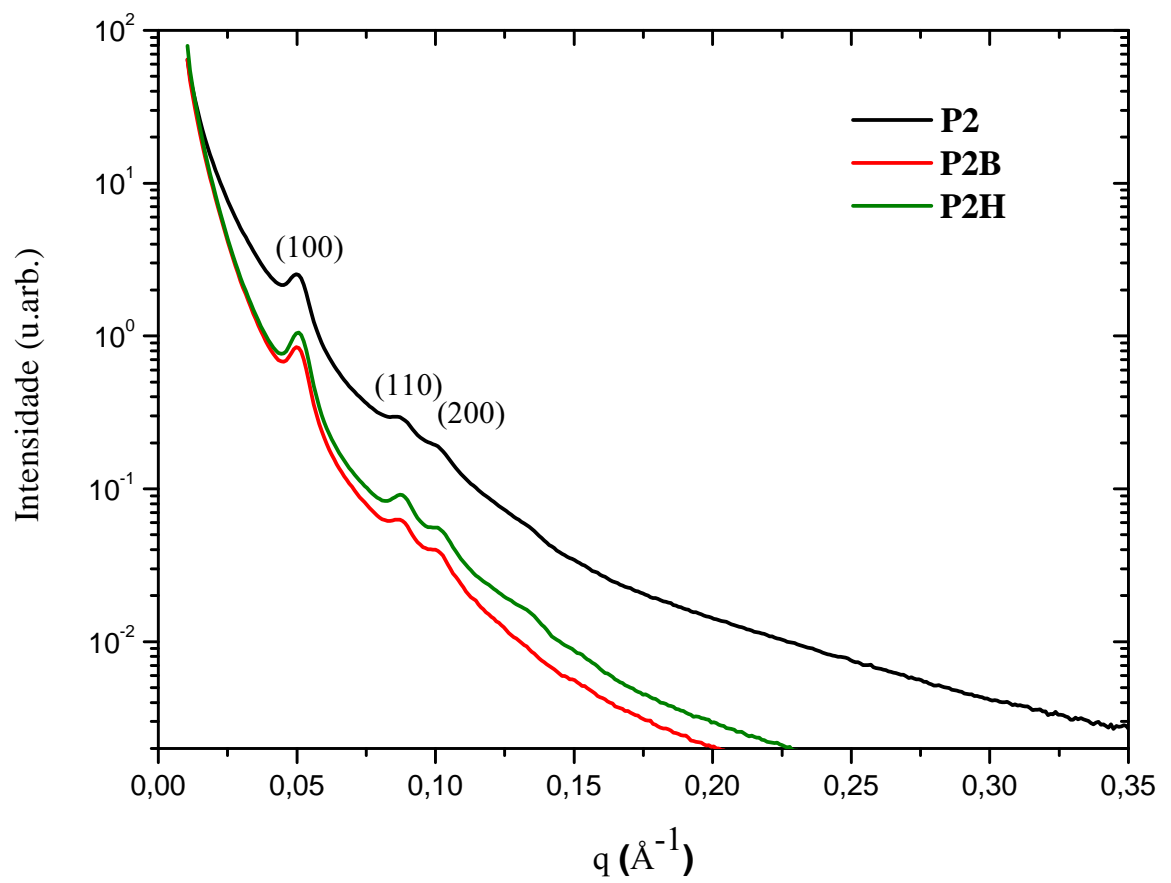

Figura 5.13: Curvas de SAXS de amostras de SBA-15 com razão TIPB/P123 igual a 2.

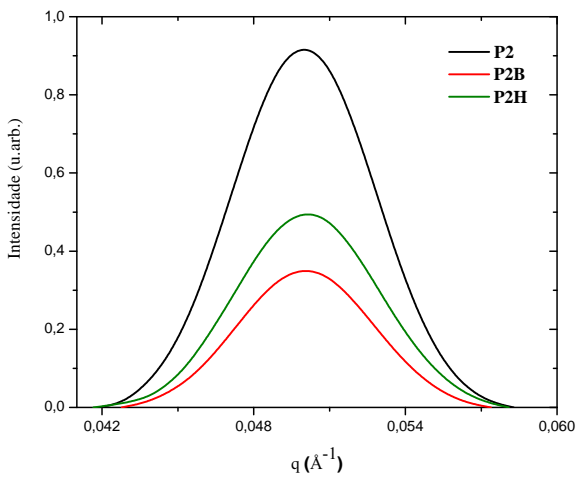

(a) $(100)$

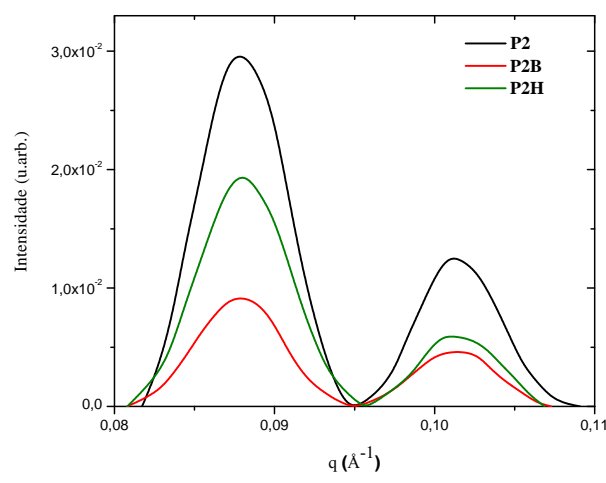

(b) (110) e (200)

Figura 5.14: Picos de difração das amostras P2, P2B e P2H. 


\begin{tabular}{cccc}
\hline & $(\mathbf{1 0 0})$ & $(\mathbf{1 1 0})$ & $(\mathbf{2 1 0})$ \\
\hline P0 & $251,23(5)$ & $11,710(40)$ & $6,410(40)$ \\
P0B & $48,12(30)$ & $3,225(30)$ & $0,862(20)$ \\
P0H & $48,73(36)$ & $3,285(40)$ & $0,810(30)$ \\
P0P & $94,96(74)$ & $6,865(70)$ & $1,685(40)$ \\
\hline P05 & $18,16(44)$ & $0,624(20)$ & $0,340(20)$ \\
P05B & $8,65(6)$ & $0,439(6)$ & $0,132(5)$ \\
P05H & $8,41(5)$ & $0,547(5)$ & $0,133(8)$ \\
\hline P2 & $6,51(3)$ & $0,230(8)$ & $0,083(4)$ \\
P2B & $2,38(1)$ & $0,065(2)$ & $0,029(2)$ \\
P2H & $3,54(4)$ & $0,142(3)$ & $0,043(5)$ \\
\hline
\end{tabular}

Tabela 5.4: Áreas integradas dos picos de difração.

A amostra com PBS foi a única a não apresentar esse comportamento, já que o seu diâmetro médio é ligeiramente maior que a amostra sem proteína, novamente indicando um preenchimento de poros de menor diâmetro pelo PBS. Também, a área superficial específica BET dessa amostra mostrou um valor menor que os valores das amostras com BSA e lgG. Isso provavelmente está relacionado ao fato de que as moléculas de PBS "competem" com as moléculas das proteínas ao se depositarem sobre a superfície da sílica, o que faz com que o preenchimento da superfície da sílica seja menos eficiente. Outra possibilidade é a obtsrução dos poros pelas proteínas, ocasionando um efeito "rolha".

A incorporação das proteínas provocou diminuição no laço das isotermas, bem com na altura máxima delas. Esse fato está relacionado à diminuição do volume total e da área superficial específica de poros. O preenchimento do volume total de poros variou de 60 a $80 \%$, confirmando o preenchimento dos poros sinalizado pelas medidas de SAXS.

A variação percentual do volume total de poros e área superficial específica BET (tabela 5.6) foi maior para as amostras com poros expandidos e seguiu uma tendência crescente, sugerindo inicialmente que amostras com diâmetros e parâmetros de rede maiores poderiam apresentar variações de volume e área superficiais ainda maiores. Porém, deve-se atentar ao fato de que quanto mais expandidos são os poros da SBA-15 mais desordenada será a rede de poros da amostra e provavelmente o grau de ordenamento deve ter alguma influência na capacidade de incorporação e liberação de proteínas.

A tabela 5.5 apresenta o resumo dos resultados de SAXS e NAI. 


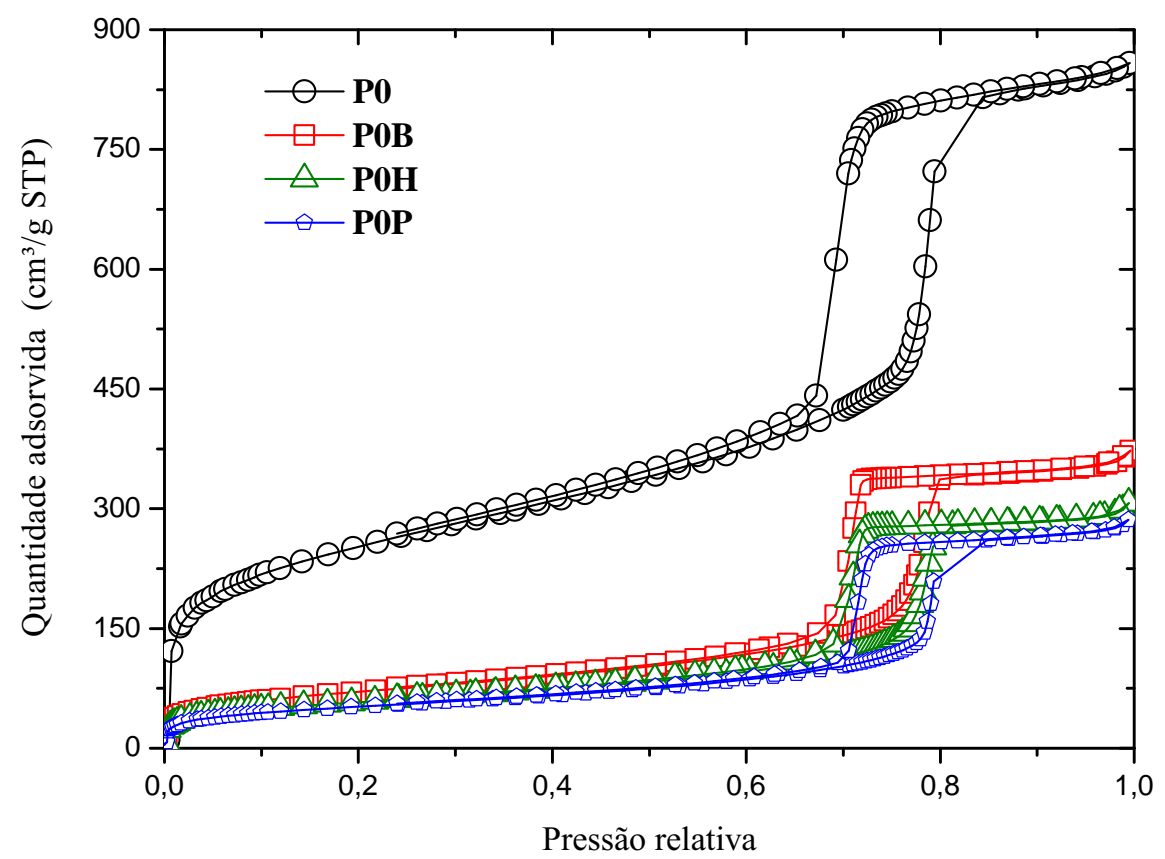

(a) Isotermas

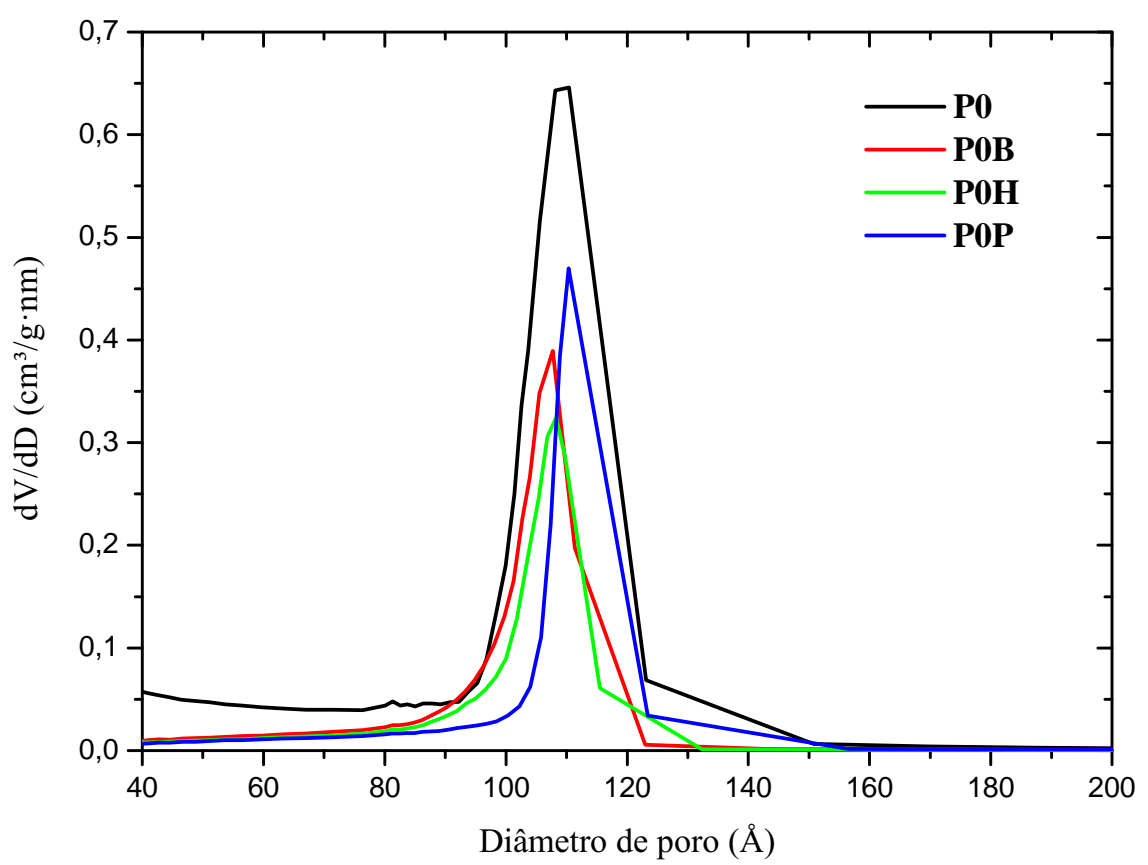

(b) Distribuição de tamanho de poros

Figura 5.15: Isotermas de adsorção e distribuição de tamanho de poros de amostras de SBA-15 convencional, com proteínas e PBS. 
Capítulo 5. ESTUDO DA INCORPORAÇÃO DE PROTEÍNAS EM SBA-15 COM POROS EXPANDIDOS

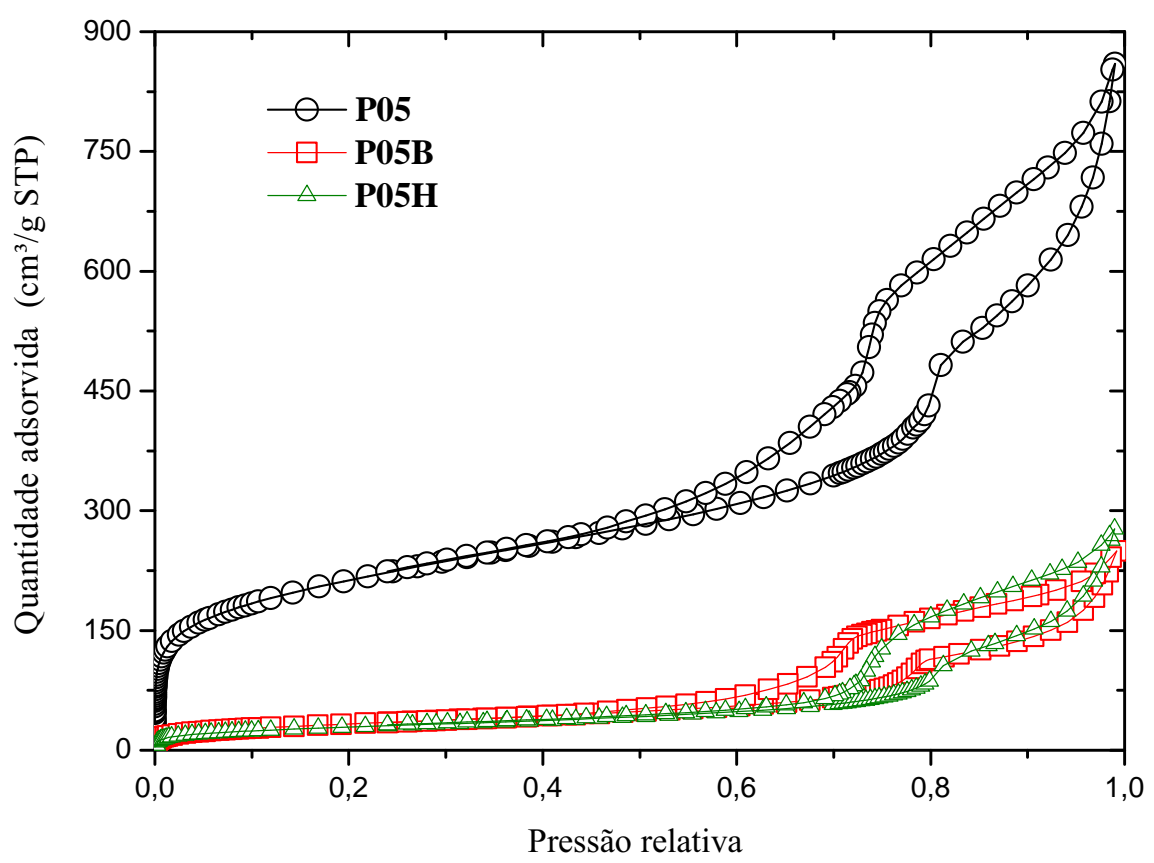

(a) Isotermas

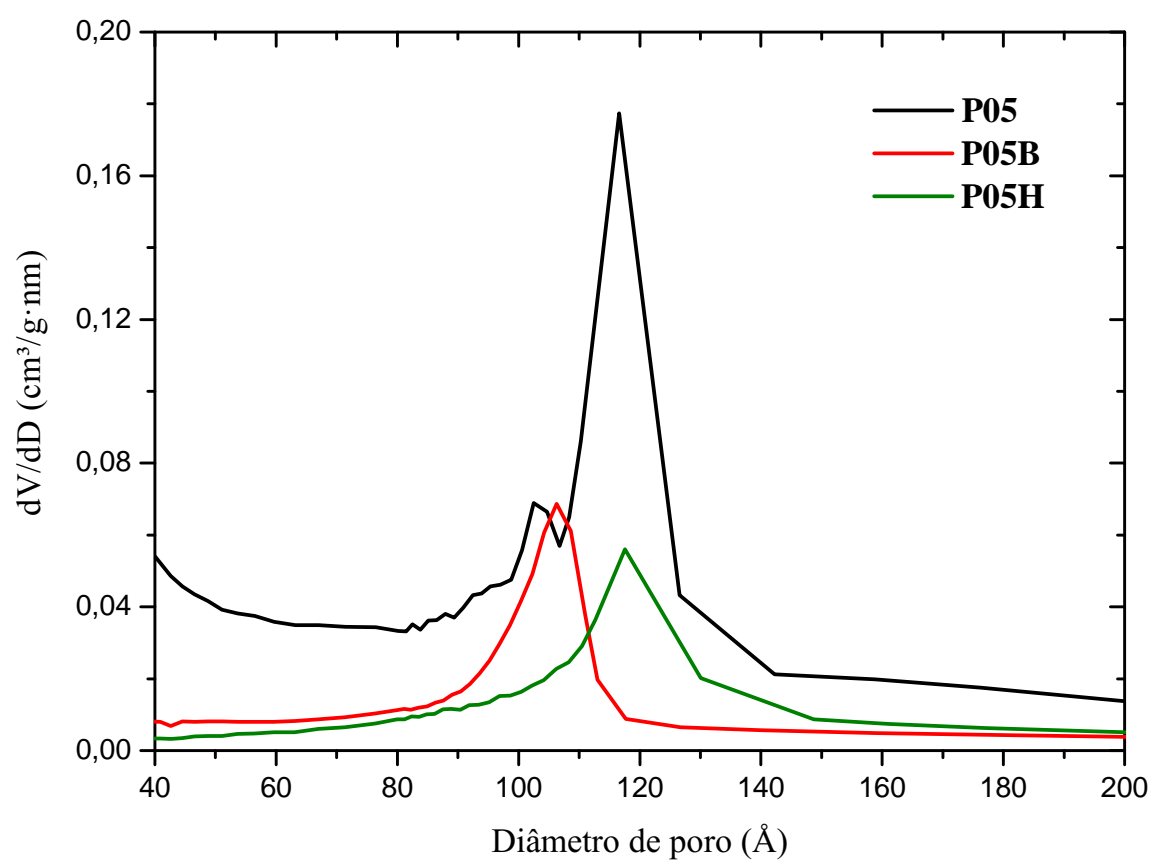

(b) Distribuição de tamanho de poros

Figura 5.16: Isoterma de adsorção e distribuição de tamanho de poros de amostras de SBA-15 com razão em massa P123/TIPB igual a 0,5. 
Capítulo 5. ESTUDO DA INCORPORAÇÃO DE PROTEÍNAS EM SBA-15 COM POROS EXPANDIDOS

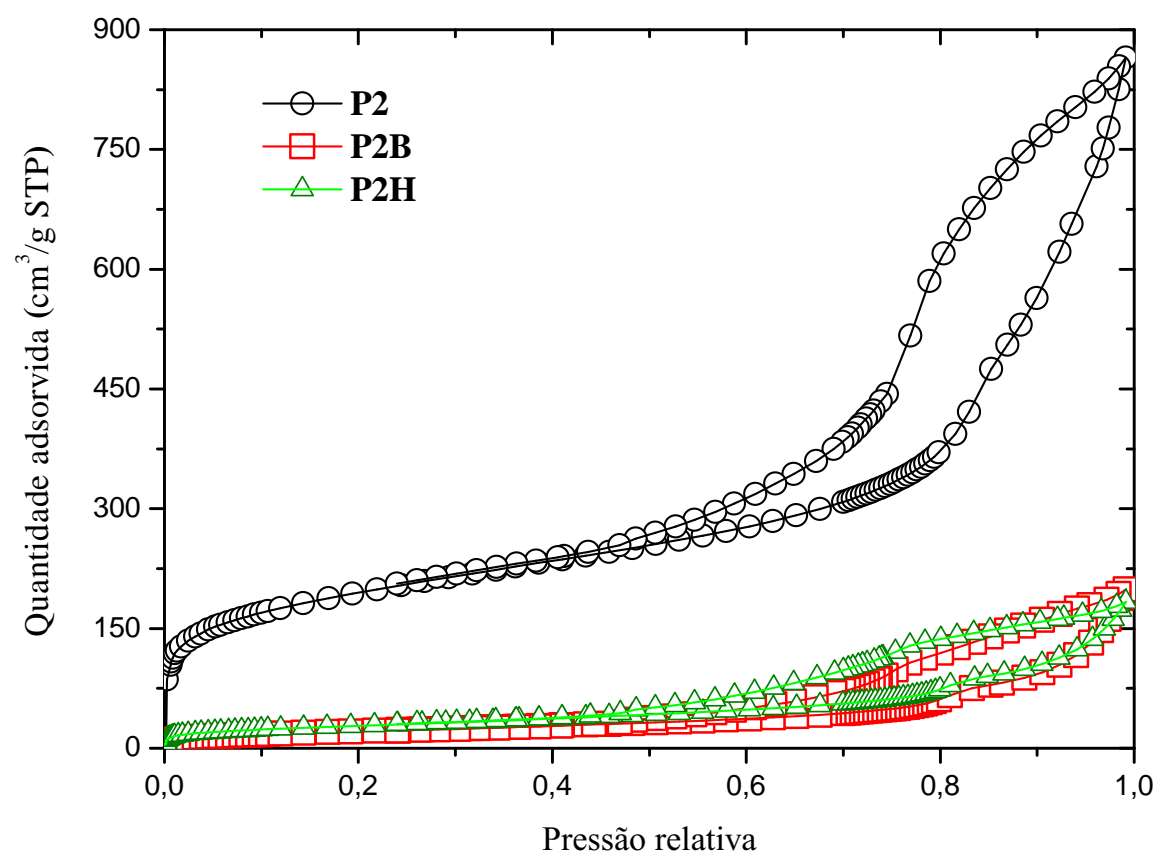

(a) Isotermas

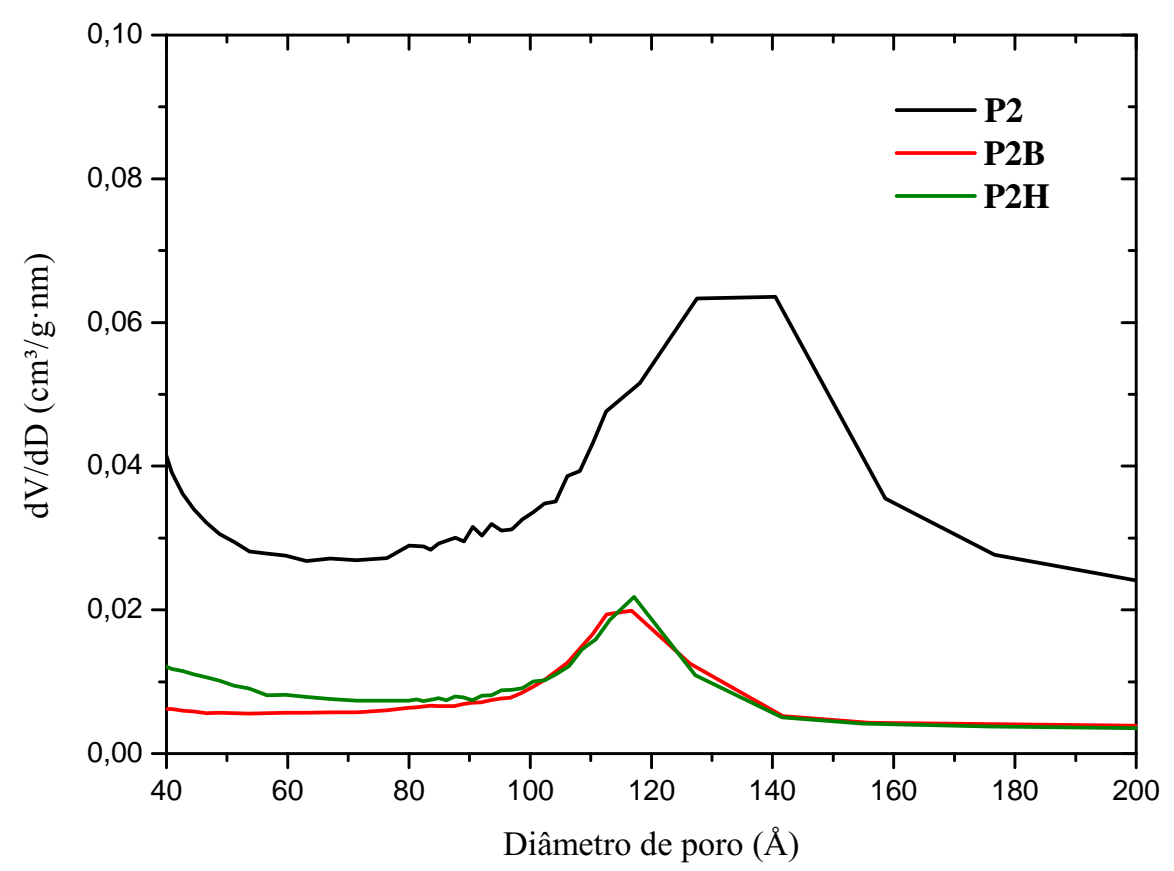

(b) Distribuição de tamanho de poros

Figura 5.17: Isoterma de adsorção e distribuição de tamanho de poros de amostras de SBA-15 com razão em massa TIPB/P123 igual a 2. 


\begin{tabular}{ccccccc}
\hline & $\begin{array}{c}\mathbf{V}_{\mathbf{t}} \\
\left(\mathbf{c m}^{\mathbf{3}} / \mathbf{g}\right)\end{array}$ & $\begin{array}{c}\mathbf{V}_{\mathbf{m}} \\
\left(\mathbf{c m}^{\mathbf{3}} / \mathbf{g}\right) \cdot 10^{-2}\end{array}$ & $\begin{array}{c}\mathbf{A}_{\mathbf{B E T}} \\
\left(\mathbf{m}^{\mathbf{2}} / \mathbf{g}\right)\end{array}$ & $\begin{array}{c}\mathbf{A}_{\mathbf{m}} \\
\left(\mathbf{m}^{\mathbf{2}} / \mathbf{g}\right)\end{array}$ & $\begin{array}{c}\mathbf{D}_{\mathbf{p}} \\
(\AA)\end{array}$ & $\begin{array}{c}\mathbf{a} \\
(\AA)\end{array}$ \\
\hline P0 & 1,33 & $12,99(25)$ & 910 & $297(4)$ & 109 & 121 \\
P0B & 0,58 & $0,34(7)$ & 256 & $15(2)$ & 107 & 121 \\
P0H & 0,47 & $0,33(5)$ & 208 & $14(1)$ & 108 & 120 \\
P0P & 0,44 & $0,33(7)$ & 188 & $14(1)$ & 111 & 120 \\
\hline P05 & 1,33 & $13,80(25)$ & 765 & $304(5)$ & 117 & 125 \\
P05B & 0,39 & $0,10(2)$ & 119 & $4,8(4)$ & 106 & 125 \\
P05H & 0,43 & $0,21(1)$ & 105 & $7,4(7)$ & 112 & 125 \\
\hline P2 & 1,34 & $13,74(22)$ & 698 & $303(4)$ & 135 & 146 \\
P2B & 0,30 & 0,00 & 78 & 0 & 116 & 145 \\
P2H & 0,28 & $0,21(2)$ & 101 & $3,5(8)$ & 117 & 145 \\
\hline
\end{tabular}

Tabela 5.5: Dados de SAXS e NAI de amostras de SBA-15 convencional e com poros expandidos com proteínas. Os erros nos cálculos dos parâmetros de rede e das áreas especíicas BET devidos aos ajustes foram iguais ou inferiores a $0,5 \%$.Aqui $V_{t}$ é o volume total de poros, $V_{m}$ é o volume de microporos, $A_{B E T}$ é a área superficial específica BET, $A_{m}$ é a área superficial específica de microporos, $D_{p}$ é o diâmetro médio de poros e $a$ é o parâmetro de rede.

\begin{tabular}{ccc}
\hline & $\Delta V_{t}(\%)$ & $\Delta A_{B E T}(\%)$ \\
\hline P0B & 56 & 72 \\
P0H & 65 & 77 \\
P0P & 67 & 79 \\
\hline P05B & 71 & 84 \\
P05H & 68 & 86 \\
\hline P2B & 78 & 89 \\
P2H & 79 & 86 \\
\hline
\end{tabular}

Tabela 5.6: Variação percentual do volume total de poros e área superficial específica BET devido à incorporação das proteínas.

\subsubsection{Modelagem dos dados de SAXS}

Nesta seção são apresentados os dados dos parâmetro obtidos dos ajustes teóricos realizados utilizando-se o modelo descrito na seção 4.1.5. Os ajustes foram realizados apenas para as amostras de SBA-15 sem TIPB porque as amostras com poros expandidos apresentaram apenas três picos de difração com intensidades integradas muito pequenas comparadas aos picos de difração da amostra convencional. As figuras 5.18 a 5.27 apresentam os resultados obtidos.

Os parâmetros obtidos pelo ajuste estão apresentados na tabela 5.7 e na tabela 5.8. Alguns parâmetros foram mantidos fixos para todas as amostras, esses parâmetros e seus valores são mostrados na tabela 5.8. Os parâmetros de rede $a$ e o domínio $D$ foram fixos pois, como demonstrado na seção 5.3, esses fatores não devem variar com a incorporação devido 
à estabilidade mecânica da SBA-15. Os fatores $v$ e $\sigma_{\text {int }}$ foram mantidos fixos porque esses parâmetros se mostraram instáveis durante os ajustes. O fator de escala do background $S c_{c o n s t}$ se mostrou instável para as amostras com proteínas. Assim, ele foi fixo em $S c_{\text {const }}=1,4 \cdot 10^{-2}$ para amostra $\mathrm{PO}$ e $S c_{\text {const }}=-0,26 \cdot 10^{-2}$ para as amostras com proteínas.

\begin{tabular}{|c|c|c|c|c|}
\hline Parâmetro & P0 & P0P & P0B & P0H \\
\hline$S c_{1}$ & $0,53(6) \cdot 10^{4}$ & $1,56(17) \cdot 10^{4}$ & $5,71(14) \cdot 10^{4}$ & $4,08(13) \cdot 10^{4}$ \\
\hline$S c_{2}$ & $0,76(20)$ & $1,35(7)$ & $1,38(13)$ & $1,17(12)$ \\
\hline$c$ & $12,6(5)$ & $4,0(4)$ & $4,0(2)$ & $4,8(2)$ \\
\hline$a(\AA)$ & $119(1)$ & $118(1)$ & $118(1)$ & $118(1)$ \\
\hline$D(\AA)$ & $8,85(69) \cdot 10^{3}$ & $8,62(44) \cdot 10^{3}$ & $8,62(44) \cdot 10^{3}$ & $8,62(44) \cdot 10^{3}$ \\
\hline$\sigma_{a}$ & $8,68(14) \cdot 10^{-2}$ & $5,81(23) \cdot 10^{-2}$ & $5,81(23) \cdot 10^{-2}$ & $5,81(23) \cdot 10^{-2}$ \\
\hline$R_{\text {in }}(\AA)$ & $54,3(3)$ & $49,0(3)$ & $50,0(8)$ & $51,1(9)$ \\
\hline$R_{\text {out }}(\AA)$ & $64,3(3)$ & $75,2(3)$ & $75,4(2)$ & $74,6(2)$ \\
\hline$\Delta \rho_{\text {out }} / \Delta \rho_{\text {in }}$ & $11(2)$ & $1,42(5)$ & $1,10(1)$ & $1,08(1)$ \\
\hline$\sigma_{R} / R$ & $11,4(2) \cdot 10^{-2}$ & $7,5(3) \cdot 10^{-2}$ & $7,6(1) \cdot 10^{-2}$ & $7,9(1) \cdot 10^{-2}$ \\
\hline$\chi^{2}$ & 4,1 & 5,2 & 9,1 & 7,9 \\
\hline
\end{tabular}

Tabela 5.7: Tabela com os valores dos parâmetros que variaram durante o ajuste realizado. 0 parâmetro $\chi^{2}$ é o qui quadrado reduzido e é uma estimativa da qualidade do ajuste.

\begin{tabular}{|c|c|}
\hline$v$ & 0,01 \\
\hline$L(\AA)$ & $5,0 \cdot 10^{3}$ \\
\hline$\sigma_{\text {int }}$ & 3,0 \\
\hline$R_{g}(\AA)$ & 50,0 \\
\hline
\end{tabular}

Tabela 5.8: Parâmetros que foram mantidos fixos durante o ajuste.

O fator de escala $S c_{1}$ apresentou aumento com a incorporação de PBS e das proteínas (figura 5.22), o que pode indicar a formação de aglomerados que provocam o espalhamento extra. Comparando HGG e BSA verifica-se que este espalhamento extra é maior para BSA.

A modificação do parâmetro $S c_{2}$ quando comparado ao valor da amostra de SBA-15 pura, similar para as amostras com PBS, HGG e BSA (figura 5.23), indica o preenchimento dos microporos pela solução de PBS, fato já evidenciado na seção 5.3.

O raio do poro $R_{\text {in }}$ diminuiu após a incorporação de PBS e não apresenta diferenças em relação às proteínas (figura 5.24). Este fato pode ser mais uma indicação do preenchimento dos poros.

A variação do parâmetro $R_{\text {out }}$ (figura 5.25) é de difícil interpretação. Porém, como os valores das amostras com proteínas e PBS são similares podemos atribuir essa variação à presença de material na sílica.

A variação na razão entre os contrastes de densidade eletrônica externa e interna $\Delta \rho_{\text {out }} / \Delta \rho_{\text {in }}$ é maior na presença das proteínas, quando comparada com a introdução de PBS (figura 5.26), o que indica a presença da proteína nos poros do material. 
Capítulo 5. ESTUDO DA INCORPORAÇÃO DE PROTEÍNAS EM SBA-15 COM POROS EXPANDIDOS

O parâmetro $c$ apresentou um decréscimo similar para as amostras com PBS e proteínas (figura 5.27), portanto esta modificação está relacionada ao preenchimento dos poros por PBS.

A variação no parâmetro de desordem $\sigma_{a}$ é similar para as amostras com PBS e proteínas e inferior ao valor da SBA-15 pura.

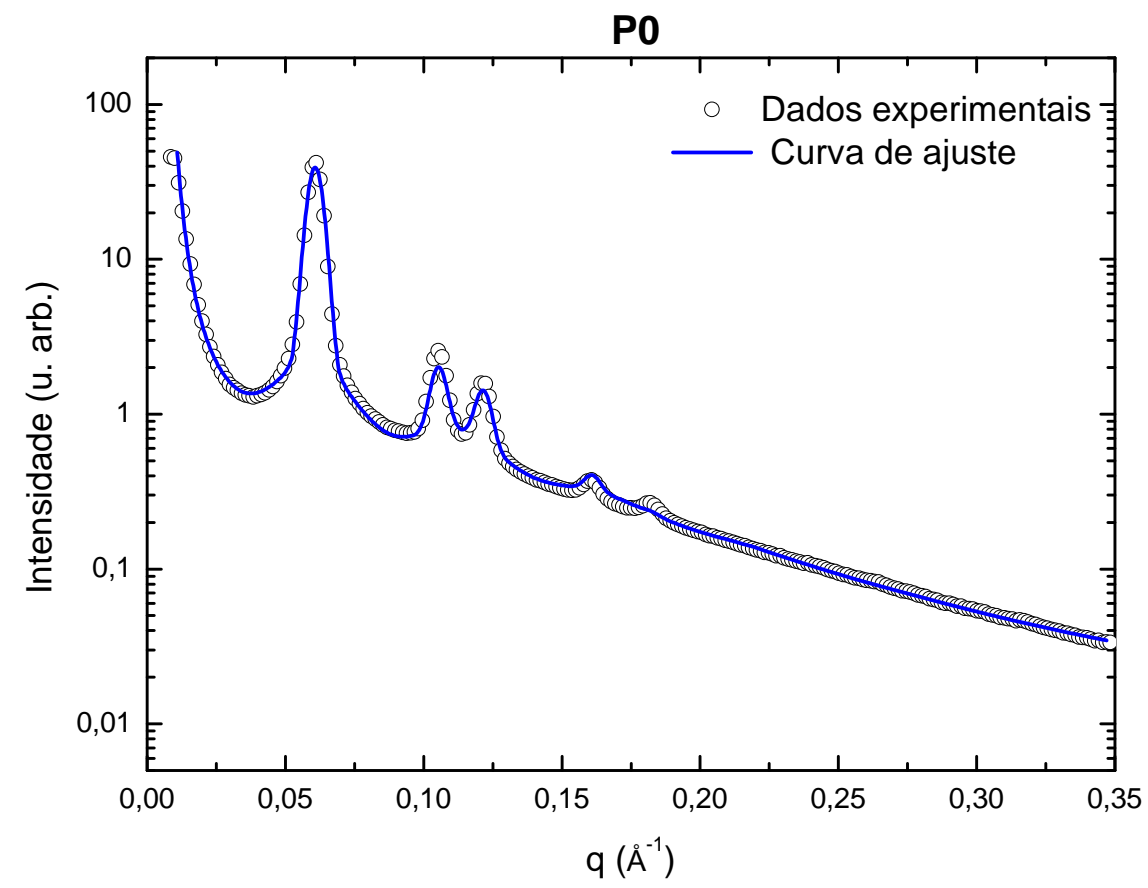

Figura 5.18: Dados experimentais e curva de ajuste da amostra P0. $\chi^{2}=4,1$. 


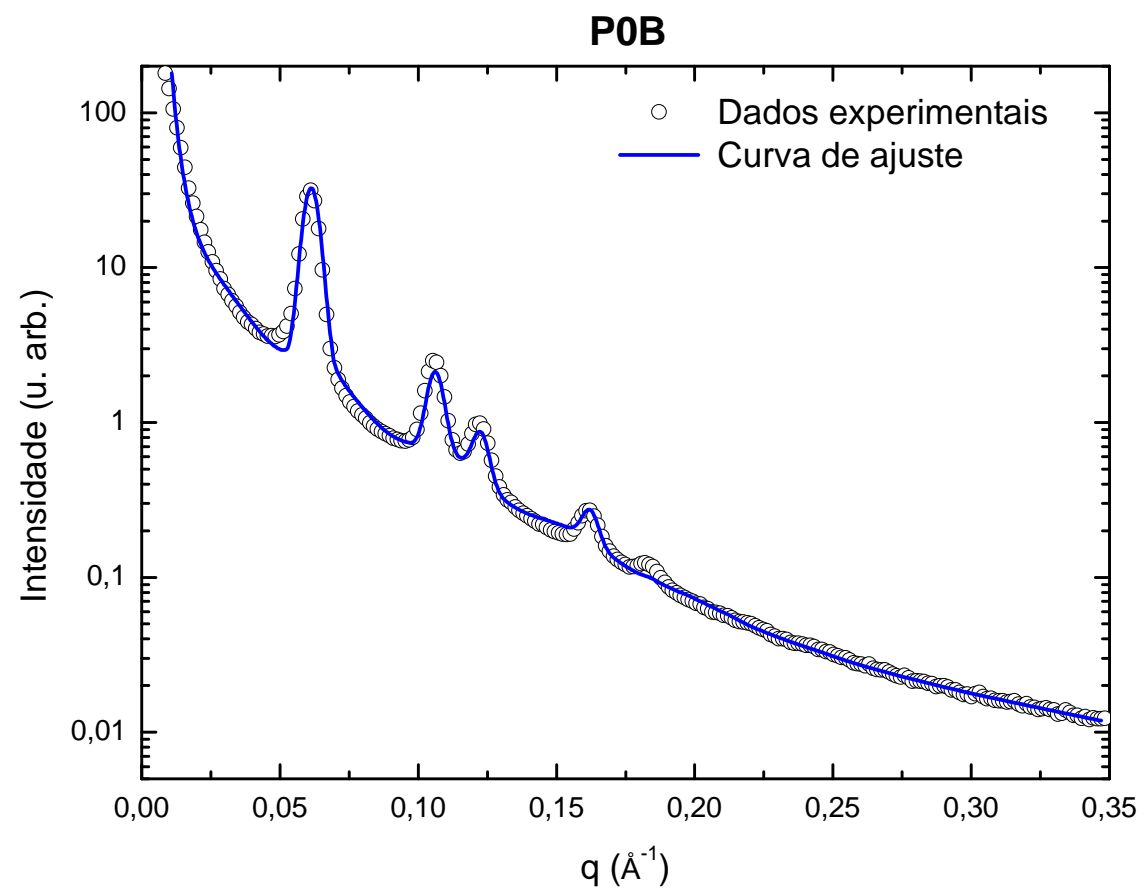

Figura 5.19: Dados experimentais e curva de ajuste da amostra P0B. $\chi^{2}=9,1$.

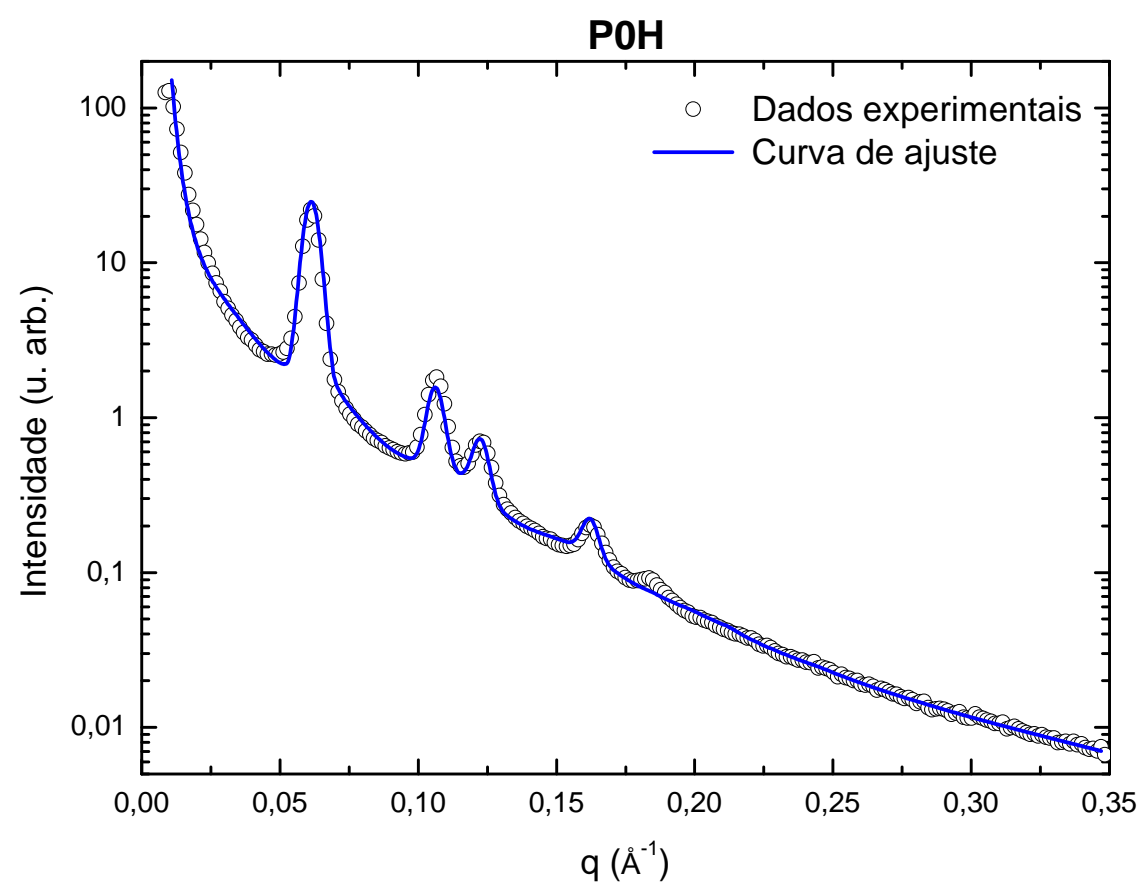

Figura 5.20: Dados experimentais e curva de ajuste da amostra POH. $\chi^{2}=7,9$. 
Capítulo 5. ESTUDO DA INCORPORAÇÃO DE PROTEÍNAS EM SBA-15 COM POROS EXPANDIDOS

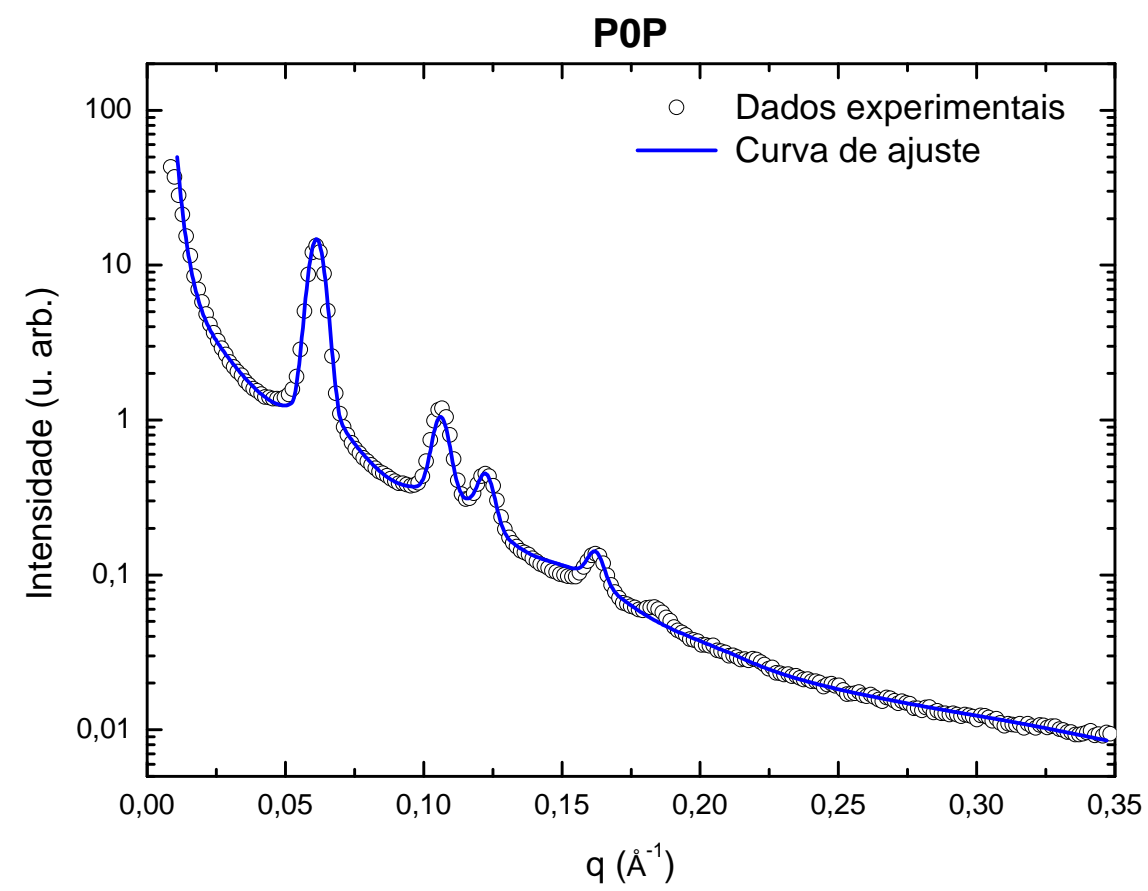

Figura 5.21: Dados experimentais e curva de ajuste da amostra POP. $\chi^{2}=5,2$.

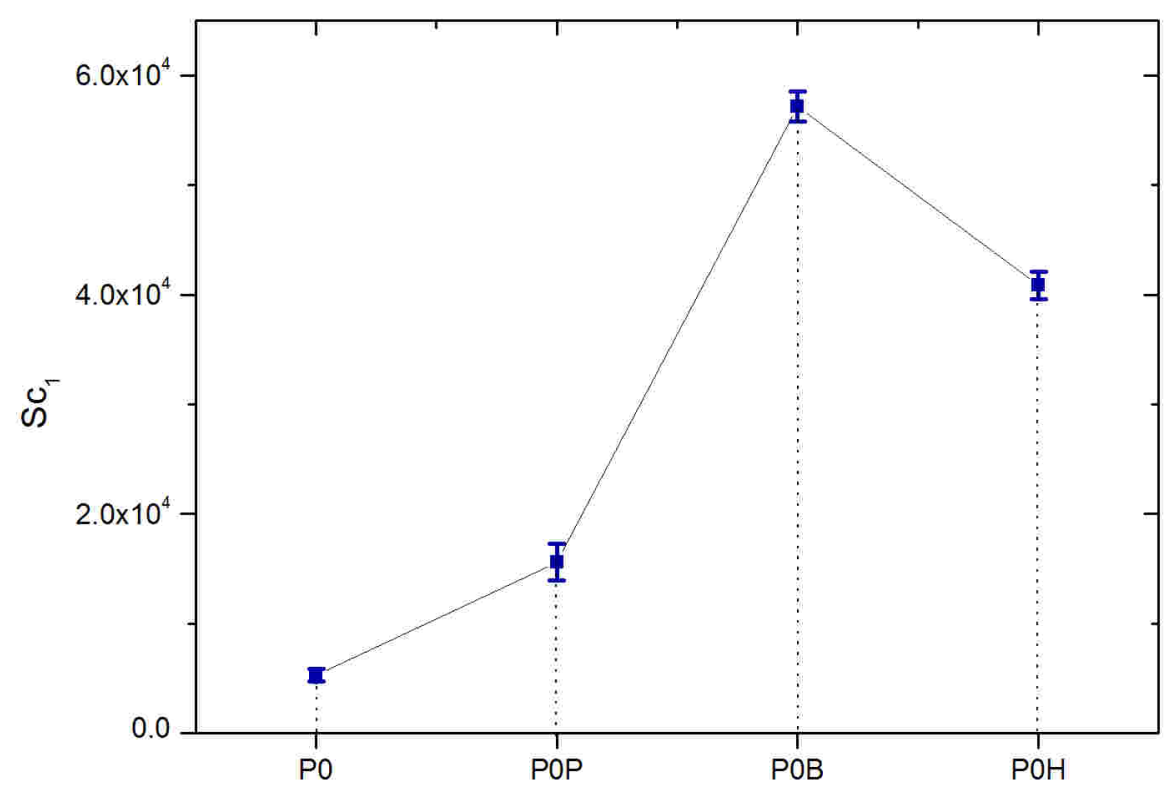

Figura 5.22: Variação do fator de escala $S c_{1}$. 
Capítulo 5. ESTUDO DA INCORPORAÇÃO DE PROTEÍNAS EM SBA-15 COM POROS EXPANDIDOS

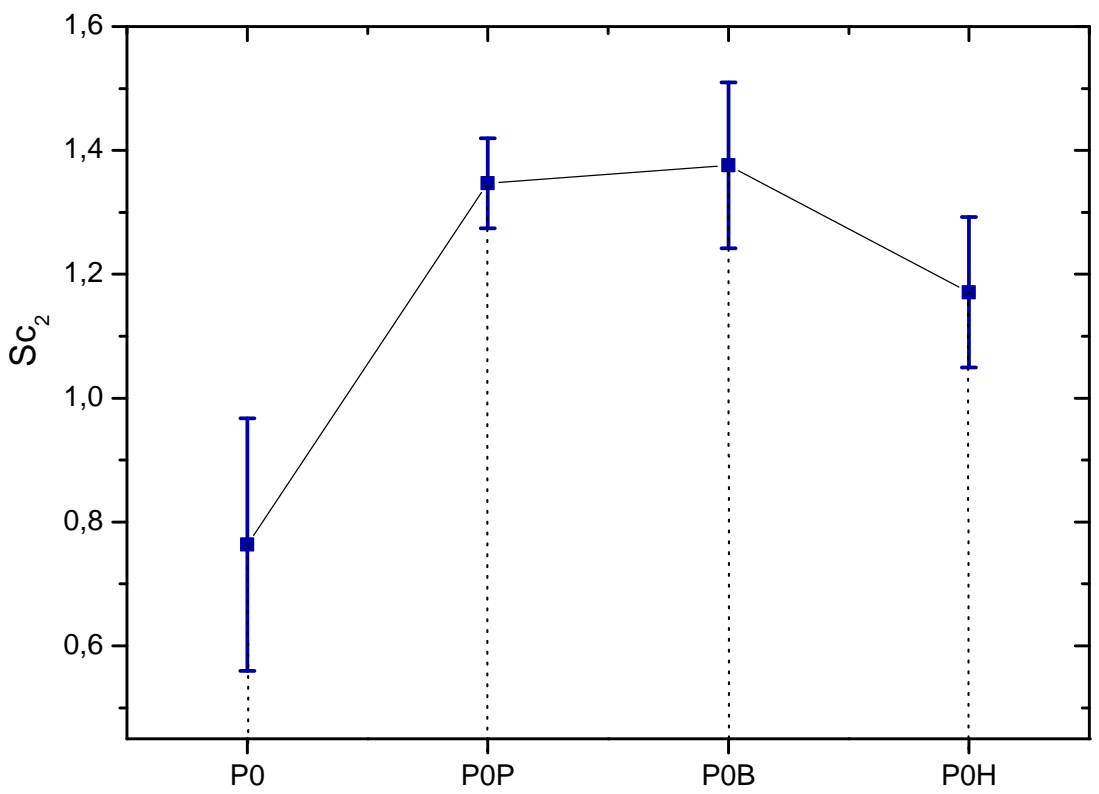

Figura 5.23: Variação do fator de escala $S c_{2}$.

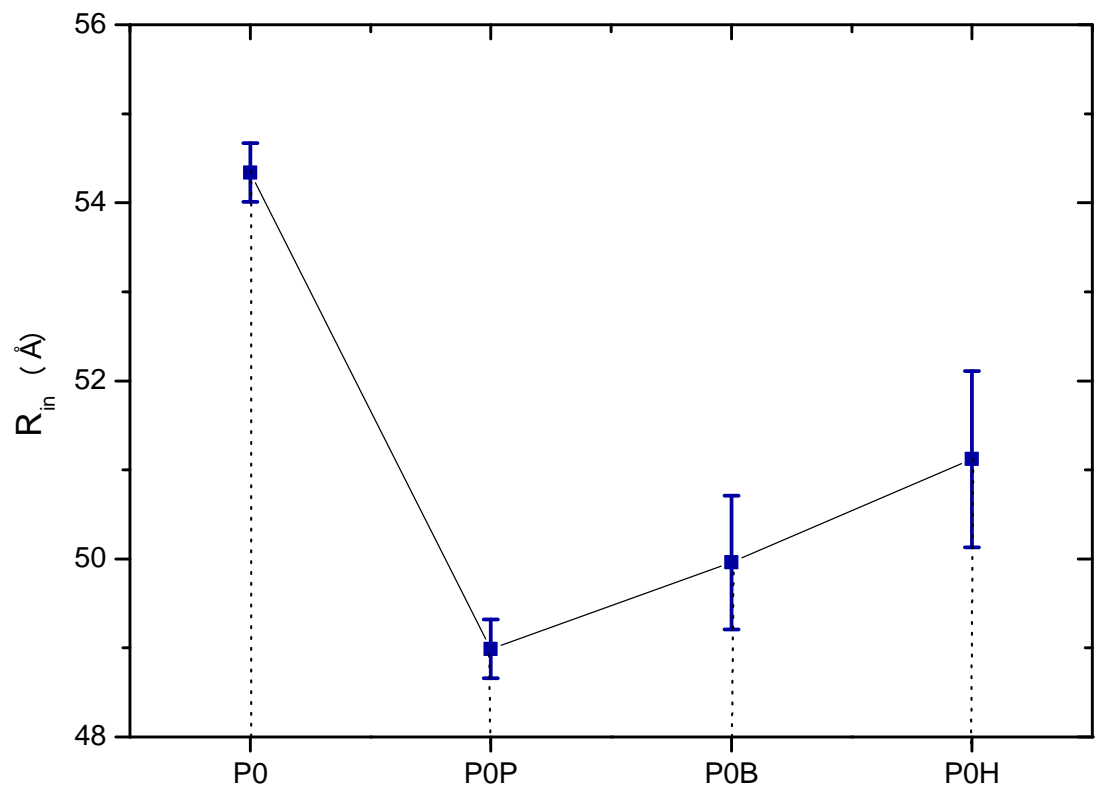

Figura 5.24: Variação do parâmetro $R_{\text {in }}$. 
Capítulo 5. ESTUDO DA INCORPORAÇÃO DE PROTEÍNAS EM SBA-15 COM POROS EXPANDIDOS

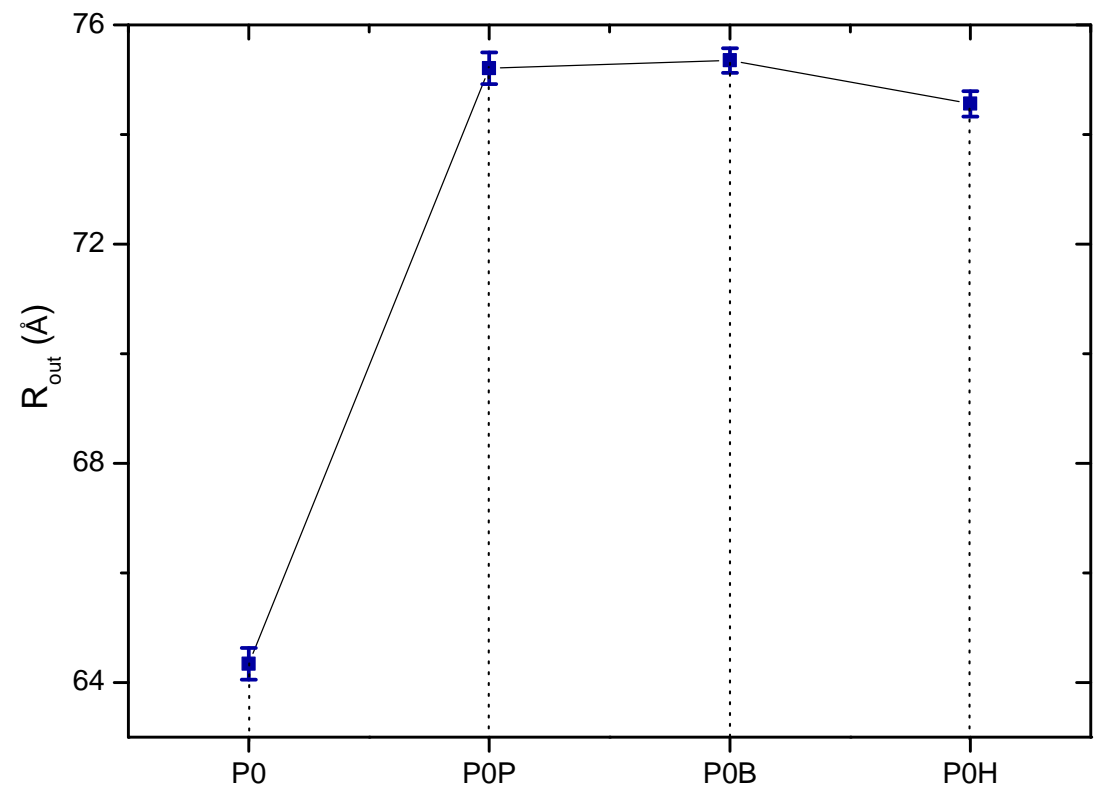

Figura 5.25: Variação do parâmetro $R_{\text {out }}$.

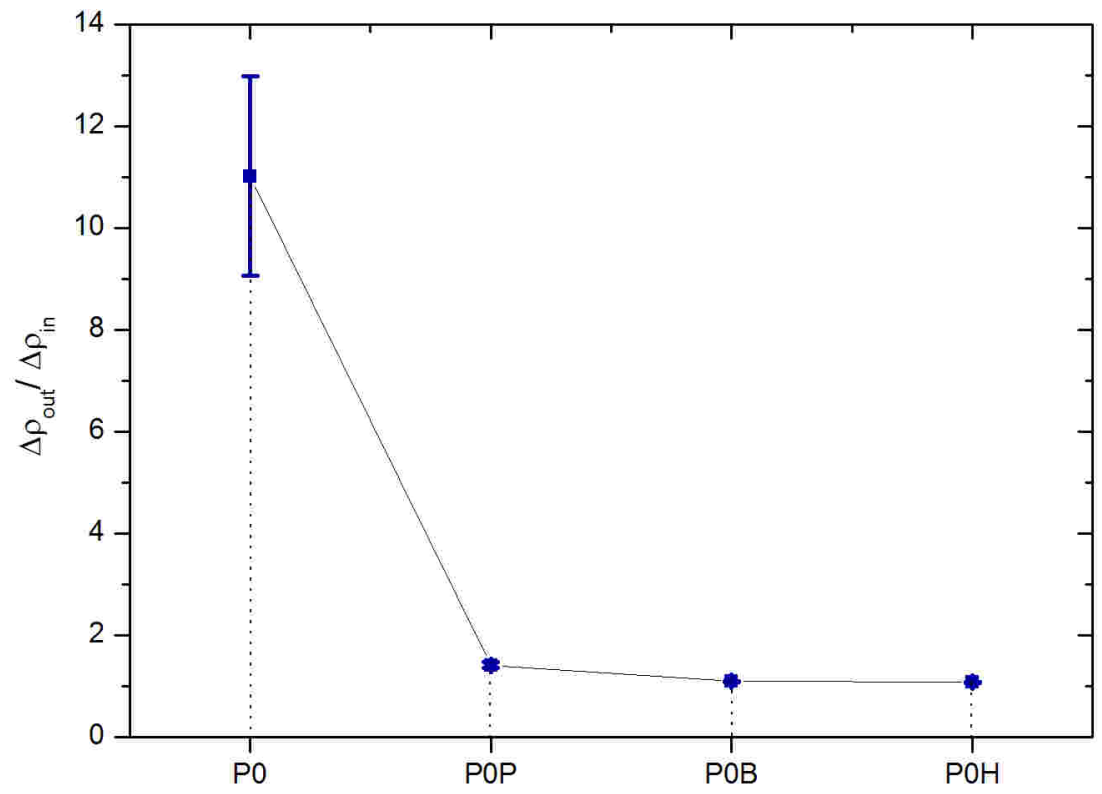

Figura 5.26: Variação do parâmetro $\rho_{\text {out }} / \rho_{\text {in }}$. 
Capítulo 5. ESTUDO DA INCORPORAÇÃO DE PROTEÍNAS EM SBA-15 COM POROS EXPANDIDOS

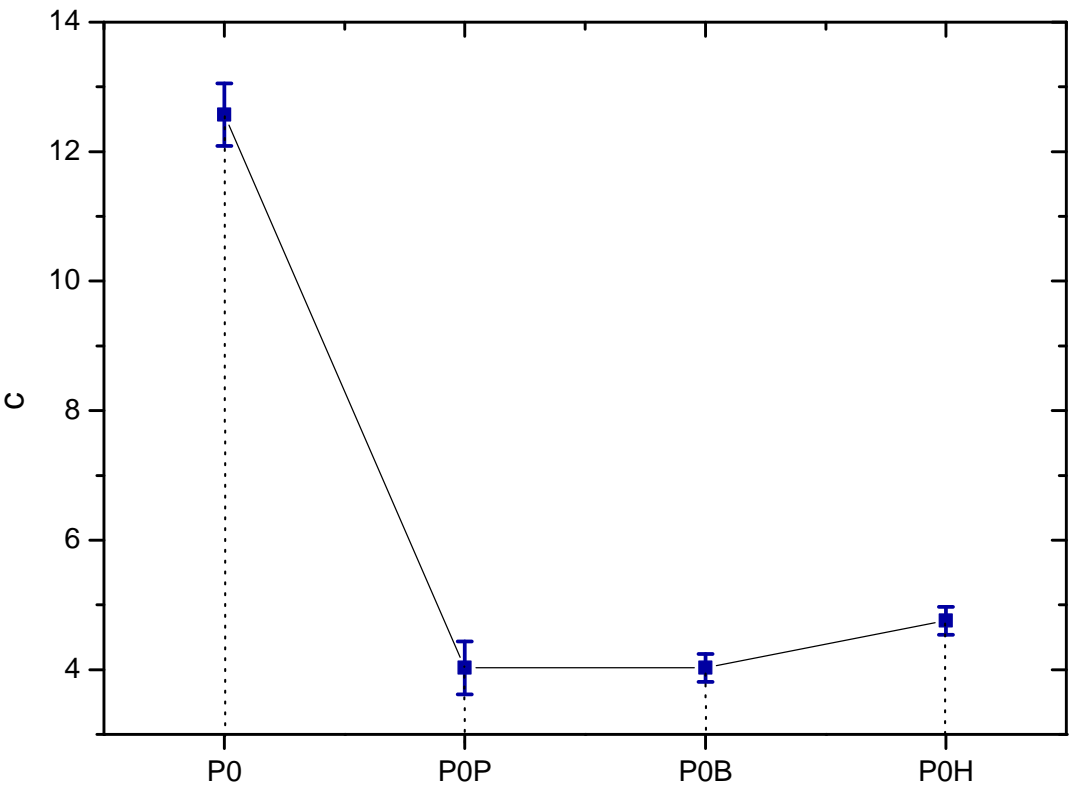

Figura 5.27: Variação do parâmetro $c$. 


\section{Determinação do teor de silício em fezes de camundongos}

Esse capítulo trata dos resultados de medidas do teor de sílicio em fezes de camundongo que receberam doses controladas de SBA-15.

\subsection{Preparação das amostras de fezes de camundongo}

As medidas foram realizadas em amostras trituradas de fezes de camundongos, recebidas do Instituto Butantan. As amostras foram coletadas de três grupos de camundongos denomenados $\mathrm{A}, \mathrm{B}$ e C. Os grupos $\mathrm{A}$ e $\mathrm{B}$ são indênticos e receberam doses de sílica, já o grupo C é o grupo controle e não recebeu quaisquer dose de sílica.

Os animais receberam, por gavagem, $1 \mathrm{mg}$ de SBA-15 em $200 \mu \mathrm{L}$ de PBS, e suas fezes foram coletadas após $6 \mathrm{~h}, 12 \mathrm{~h}, 24 \mathrm{~h}$ e $48 \mathrm{~h}$. Após $6 \mathrm{~h}$ de administração aos animais, cada grupo foi colocado em caixas limpas durante $30 \mathrm{~min}$, e todas as fezes secretadas durante este período foram coletadas e acondicionadas em tubos Falcon a $4{ }^{\circ} \mathrm{C}$ até a sua utilização. $\mathrm{O}$ mesmo procedimento foi realizado após $12 \mathrm{~h}, 24 \mathrm{~h}$ e $48 \mathrm{~h}$.

\begin{tabular}{|c|c|c|}
\hline Grupo & Gavagem & $\mathbf{N}^{\mathbf{0}}$ de animais \\
\hline A (Experimental) & $1 \mathrm{mg}$ de SBA-15 em $200 \mu \mathrm{L}$ de PBS & 3 \\
B (Experimental) & $1 \mathrm{mg}$ de SBA-15 em $200 \mu \mathrm{L}$ de PBS & 3 \\
C (Controle) & $200 \mu \mathrm{L}$ de PBS & 3 \\
\hline
\end{tabular}

Tabela 6.1: Grupos de camundongos utilizados

O animais receberam uma segunda dose de sílica com o objetivo de simular a dose de reforço que é administrada na vacinação. Essa segunda dose foi administrada sete dias após a primeira administração e os animais receberam novamente a mesma quantidade de sílica e PBS. O mesmo procedimento de coleta foi aplicado e amostras de fezes foram recolhidas após $6 \mathrm{~h}$ e $24 \mathrm{~h}$ da segunda administração.

Todas as amostras foram calcinadas a $900{ }^{0} \mathrm{C}$ por 4 horas para facilitar do processo de identificação do elemento silício. Após a calcinação essas amostras foram convertidas em pastilhas conforme procedimento descrito na seção 4.3.1.

O número no nome das amostras indica o tempo de coleta; assim, por exemplo, a amostra A12 é a amostra de fezes do grupo A coletada 12 horas após a administração, a amostra B6 é a amostra de fezes do grupo B coletada após 6 horas e assim por diante. A letra "r" indica 
amostras de fezes coletadas após os grupos receberem doses de reforço ${ }^{1}$. Para essas amostras a mesma regra é válida: o número indica o tempo após a administração da dose de reforço. A concentração de silício calculada para todas as amostras está apresentada na tabela 6.2.

\subsection{Resultados e discussão}

O desvio padrão experimental do grupo controle foi calculado $\left(\sigma=66 \cdot 10^{1} \mathrm{ppm}\right)$. O limiar mostrado na figura 6.1 foi então determinado com base na média do teor de silício apresentado pelo gupo controle e os seu desvio padrão experimental.

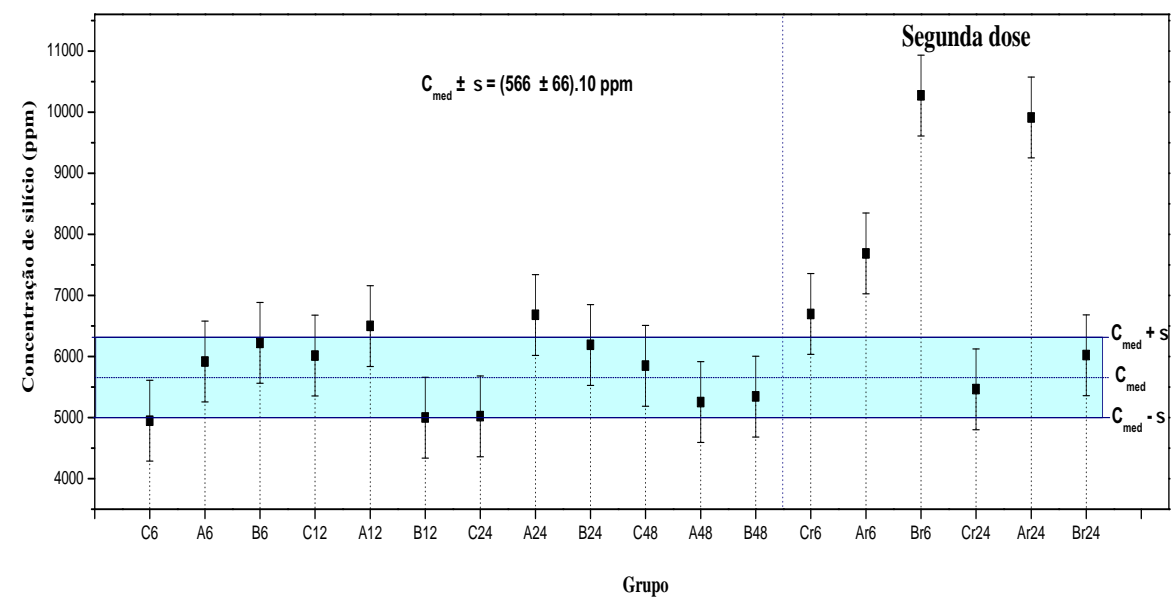

Figura 6.1: Concentração de sílicio em fezes de camundongo que receberam SBA-15.

Os resultados evidenciam claramente a eliminação da SBA-15 pelas fezes após a segunda administração, já que os teores de silício dessas amostras estão acima do limiar do grupo controle.

A diferença significativa entre os valores dos Grupos A, B e C após a segunda administração deve se correlacionar com o acúmulo da SBA-15 em macrófagos e outras células apresentadoras de antígenos, acarretando em morte celular e consequente eliminação.

\footnotetext{
${ }^{1}$ Deve-se salientar que, obviamente, as amostras do grupo controle Cr6 e Cr24 não receberam quaisquer dose de sílica. A letra "r"deste grupo indica que a amostra foi coletada após a dose de reforço ser administrada para os grupos $A$ e $B$.
} 


\begin{tabular}{|c|c|}
\hline Amostra & C(ppm)x10 \\
\hline A6 & 5,917 \\
B6 & 6,222 \\
C6 & 4,948 \\
\hline A12 & 6,497 \\
B12 & 5,000 \\
C12 & 6,014 \\
\hline A24 & 6,679 \\
B24 & 6,188 \\
C24 & 5,020 \\
\hline A48 & 5,254 \\
B48 & 5,344 \\
C48 & 5,848 \\
\hline Ar6 & 7,686 \\
Br6 & 10,270 \\
Cr6 & 6,695 \\
\hline Ar24 & 9,910 \\
Br24 & 6,020 \\
Cr24 & 5,463 \\
\hline
\end{tabular}

Tabela 6.2: Concentração de sílicio das amostras de fezes de camundongo. As incertezas devidas aos ajustes da função Gaussiana para a determinação do número de contagens do elemento no espectro foram iguais ou menores que $1 \%$. 



\section{Controle de qualidade de amostras de SBA-15}

É importante salientar que a aplicação de materiais para uso humano é controlada por agências reguladoras como a Agência Nacional de Vigilância Sanitária (Anvisa). Neste sentido, o uso da SBA-15 como adjuvante imunológico deve seguir um protocolo de síntese detalhado, com propriedades reprodutíveis do material.

Tendo em vista que a SBA-15 será utilizada futuramente como adjuvante de vacinas um controle de qualidade de amostras de SBA-15 produzidas pela Cristália Produtos Químicos e Farmacêuticos Ltda foi realizado. Essas amostras serão utilizadas para a formulação de vacina oral comercial contra Hepatite B. Os resultados das caracterizações realizadas estão mostrados nas tabelas a seguir.

\begin{tabular}{|c|c|c|c|c|c|}
\hline \multirow{2}{*}{ Parâmetro } & \multirow{2}{*}{ Esperado ${ }^{1}$} & \multicolumn{4}{|c|}{ Amostras } \\
\hline & & $28 / 10$ & $30 / 10$ & $04 / 11$ & $0082 / 14$ \\
\hline $\mathrm{a}(\AA)$ & 100 a 130 & 119 & 119 & 119 & 121 \\
\hline$A_{\text {BET }}\left(m^{2} / g\right)$ & 700 a 1100 & 909 & 790 & 791 & 852 \\
\hline$V_{t}\left(\mathrm{~cm}^{3} / \mathrm{g}\right)$ & 0,8 a 2,5 & 1,28 & 1,17 & 1,20 & 1,90 \\
\hline$D_{p}(\AA)$ & 80 a 120 & 109 & 104 & 103 & 107 \\
\hline
\end{tabular}

Tabela 7.1: Dados do controle de qualidade realizado em diferentes amostras de SBA-15.

\begin{tabular}{cccccc}
\hline \multirow{2}{*}{ Parâmetro } & \multirow{2}{*}{ Esperado } & \multicolumn{4}{c}{ Amostras } \\
\cline { 3 - 6 } & & $\mathbf{0 2 1 1 / 1 4}$ & $\mathbf{0 1 0 0 0 0 3}$ & $\mathbf{0 2 4 4} / \mathbf{1 4}$ & $\mathbf{0 2 8 1 / 1 4}$ \\
\hline $\mathrm{a}(\AA)$ & 100 a 130 & 119 & 121 & 116 & 116 \\
\hline $\mathrm{A}_{\mathrm{BET}}\left(\mathrm{m}^{2} / \mathrm{g}\right)$ & 700 a 1100 & 789 & 848 & 779 & 909 \\
\hline $\mathrm{V}_{\mathrm{t}}\left(\mathrm{cm}^{3} / \mathrm{g}\right)$ & 0,8 a 2,5 & 1,88 & 2,02 & 1,78 & 1,19 \\
\hline $\mathrm{D}_{\mathrm{p}}(\AA)$ & 80 a 120 & 105 & 110 & 103 & 104 \\
\hline
\end{tabular}

Tabela 7.2: Dados do controle de qualidade realizado em diferentes amostras de SBA-15.

A similaridade dos valores de diâmetro, volume e área superficial específicos de poro das diversas amostras indica que essas amostras são sintetizadas de forma reprodutível.

Os gráficos realizados são mostrados nas figuras 7.1 a 7.9 e mostram que as curvas de SAXS são similares, apresentando cinco picos de difração bem definidos, mostrando que as amostras apresentam rede de poros bem ordenada. As diferenças em intensidade observadas se devem a diferentes fatores de absorção. Os dados de NAI revelam que as amostras têm volume de poros e área superficial específica BET comparáveis à SBA-15 reportada na literatura. As curvas de distribuição de diâmetros de poro revelam uma estreita distribuição de

\footnotetext{
${ }^{1}$ Esses valores foram estabelecidos com base em valores de parâmetros geralmente obtidos na literatura e em estudos anteriores.
} 
diâmetros apresentando valores que variam de 100 a $110 \AA$, valores muito similares aos obtidos em sínteses anteriores.

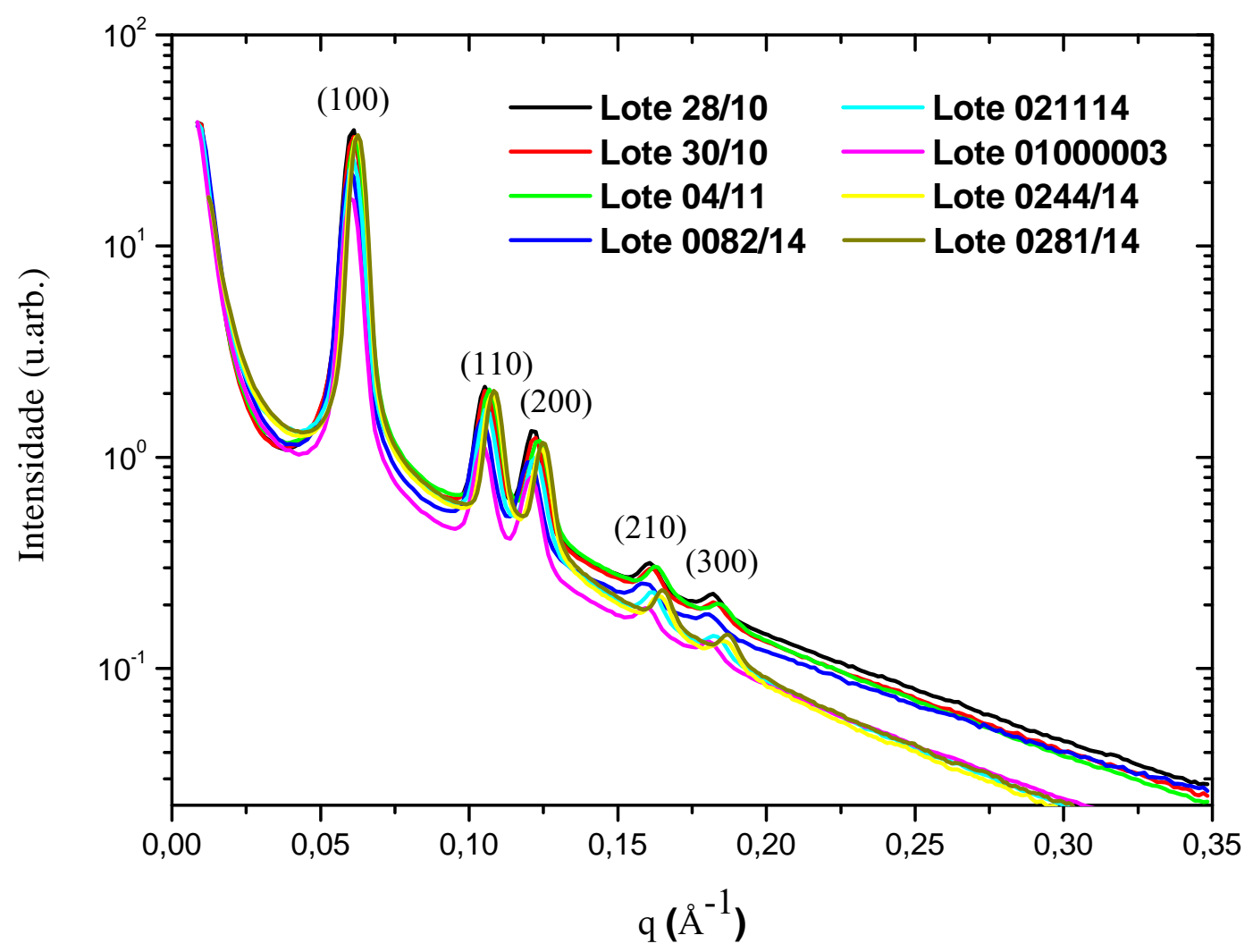

Figura 7.1: Curvas de SAXS de amostras de SBA-15 do controle de qualidade da Cristália. 


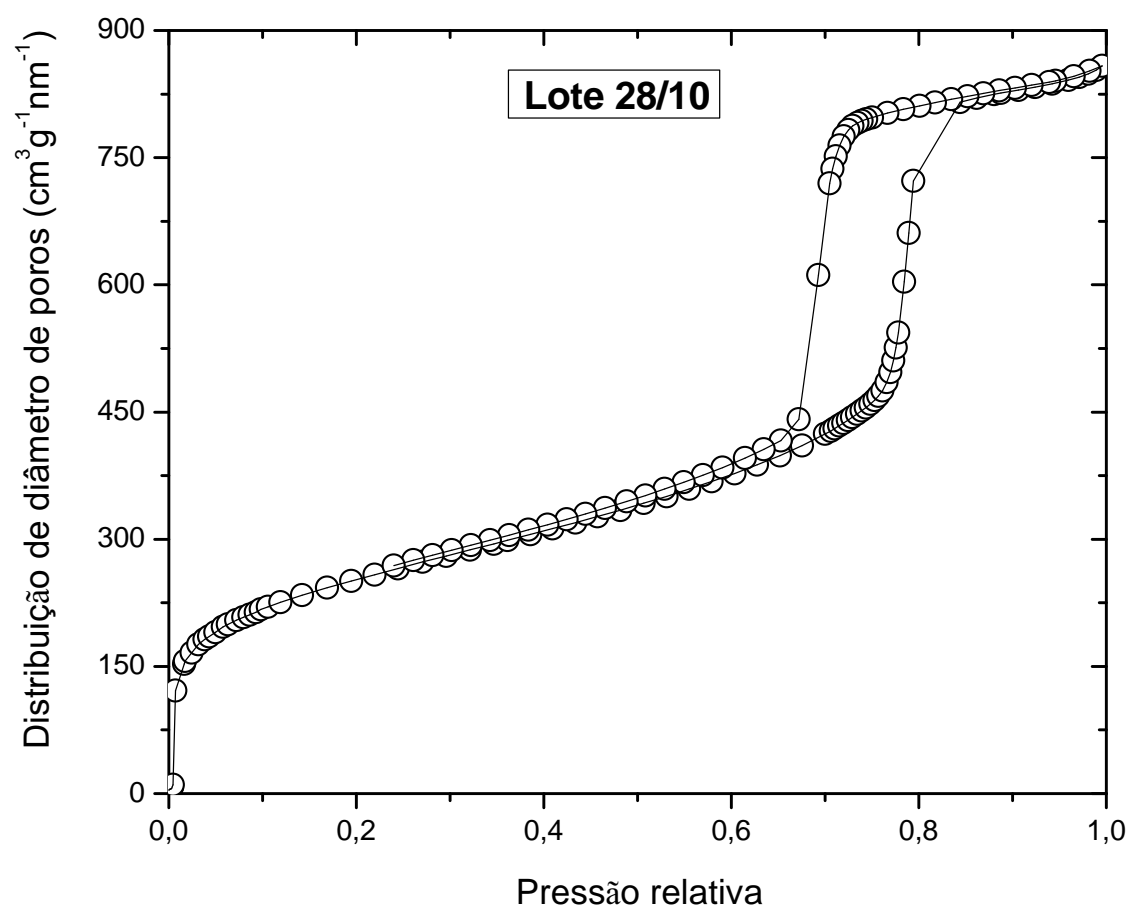

(a) Isoterma de adsorção

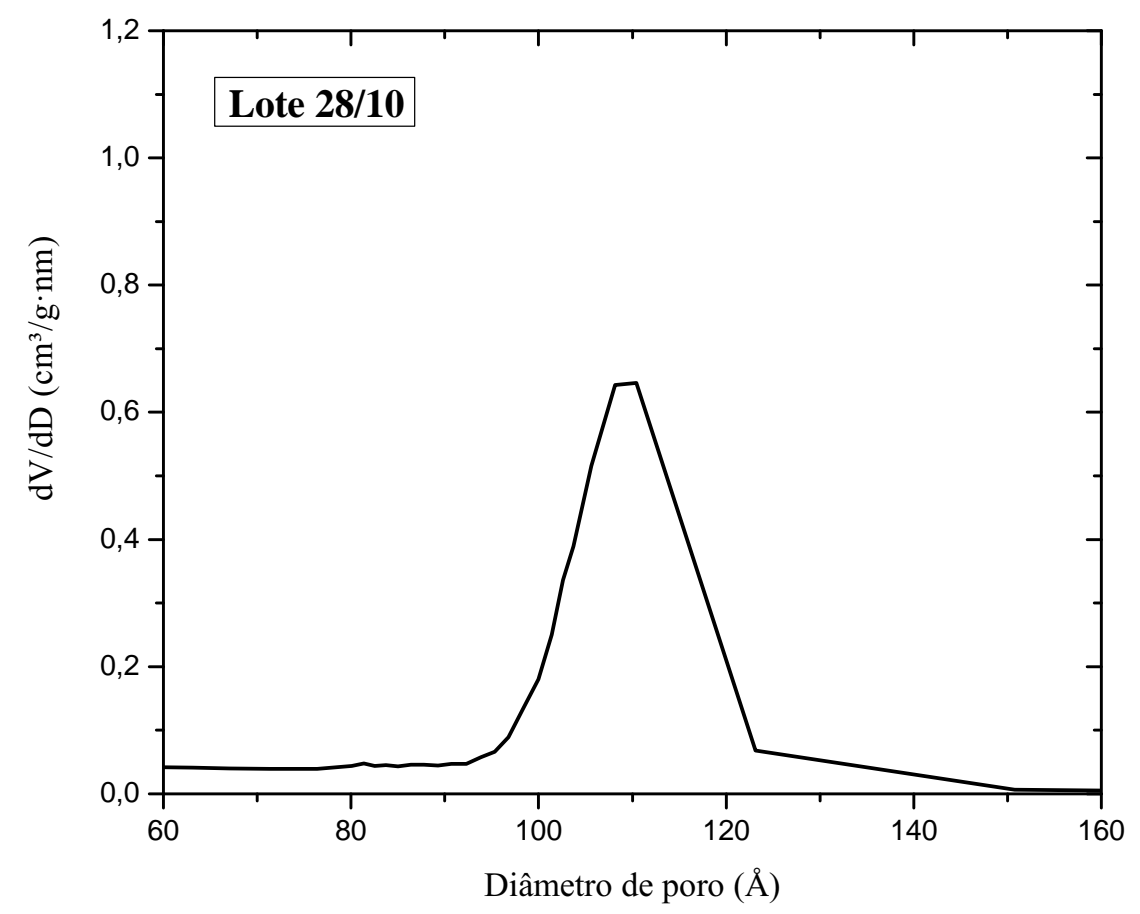

(b) Distribuição de tamanho de poro

Figura 7.2: Gráficos de NAI da amostra de SBA-15 Lote 28/10. 


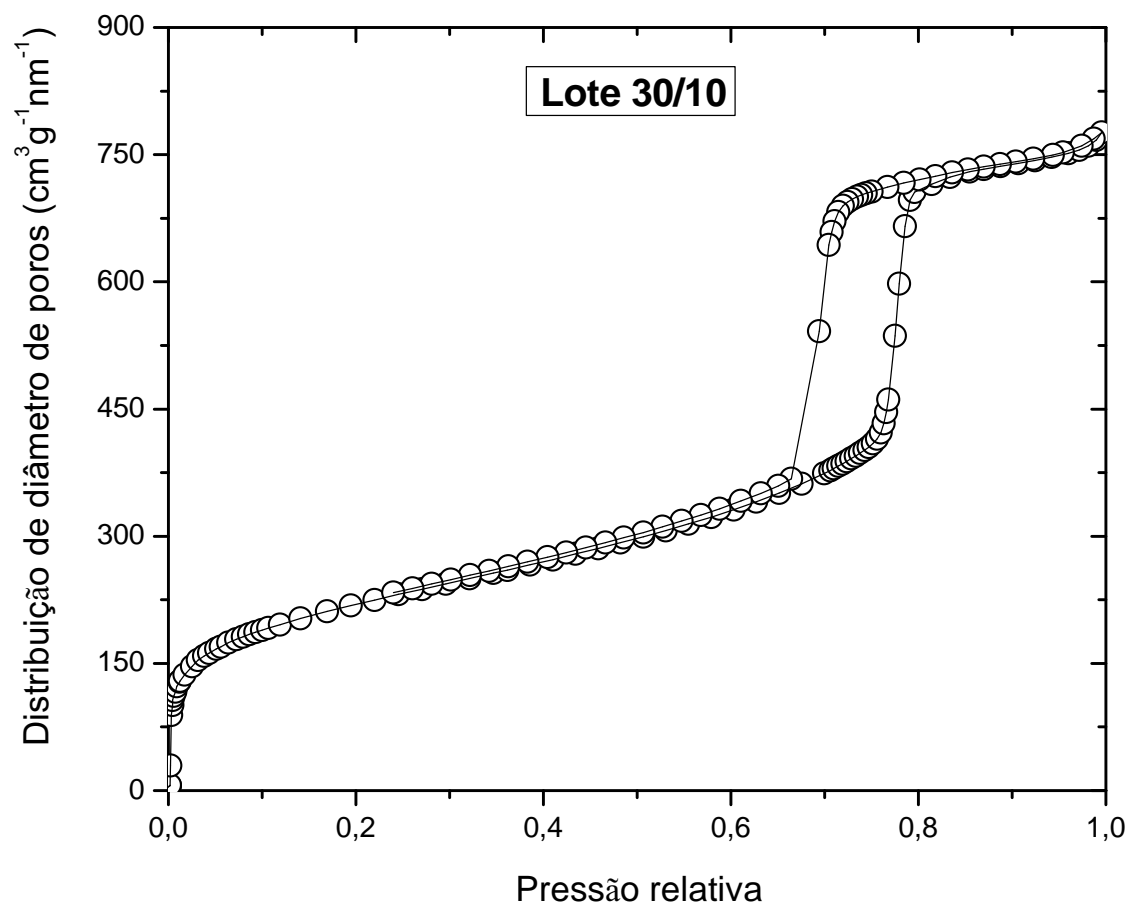

(a) Isoterma de adsorção

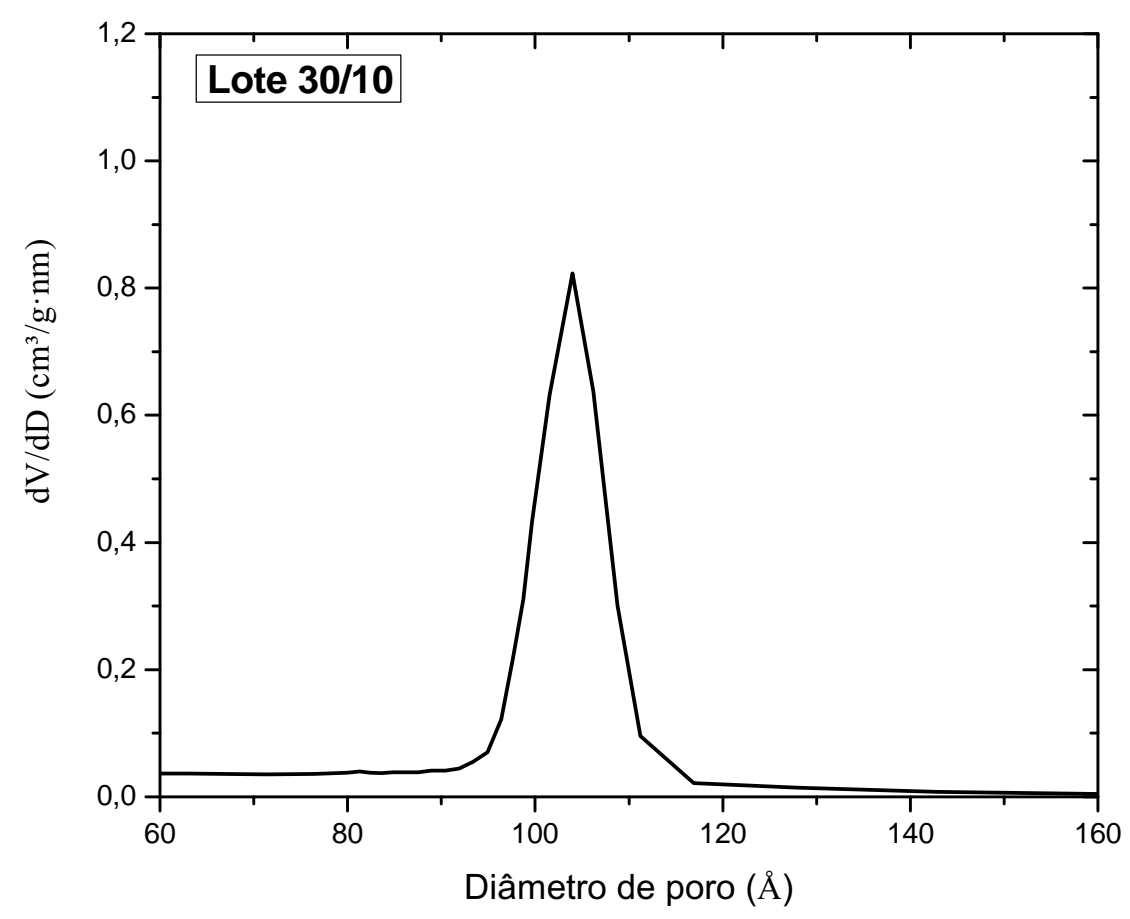

(b) Distribuição de tamanho de poro

Figura 7.3: Gráficos de NAI da amostra de SBA-15 Lote 30/10. 


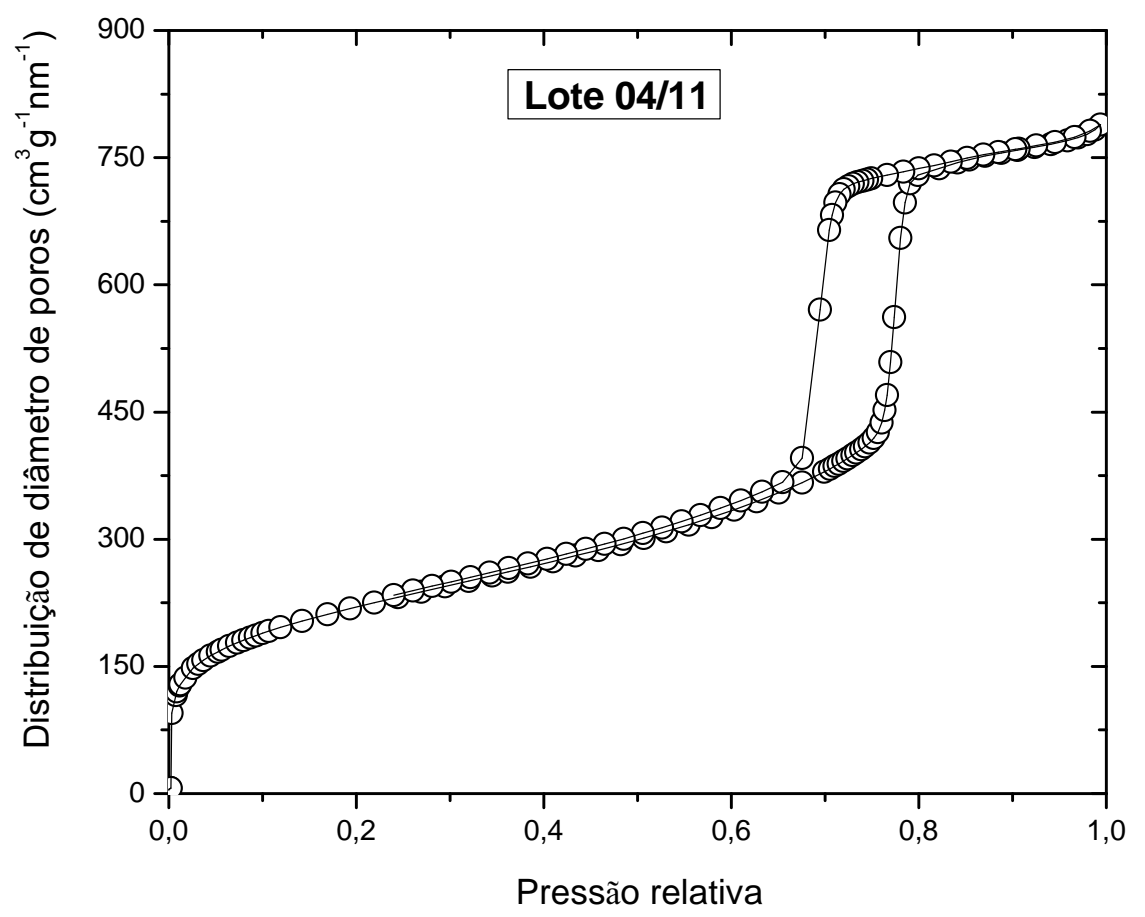

(a) Isoterma de adsorção

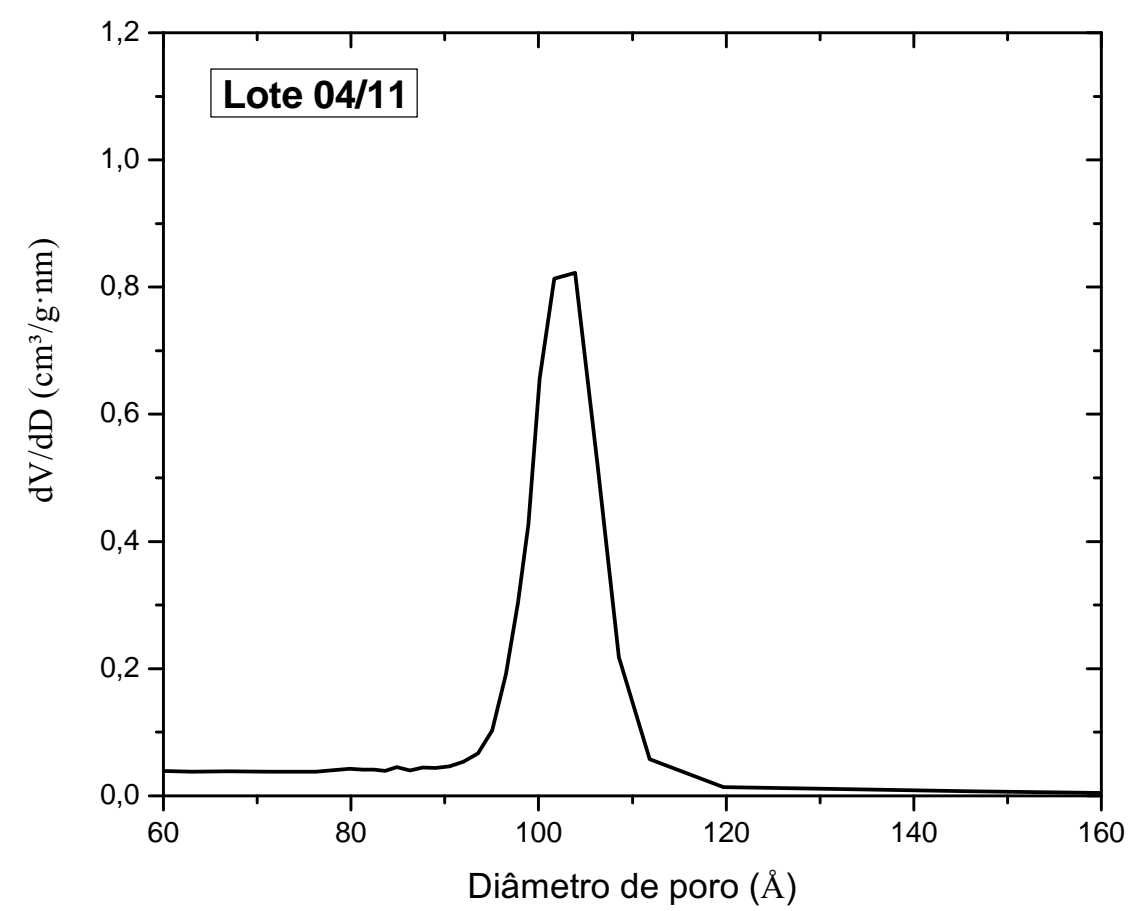

(b) Distribuição de tamanho de poro

Figura 7.4: Gráficos de NAI da amostra de SBA-15 Lote 04/11. 


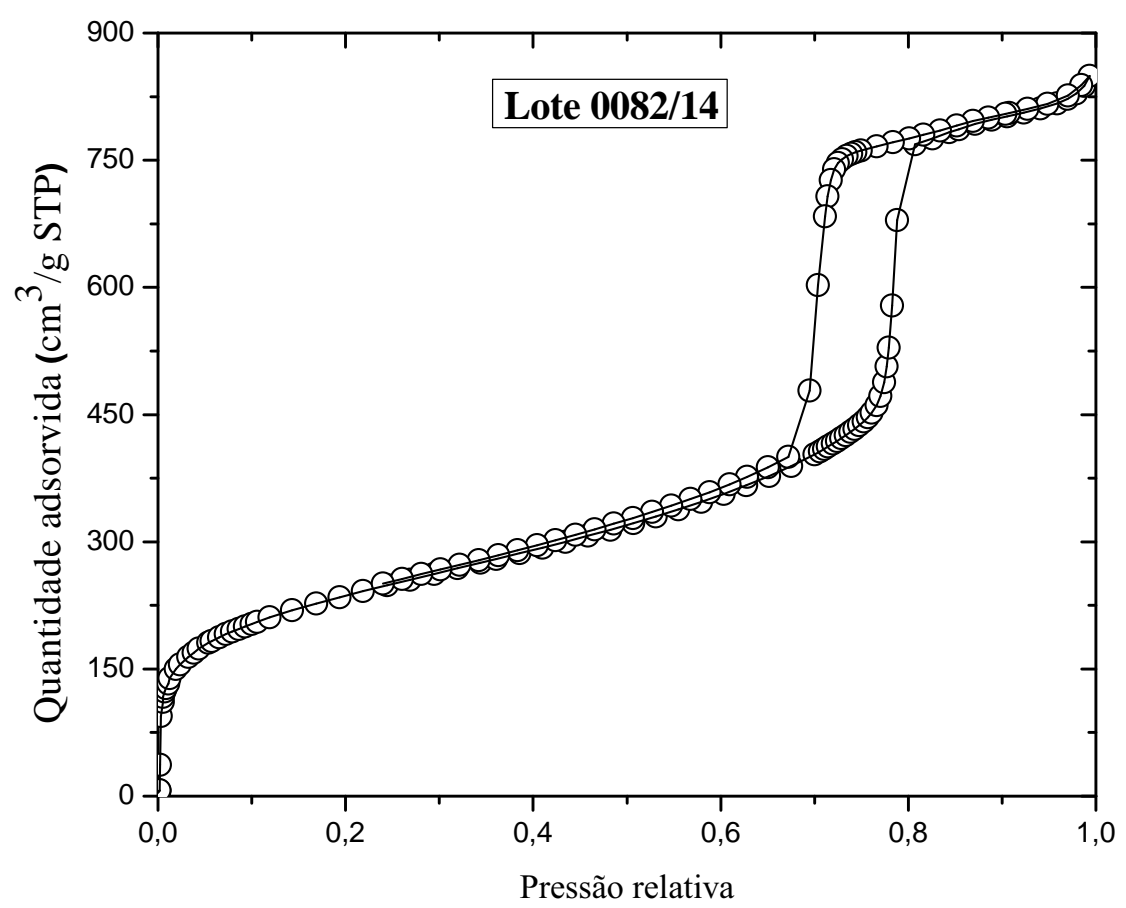

(a) Isoterma de adsorção

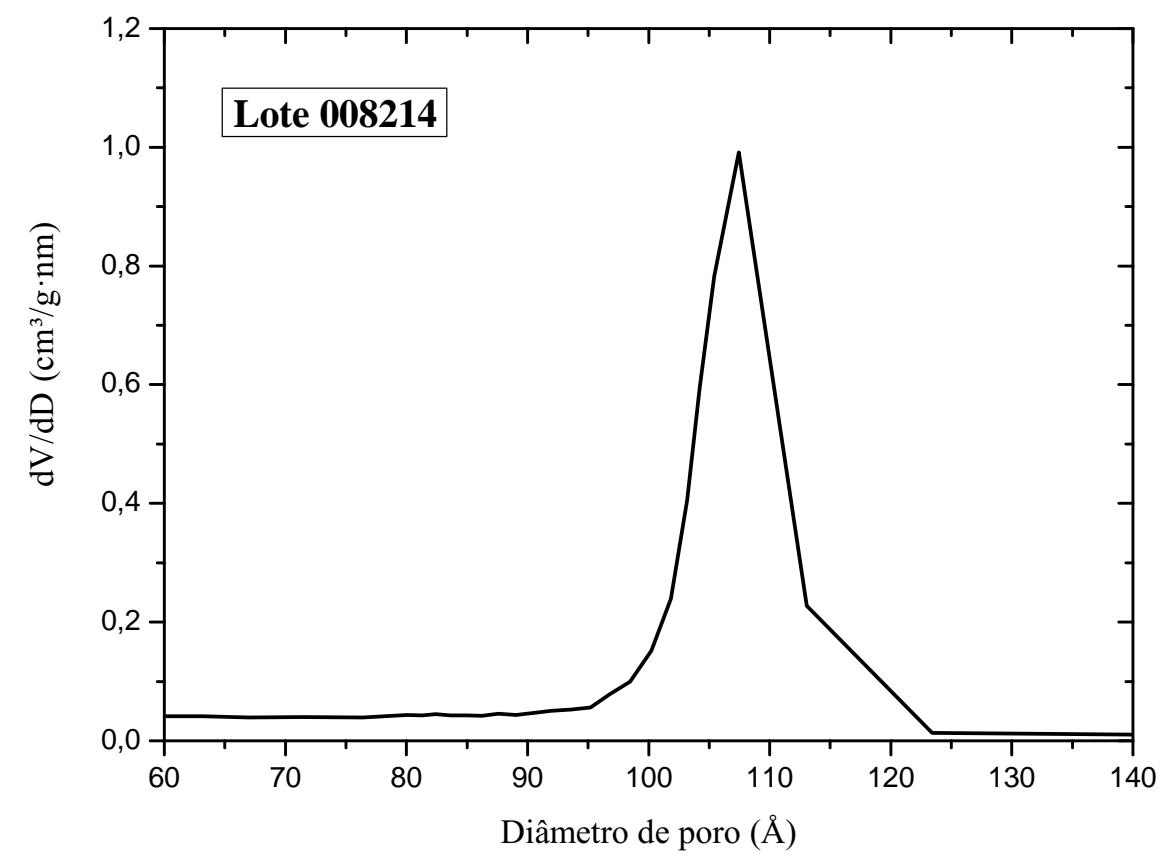

(b) Distribuição de tamanho de poro

Figura 7.5: Gráficos de NAI da amostra de SBA-15 Lote 0082/14. 


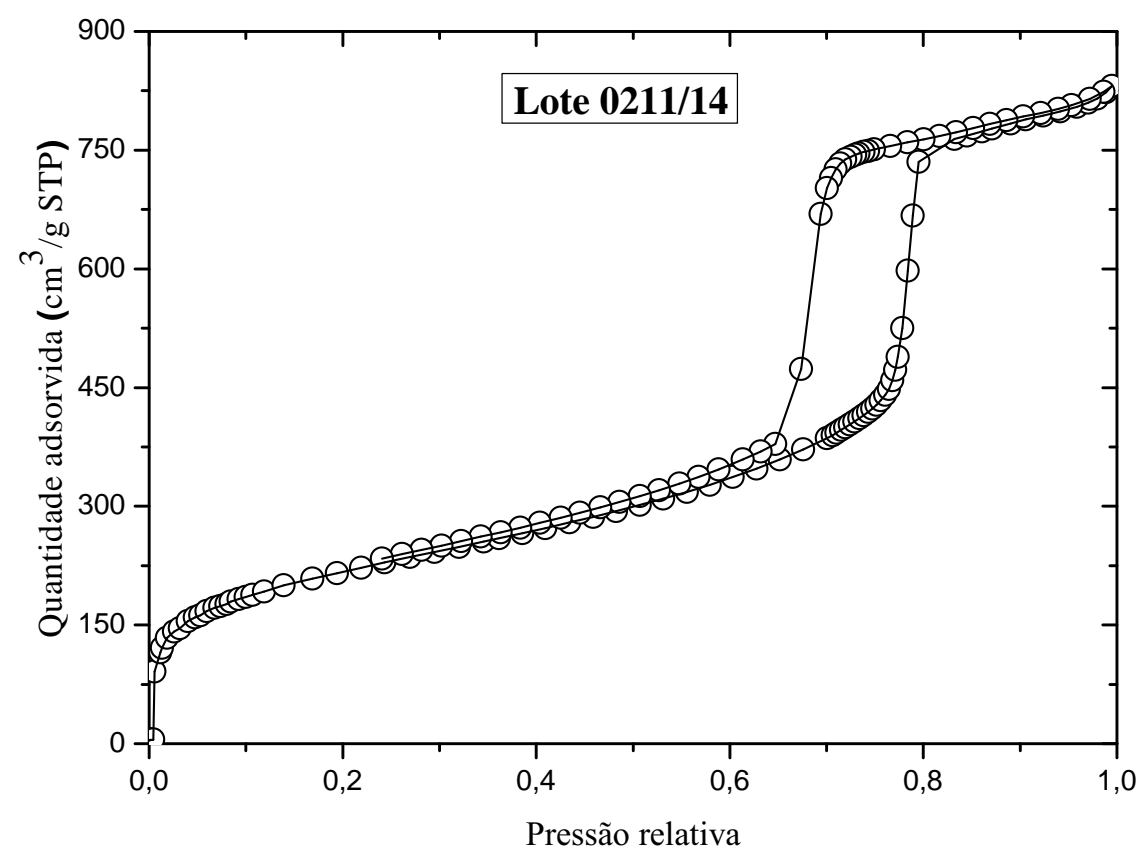

(a) Isoterma de adsorção

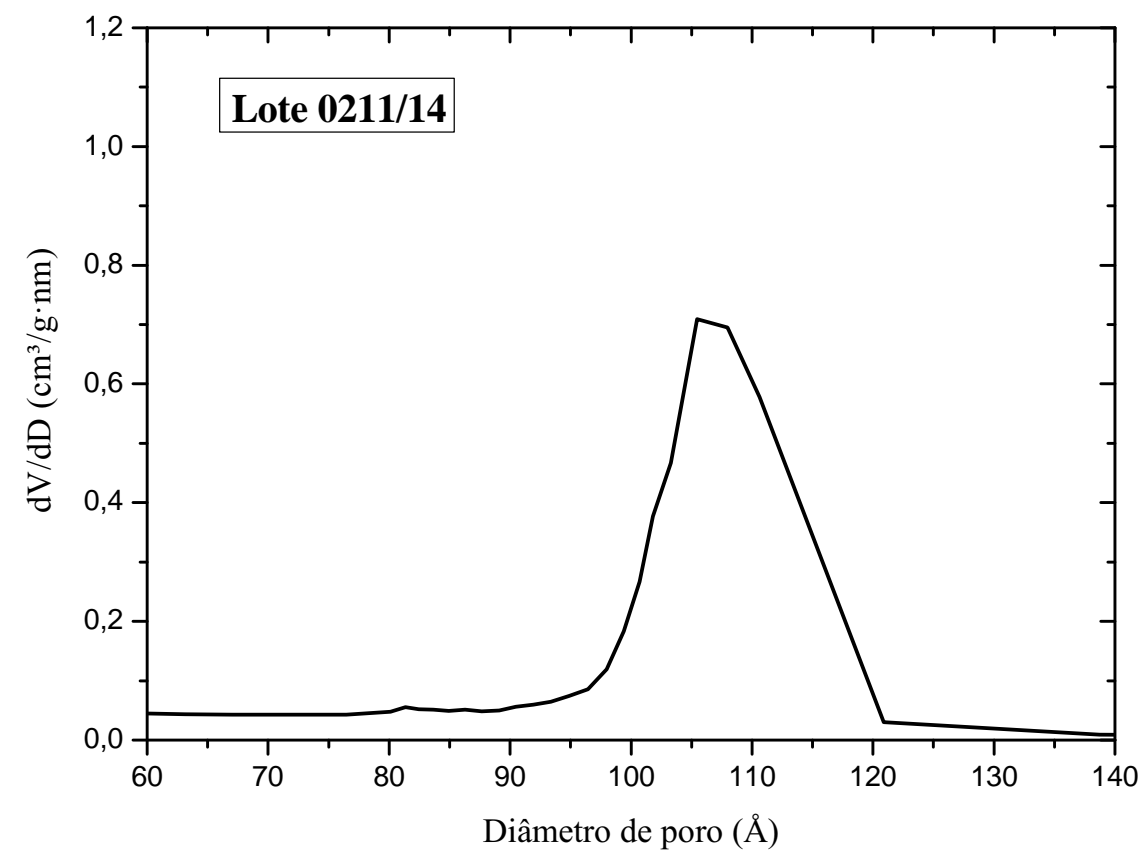

(b) Distribuição de tamanho de poro

Figura 7.6: Gráficos de NAI da amostra de SBA-15 Lote 0211/14. 


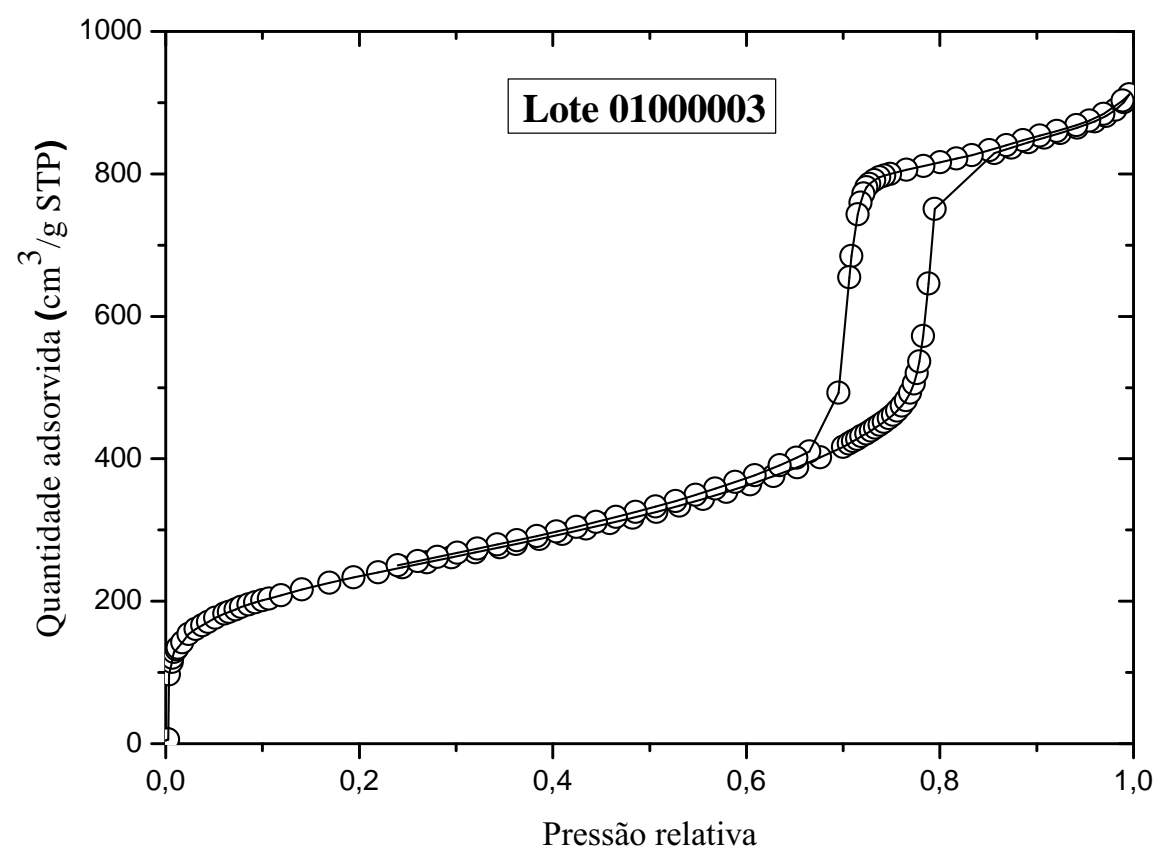

(a) Isoterma de adsorção

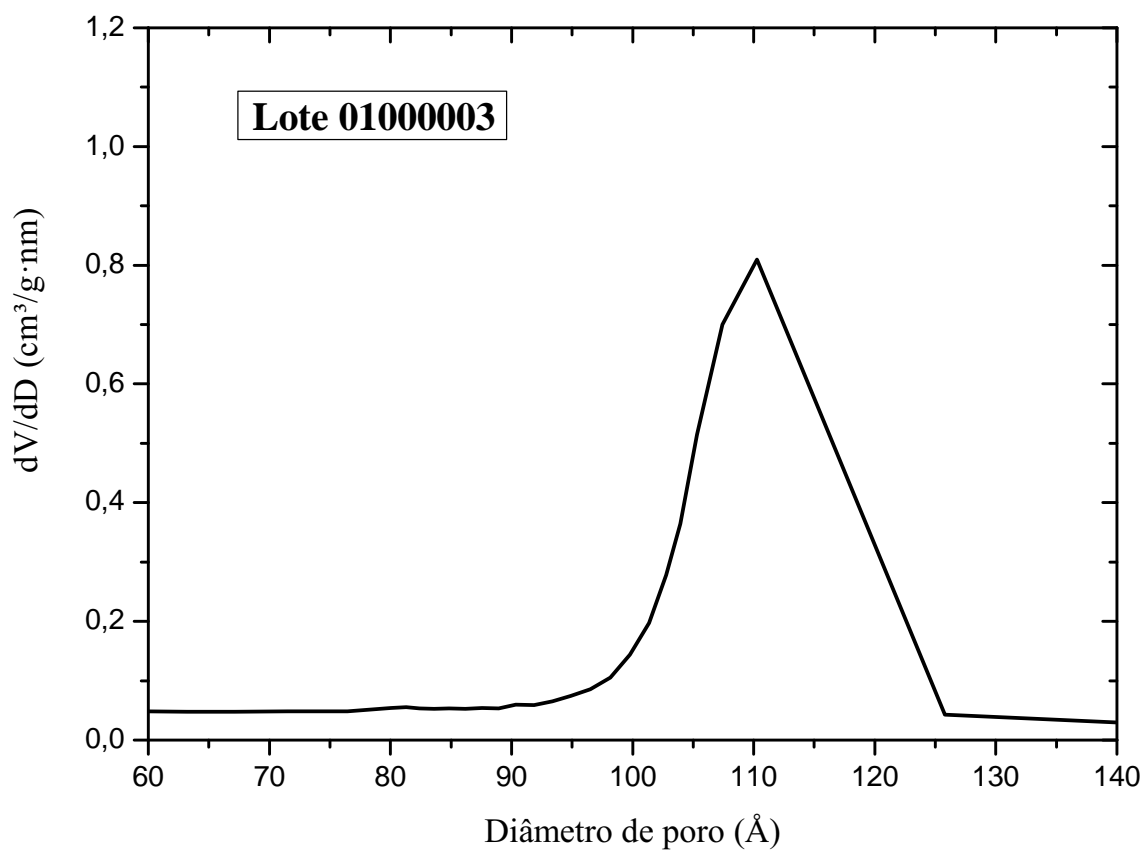

(b) Distribuição de tamanho de poro

Figura 7.7: Gráficos de NAI da amostra de SBA-15 Lote 01000003. 


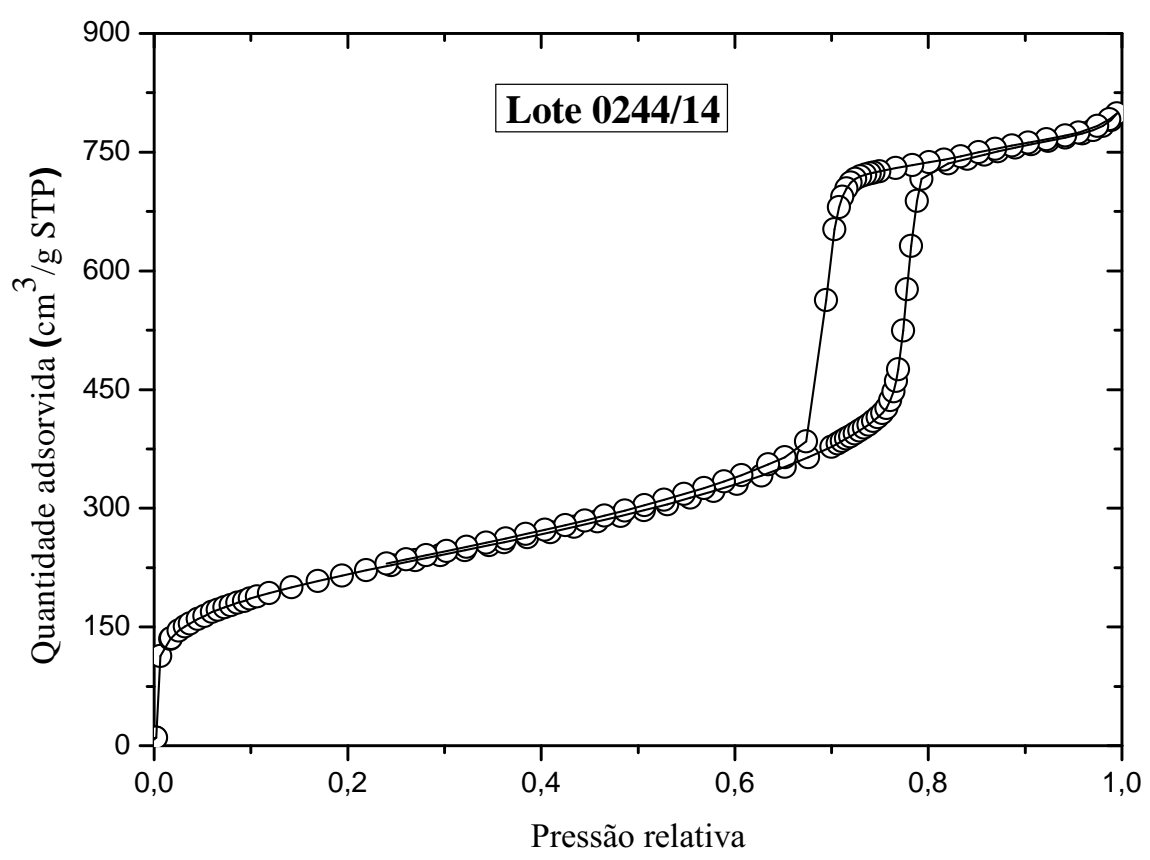

(a) Isoterma de adsorção

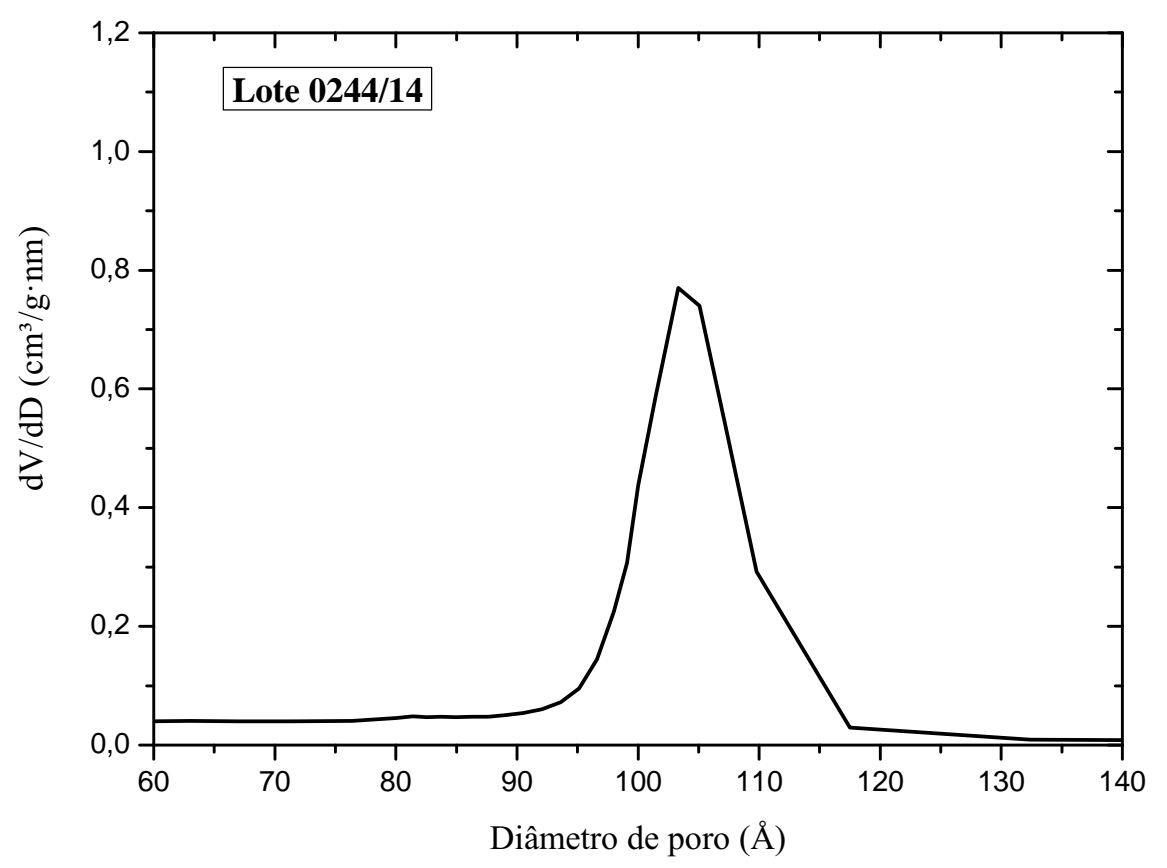

(b) Distribuição de tamanho de poro

Figura 7.8: Gráficos de NAI da amostra de SBA-15 Lote 0244/14. 


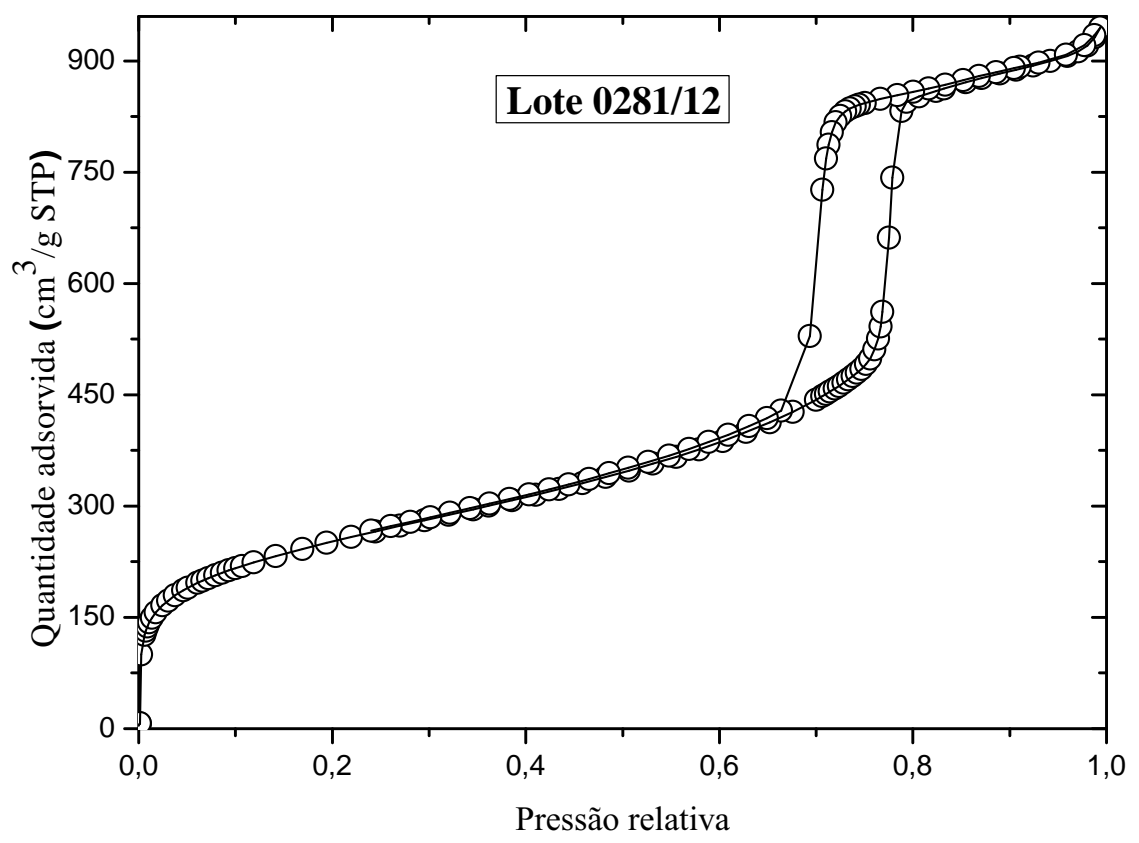

(a) Isoterma de adsorção

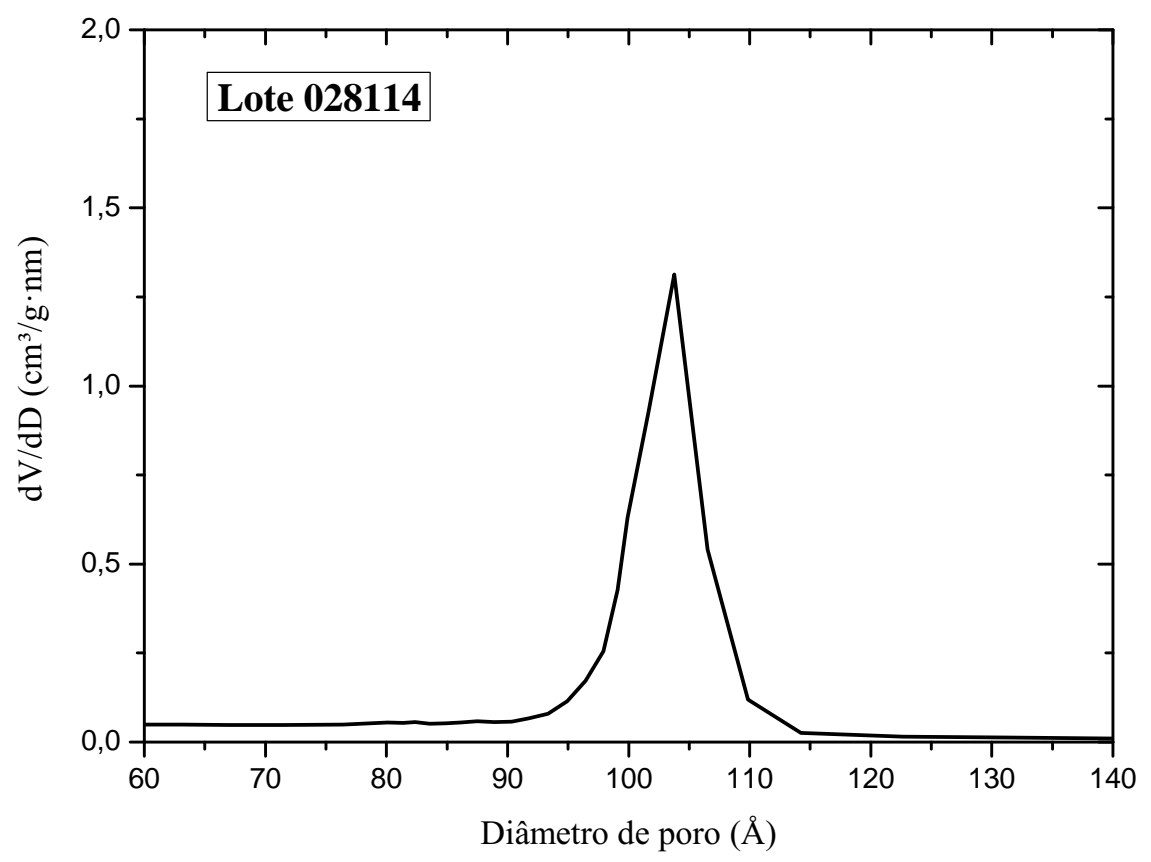

(b) Distribuição de tamanho de poro

Figura 7.9: Gráficos de NAI da amostra de SBA-15 Lote 0281/12. 


\section{CONCLUSÕES E PERSPECTIVAS}

Neste trabalho mostramos que a adição de TIPB deu origem a uma sílica com poros maiores e rede de poros mais desordenada. As medidas de SAXS indicaram que a rede de poros ainda permaneceu hexagonal após a adição de TIPB. O aumento no diâmetro de poro e parâmetro de rede atingiram valores da ordem de 24 e 20 \%, respectivamente. Para a obtenção de um maior diâmetro médio de poros são necessárias alterações de outros parâmetros da síntese como, por exemplo, a temperatura de síntese (CAO; KRUK, 2010). O grau de ordenamento foi satisfatório quando considerada a grande quantidade de TIPB utilizada ${ }^{1}$.

Foi possível realizar estimativas das dimensões das proteínas utilizadas a fim de verificar se as suas dimensões são compatíveis com a incorporação nos poros da sílica. Resultados mostraram que as proteínas BSA e IgG têm dimensões compatíveis com suas incorporações no interior dos mesoporos das amostras de SBA-15 utilizadas. Essas dimensões são da mesma ordem do diâmetro médio dos poros das amostras de sílica.

As medidas referentes à incorporação de proteínas revelaram que os microporos foram quase totalmente preenchidos pelo PBS. Também, a rede ordenada de poros não foi perturbada pela incorporação dessas proteínas já que o parâmetro de rede não foi alterado. Embora tenha sido demonstrado que as proteínas poderiam ser incorporadas no interior dos poros, a maior parte das proteínas provavelmente permaneceu na macroporosidade do material já que não houve diferença significativa entre os dados das caracterizações da BSA e lgG. As porcentagens de volume total de poros e área superficial específica BET preenchidos pela incorporação seguiram pequeno aumento de acordo com o diâmetro médio de poros, provavelmente porque o maior diâmetro provocou uma melhor incorporação das moléculas de proteína e/ou PBS na superfície do material. O volume total de poros teve diminuição de 56 a 79 \% e a área superficial específica BET de 72 a $89 \%$.

O preenchimento dos microporos pelo PBS e a presença das proteínas nos poros da sílica foram confirmados pelos ajuste dos dados de SAXS a partir de um modelo teórico.

Para complementar as informações obtidas neste trabalho podem ser feitas caracterizações de microscopia eletrônica de varredura (SEM) e de transmissão (TEM) em estudos futuros. Desta forma, poderiam ser obtidas informações adicionais sobre o interior dos poros e a superfície externa e assim analisar se as proteínas efetivamente penetraram no interior dos mesoporos ou permaneceram na macroporosidade.

Como sequência desse trabalho a funcionaização da sílica associada à expansão dos poros poderiam ser estudadas. A funcionalização da sílica geralmente ocasiona diminuição de volume e diâmetro médio, já que as moléculas utilizadas no processo ocupam espaço no interior dos poros, assim a expansão dos poros poderia ser uma alternativa para minimizar ao menos a

\footnotetext{
${ }^{1}$ Grande quantidade em relação à quantidade de polímero utilizada nas sínteses, que foi 1g.
} 
diminuição de diâmetro médio.

Sobre a acumulação de silício no organismo dos camundongos, as análises de fezes por PIXE mostraram que a diferença significativa entre os valores dos Grupos A, B e C após a segunda administração deve se correlacionar com o acúmulo da SBA-15 em macrófagos e outras células apresentadoras de antígenos, acarretando em morte celular e consequente eliminação, resultado importante para o uso deste material como adjuvante.

Os resultados das caracterizações realizadas nas amostras do controle de qualidade da Cristália Produtos Químicos e Farmacêuticos Ltda. estão dentro da faixa de valores esperados, o que leva à conclusão de que essas amostras são reprodutíveis para a produção de vacina de via oral em larga escala. 


\section{REFERÊNCIAS ${ }^{1}$}

ABURAYA, J. H. Padronização de Análises PIXE de Amostras Sólidas em Alvos Espessos. Dissertação (Dissertação de Mestrado) - Instituto de Física da Universidade de São Paulo, 2005.

ALBUQUERQUE, M. Síntese, caracterização e aplicação de catalisadores heterogêneos para a produção de biocombustíveis. 2008.

BAGSHAW, S. A.; PROUZET, E.; PINNAVAIA, T. J. Templating of mesoporous molecular sieves by nonionic polyethylene oxide surfactants. Science, American Association for the Advancement of Science, v. 269, n. 5228, p. 1242-1244, 1995.

BARRETT, E. P.; JOYNER, L. G.; HALENDA, P. P. The determination of pore volume and area distributions in porous substances. i. computations from nitrogen isotherms. Journal of the American Chemical society, ACS Publications, v. 73, n. 1, p. 373-380, 1951.

BECK, J. et al. A new family of mesoporous molecular sieves prepared with liquid crystal templates. Journal of the American Chemical Society, ACS Publications, v. 114, n. 27, p. 10834-10843, 1992.

BRAGG, W. L. The diffraction of x-rays by cristals. Nobel Lecture, September 6, 1922, 1922.

BRINKER, C. J.; SCHERER, G. W. Sol-gel science: the physics and chemistry of sol-gel processing. [S.I.]: Access Online via Elsevier, 1990.

BRUNAUER, S. et al. On a theory of the van der waals adsorption of gases. Journal of the American Chemical Society, ACS Publications, v. 62, n. 7, p. 1723-1732, 1940.

BRUNAUER, S.; EMMETT, P. H.; TELLER, E. Adsorption of gases in multimolecular layers. Journal of the American Chemical Society, ACS Publications, v. 60, n. 2, p. 309-319, 1938.

CAO, L.; KRUK, M. Synthesis of large-pore sba-15 silica from tetramethyl orthosilicate using triisopropylbenzene as micelle expander. Colloids and Surfaces A: Physicochemical and Engineering Aspects, Elsevier, v. 357, n. 1, p. 91-96, 2010.

CAO, L.; MAN, T.; KRUK, M. Synthesis of ultra-large-pore sba-15 silica with two-dimensional hexagonal structure using triisopropylbenzene as micelle expander. Chemistry of Materials, ACS Publications, v. 21, n. 6, p. 1144-1153, 2009.

CARVALHO, L. V. et al. Immunological parameters related to the adjuvant effect of the ordered mesoporous silica sba-15. Vaccine, Elsevier, v. 28, n. 50, p. 7829-7836, 2010.

CHARNAY, C. et al. Inclusion of ibuprofen in mesoporous templated silica: drug loading and release property. European Journal of Pharmaceutics and Biopharmaceutics, Elsevier, v. 57, n. 3, p. 533-540, 2004.

CIESLA, U.; SCHÜTH, F. Ordered mesoporous materials. Microporous and Mesoporous Materials, Elsevier, v. 27, n. 2, p. 131-149, 1999.

\footnotetext{
${ }^{1}$ De acordo com a Associação Brasileira de Normas Técnicas. NBR 6023.
} 
CULLITY, B. D.; STOCK, S. R. Elements of X-ray Diffraction. [S.I.]: Prentice hall Upper Saddle River, NJ, 2001.

DIAZ, J. F.; JR, K. J. B. Enzyme immobilization in mcm-41 molecular sieve. Journal of Molecular Catalysis B: Enzymatic, Elsevier, v. 2, n. 2, p. 115-126, 1996.

FÖRSTER, S. et al. Scattering curves of ordered mesoscopic materials. The Journal of Physical Chemistry B, ACS Publications, v. 109, n. 4, p. 1347-1360, 2005.

FREIBERGER, N.; GLATTER, O. Small-angle scattering from hexagonal liquid crystals. The Journal of Physical Chemistry B, ACS Publications, v. 110, n. 30, p. 14719-14727, 2006.

GLATTER, O.; KRATKY, O. Small angle X-ray scattering. [S.I.]: Academic press London, 1982.

GUINIER, A. X-ray diffraction: in crystals, imperfect crystals, and amorphous bodies. [S.I.]: Courier Dover Publications, 1994.

HAN, Y.-J.; KIM, J. M.; STUCKY, G. D. Preparation of noble metal nanowires using hexagonal mesoporous silica sba-15. Chemistry of materials, ACS Publications, v. 12, n. 8, p. 2068-2069, 2000.

HENCH, L. L.; WEST, J. K. The sol-gel process. Chemical Reviews, ACS Publications, v. 90, n. 1 , p. 33-72, 1990.

JARONIEC, M.; SOLOVYOV, L. A. Improvement of the kruk-jaroniec-sayari method for pore size analysis of ordered silicas with cylindrical mesopores. Langmuir, ACS Publications, v. 22, n. 16, p. 6757-6760, 2006.

JOHANSSON, S. A.; CAMPBELL, J. L.; MALMQVIST, K. G. Particle-induced X-ray emission spectrometry (PIXE). [S.I.]: John Wiley \& Sons, 1995.

KISLER, J. M. et al. Separation of biological molecules using mesoporous molecular sieves. Microporous and mesoporous materials, Elsevier, v. 44, p. 769-774, 2001.

KONAREV, P.; PETOUKHOV, M.; SVERGUN, D. Massha-a graphics system for rigid-body modelling of macromolecular complexes against solution scattering data. Journal of Applied Crystallography, International Union of Crystallography, v. 34, n. 4, p. 527-532, 2001.

KONAREV, P. V. et al. Primus: a windows pc-based system for small-angle scattering data analysis. Journal of Applied Crystallography, International Union of Crystallography, v. 36, n. 5, p. 1277-1282, 2003.

KRESGE, C. et al. Ordered mesoporous molecular sieves synthesized by a liquid-crystal template mechanism. nature, v. 359, n. 6397, p. 710-712, 1992.

KRUK, M.; JARONIEC, M.; SAYARI, A. Application of large pore mcm-41 molecular sieves to improve pore size analysis using nitrogen adsorption measurements. Langmuir, ACS Publications, v. 13, n. 23, p. 6267-6273, 1997.

LIN, Y.-S. et al. Well-ordered mesoporous silica nanoparticles as cell markers. Chemistry of Materials, ACS Publications, v. 17, n. 18, p. 4570-4573, 2005.

LINDNER, P.; ZEMB, T. Neutron, X-rays and Light. Scattering Methods Applied to Soft Condensed Matter. [S.I.]: Elsevier, 2002. 
LIPPENS, B.; LINSEN, B.; BOER, J. D. Studies on pore systems in catalysts i. the adsorption of nitrogen; apparatus and calculation. Journal of Catalysis, Elsevier, v. 3, n. 1, p. 32-37, 1964.

MANET, S. et al. Kinetics of the formation of $2 \mathrm{~d}$-hexagonal silica nanostructured materials by nonionic block copolymer templating in solution. The journal of physical chemistry $B$, ACS Publications, v. 115, n. 39, p. 11330-11344, 2011.

MARIANO-NETO, F. Aplicabilidade da Silica Mesoporosa Ordenada como Adjuvante Imunológico. Dissertação (Dissertação de Mestrado) — Instituto de Física da Universidade de São Paulo, 2008.

MASEL, R. I. Principles of adsorption and reaction on solid surfaces. [S.I.]: Wiley New York, 1996.

MATOS, J. R. et al. Toward the synthesis of extra-large-pore mcm-41 analogues. Chemistry of materials, ACS Publications, v. 13, n. 5, p. 1726-1731, 2001.

MERCURI, L. P. et al. Ordered mesoporous silica sba-15: A new effective adjuvant to induce antibody response. Small, Wiley Online Library, v. 2, n. 2, p. 254-256, 2006.

MIKHAIL, R. S.; BRUNAUER, S.; BODOR, E. Investigations of a complete pore structure analysis: I. analysis of micropores. Journal of colloid and interface science, Elsevier, v. 26, n. 1, p. 45-53, 1968.

POLLOCK, R. A. et al. Size and spatial distribution of micropores in sba-15 using $\mathrm{cm}$-sans. Chemistry of Materials, ACS Publications, v. 23, n. 17, p. 3828-3840, 2011.

ROUQUEROL, J.; ROUQUEROL, F.; SING, K. S. Adsorption by powders and porous solids. [S.I.]: Academic press, 1998.

RUTHSTEIN, S.; FRYDMAN, V.; GOLDFARB, D. Study of the initial formation stages of the mesoporous material sba-15 using spin-labeled block co-polymer templates. The Journal of Physical Chemistry B, ACS Publications, v. 108, n. 26, p. 9016-9022, 2004.

SAYARI, A.; LIU, P. Non-silica periodic mesostructured materials: recent progress. Microporous materials, Elsevier, v. 12, n. 4, p. 149-177, 1997.

SAYLE, R. A.; MILNER-WHITE, E. J. Rasmol: biomolecular graphics for all. Trends in biochemical sciences, Elsevier, v. 20, n. 9, p. 374-376, 1995.

SEMENYUK, A.; SVERGUN, D. Gnom-a program package for small-angle scattering data processing. Journal of Applied Crystallography, International Union of Crystallography, v. 24, n. 5, p. 537-540, 1991.

SING, K. S. Reporting physisorption data for gas/solid systems with special reference to the determination of surface area and porosity (recommendations 1984). Pure and applied chemistry, v. 57, n. 4, p. 603-619, 1985.

SUNDBLOM, A. et al. Modeling in situ small-angle $x$-ray scattering measurements following the formation of mesostructured silica. The Journal of Physical Chemistry C, ACS Publications, v. 113, n. 18, p. $7706-7713,2009$.

WU, C.-G.; BEIN, T. Conducting carbon wires in ordered, nanometer-sized channels. Science, p. 1013-1015, 1994. 
WU, C.-G.; BEIN, T. Conducting carbon wires in ordered, nanometer-sized channels. Science, p. 1013-1015, 1994.

WU, C.-G.; BEIN, T. Conducting polyaniline filaments in a mesoporous channel host. Science, p. $1757-1759,1994$.

ZHAO, D. et al. Triblock copolymer syntheses of mesoporous silica with periodic 50 to 300 angstrom pores. Science, American Association for the Advancement of Science, v. 279, n. 5350, p. 548-552, 1998.

ZHAO, D. et al. Nonionic triblock and star diblock copolymer and oligomeric surfactant syntheses of highly ordered, hydrothermally stable, mesoporous silica structures. Journal of the American Chemical Society, ACS Publications, v. 120, n. 24, p. 6024-6036, 1998. 
APÊNDICES 


\section{A. Dedução do vetor espalhamento q}

O vetor espalhamento $\vec{q}$ é definido como:

$$
\vec{q}=\vec{s}-\overrightarrow{s_{0}}
$$

De acordo com a figura A.1 a representação desses três vetores forma um triângulo isósceles.

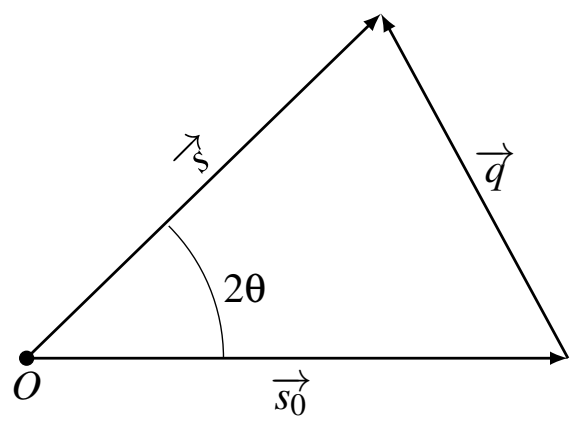

Figura A.1: Vetor espalhamento $(\vec{q})$, vetor de onda do feixe incidente $\left(\overrightarrow{s_{0}}\right)$ e do feixe espalhado $(\vec{s})$.

Aplicando a Lei dos cossenos:

$$
q^{2}=s^{2}+s_{0}^{2}-2 \cdot s \cdot s_{0} \cdot \cos 2 \theta
$$

Como se trata de espalhamento elástico, temos que:

$$
s=s_{0}=\frac{2 \pi}{\lambda}
$$

Fazendo essa substitução na equação A.2:

$$
\begin{array}{r}
q^{2}=2 s^{2}(1-\cos 2 \theta) \\
q^{2}=2 s^{2}\left(1-\cos ^{2} \theta+\operatorname{sen}^{2} \theta\right) \\
q^{2}=2 s^{2}\left(2 \operatorname{sen}^{2} \theta\right) \\
q= \pm 2 s \cdot \operatorname{sen} \theta
\end{array}
$$

E finalmente, substituindo o módulo de $\vec{S}$ e evidenciando apenas o valor positivo da equação A.7, temos que:

$$
q=\frac{4 \pi}{\lambda} \sin \theta
$$




\section{A.1 Razões entre os valores de q para uma rede hexagonal}

Partindo da definição de $q$ (equação 4.4) e da definição de $d$ (equação 4.5) para uma rede cristalina hexagonal mostradas no capítulo 4, podemos escrever a razão entre as posições de um pico de difração de índice $(h k l)$ e do pico de difração de índice (100) como:

$$
\frac{q_{(h k l)}}{q_{(100)}}=\frac{d_{(100)}}{d_{(h k l)}}=\frac{\sqrt{(4 / 3) \cdot\left(h^{2}+h \cdot k+k^{2}\right) / a^{2}}}{\sqrt{(4 / 3) \cdot 1 / a^{2}}}
$$

De forma que chegamos à:

$$
\frac{q_{(h k l)}}{q_{(100)}}=\sqrt{h^{2}+h \cdot k+k^{2}}
$$

Substituindo os índices $(h k l)$ dos picos de difração presentes nas curvas de SAXS da SBA-15 chegamos aos valores listados na tabela A.1.

\begin{tabular}{|c|c|c|c|}
\hline $\mathbf{q}_{(\mathbf{1 1 0})} / \mathbf{q}_{(\mathbf{1 0 0})}$ & $\mathbf{q}_{(\mathbf{2 0 0})} / \mathbf{q}_{(\mathbf{1 0 0})}$ & $\mathbf{q}_{(\mathbf{2 1 0})} / \mathbf{q}_{(\mathbf{1 0 0})}$ & $\mathbf{q}_{(\mathbf{3 0 0})} / \mathbf{q}_{(\mathbf{1 0 0})}$ \\
\hline$\sqrt{3}$ & $\sqrt{4}$ & $\sqrt{7}$ & $\sqrt{9}$ \\
\hline
\end{tabular}

Tabela A.1: Razões entre as posições dos picos de difração no espaço recíproco de uma rede hexagonal de acordo com equação A.10.

Tendo em vista que a equação A.10 foi deduzida para uma rede hexagonal, chega-se a conclusão que se a rede cristalina for hexagonal as razões entre as posições dos picos de difração terão os mesmos valores mostrados na tabela A.1.

A tabela a seguir apresenta os valores centrais em $q$ dos picos de reflexão das amostras convencional e com poros expandidos de SBA-15. Esses valores foram utilizados para os cálculos das razões apresentadas na tabela 5.1 no capítulo 5 .

\begin{tabular}{|c|c|c|c|c|c|}
\hline & $q_{(100)}$ & $q_{(110)}$ & $q_{(200)}$ & $q_{(210)}$ & $q_{(300)}$ \\
\hline \hline P0 & 0,0601 & 0,1042 & 0,1199 & 0,1590 & 0,18017 \\
\hline P05 & 0,0582 & 0,1005 & 0,1159 & - & - \\
\hline P2 & 0,0499 & 0,0869 & 0,1008 & - & - \\
\hline
\end{tabular}

Tabela A.2: Valores de $q$ referentes aos picos de difração das amostras P0, P05 e P2 em $\AA^{-1}$. 


\section{B. Método BET}

Vamos considerar que, para um dado valor da pressão $p$ abaixo da pressão de saturação $p_{0}$, camadas $0,1,2 \ldots i$ de moléculas adsorvidas ocupam frações $\theta_{0}, \theta_{1}, \theta_{2} \ldots \theta_{i}$ da superfície de um sólido, como mostrado na figura B.1.

No equilíbrio, as frações da superfície nua e da primeira camada permanecem estáveis de forma que a taxa de condensação da superfície nua é igual a taxa de evaporação da primeira camada ${ }^{1}$ :

$$
a_{1} p \theta_{0}=b_{1} \theta_{1} \exp \left(-\frac{E_{1}}{R T}\right)
$$

Onde $a_{1}$ e $b_{1}$ são constantes de adsorção e dessorção da primeira camada, $R$ é a constante dos gases ideais, $T$ é a temperatura e $E_{1}$ é o calor de adsorção da primeira camada. Essa é essencialmente a equação de Langmuir para a adsorção monocamadas e assume que $a_{1}, b_{1}$ e $E_{1}$ são independentes da quantidade de moléculas adsorvidas.

O mesmo pode ser aplicado à todas as camadas de forma que, generalizando o resultado, temos:

$$
a_{i} p \theta_{i-1}=b_{i} \theta i \exp \left(-\frac{E_{i}}{R T}\right)
$$

O volume total de moléculas adsorvidas $V$ pode ser determinada em termos dessas frações através da relação:

$$
V=V_{m} \sum_{i=1}^{\infty} i \theta_{i}
$$

Onde $V_{m}$ é volume ocupado por uma monocamada quando ela está totalmente preenchida. O "i"na equação acima foi colocado por que cada camada possui um número $i$ de moléculas.

A somatória das frações de todas as superfícies é igual à unidade:

$$
\sum_{i=0}^{\infty} \theta_{i}=1
$$

Tendo isso em vista podemos escrever a equação B.3 como:

$$
\frac{V}{V_{m}}=\frac{\sum_{i=1}^{\infty} i \theta_{i}}{\sum_{i=0}^{\infty} \theta_{i}}
$$

\footnotetext{
${ }^{1} \mathrm{~A}$ taxa de evaporação dessa equação é dada pela Distribuição de Boltzmann.
} 
Nesta figura:

$$
\begin{aligned}
& \theta_{0}=2 / 11 \\
& \theta_{1}=1 / 11 \\
& \theta_{2}=3 / 11 \\
& \theta_{3}=1 / 11 \\
& \theta_{4}=3 / 11 \\
& \theta_{5}=1 / 11
\end{aligned}
$$

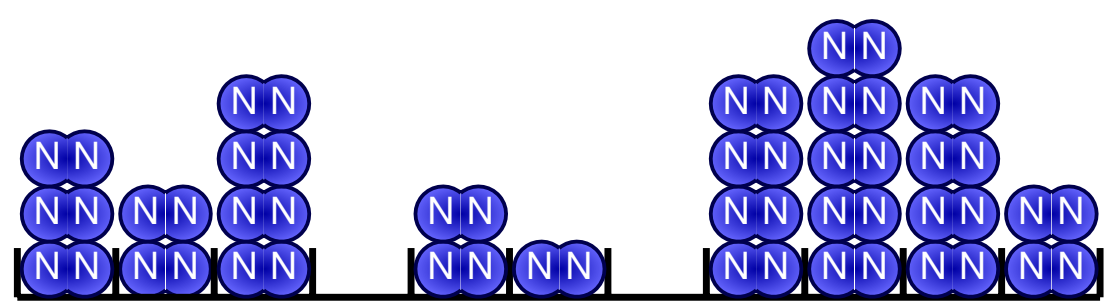

Figura B.1: Ilustração do processo de adsorção multicamadas.

Antes de continuar é necessário fazer algumas considerações: É assumido que a energia de adsorção da segunda camada em diante tem o mesmo valor que a energia de liquefação. Portanto:

$$
E_{2}=E_{3}=E_{4}=\ldots=E_{L}
$$

Uma vez que todas as camadas tem a mesma propriedade, temos que:

$$
\frac{b_{2}}{a_{2}}=\frac{b_{3}}{a_{3}}=\ldots=\frac{b_{i}}{a_{i}}=g
$$

Isso torna possível expressar $\theta_{i}$ em termos de $\theta_{0}$. Assim, rearranjando a equação B.1 temos:

$$
\begin{gathered}
\theta_{1}=y \theta_{0} \quad \text { onde } y=\frac{a_{1}}{b_{1}} p \exp \left(\frac{E_{1}}{R T}\right) \\
\theta_{2}=x \theta_{1} \text { onde } x=\frac{p}{g} \exp \left(\frac{E_{L}}{R T}\right)
\end{gathered}
$$

Para a fração da terceira camada temos $\theta_{3}=x \theta_{2}=x^{2} \theta_{1}$. Generalizando para todas as camadas obtemos:

$$
\theta_{i}=x^{i-1} \theta_{1}=y x^{i-1} \theta_{0}=c x^{i} \theta_{0}
$$

Onde a constante $c$ é definida como:

$$
c=\frac{y}{x}=\frac{a_{1}}{b_{1}} g \exp \left(\frac{E_{1}-E_{L}}{R T}\right)
$$

Agora podemos reescrever $\theta_{i}$ da equação B.5 como: 


$$
\frac{V}{V_{m}}=\frac{\sum_{i=1}^{\infty} i \theta_{i}}{\sum_{i=0}^{\infty} \theta_{i}}=\frac{c \theta_{0} \sum_{i=1}^{\infty} i x^{i}}{\theta_{0}+\sum_{i=1}^{\infty} \theta_{i}}=\frac{c \theta_{0} \sum_{i=1}^{\infty} i x^{i}}{\theta_{0}+c \theta_{0} \sum_{i=1}^{\infty} x^{i}}
$$

As duas progressões geométricas aqui tem valores:

$$
\begin{gathered}
\sum_{i=1}^{\infty} x^{i}=\frac{x}{1-x} \\
\sum_{i=1}^{\infty} i x^{i}=\frac{x}{(1-x)^{2}}
\end{gathered}
$$

Substituindo essas progressões geométricas obtemos, após algum algebrismo:

$$
\frac{V}{V_{m}}=\frac{c x}{(1-x)(1-x+c x)}
$$

Quando $x=1$ a quantidade adsorvida $V$ é infinita assim como quantidade de camadas $(i=\infty)$. Nessas condições a pressão $p$ é igual a pressão de saturação $p_{0}$ e da definição de $x$ (equação B.9) conclui-se que:

$$
x=\frac{p}{p_{0}}
$$

Substituindo $x$ na equação B.15 e reordenando os termos, chegamos a forma linear da equação BET:

$$
\frac{p / p_{0}}{V\left(1-p / p_{0}\right)}=\frac{c-1}{V_{m} c}\left(\frac{p}{p_{0}}\right)+\frac{1}{V_{m} c}
$$




\section{Método BJH}

Para a dedução da expressão matemática do volume de poro pelo método BJH, considerese uma rede de poros cilíndricos de comprimento $l$ abertos em ambas extremidades sujeita a uma pressão relativa praticamente igual à unidade, de maneira que todos os poros estejam preenchidos. Levando em conta que poros com um mesmo raio respondem da mesma forma à variação de pressão relativa $\left(p / p_{0}\right)$, se a pressão relativa for diminuída de um valor muito pequeno o maior poro, de raio $r_{p 1}$, que está preenchido com um filme de espessura $t_{1}$ e um condensado capilar de raio $r_{k 1}$, terá seu condensado esvaziado e uma redução $\Delta t_{1}$ na camada de filme. Podemos relacionar o volume do gás dessorvido $\Delta V_{1}$ com o volume de poro através da seguinte razão:

$$
\frac{V_{p 1}}{\Delta V_{1}}=\frac{\pi r_{p 1}^{2} \cdot l}{\pi\left(r_{k 1}+\Delta t_{1}\right)^{2} \cdot l} \quad \Longrightarrow \quad V_{p 1}=\frac{r_{p 1}^{2}}{\left(r_{k 1}+\Delta t_{1}\right)^{2}} \Delta V_{1}
$$

Onde $V_{p 1}$ e $r_{k 1}$ são o volume e o raio de Kelvin do poro esvaziado durante a redução de pressão relativa, respectivamente.

Porém, quando efetuamos o segundo passo de dessorção, devemos considerar que o volume de gás dessorvido se deve não só à evaporação de gás da primeira camada de filme e do condensado capilar do segundo poro, mas também à evaporação da segunda camada de filme do poro anterior. Assim, o volume do segundo poro é:

$$
V_{p 2}=\frac{r_{p 2}^{2}}{\left(r_{k 2}+\Delta t_{2}\right)^{2}}\left(\Delta V_{2}-V_{\Delta t_{2}}\right)
$$

$\mathrm{Na}$ qual $\Delta V_{2}$ é o volume de gás dessorvido durante o segundo passo de dessorção, $V_{\Delta t_{2}}$ é volume de gás dessorvido devido a evaporação da segunda camada de filme do primeiro poro. $O$ volume $V_{\Delta t_{2}}$ pode ser calculado levando em conta a área média $A_{c}$ do capilar entre o primeiro e segundo passos de dessorção (vide figura C.1) no primeiro poro. Para isso podemos usar a razão entre as áreas $A_{c 1}$ e $A_{p 1}$ (área do poro de raio médio $\bar{r}_{p}$ de índice 1):

$$
\frac{A_{c 1}}{A_{p 1}}=\frac{2 \pi\left(\bar{r}_{p 1}-t_{\bar{r} 1}\right) \cdot l}{2 \pi \bar{r}_{p 1} \cdot l} \quad \Longrightarrow \quad A_{c 1}=\frac{\left(\bar{r}_{p 1}-t_{\bar{r} 1}\right)}{\bar{r}_{p 1}} A_{p 1}
$$

Onde $\bar{r}_{p}$ é o raio médio de poro, $t \bar{r}$ é a espessura média ${ }^{1}$ correspondente da camada de filme entre os primeiros e segundo passos da dessorção e $A_{p 1}=2 \cdot V_{p 1} / r_{p 1}$ é a área superficial específica de poro. $O$ volume devido à evaporação $\Delta t$ finalmente pode ser calculado através da relação $V_{\Delta t}=\Delta t \cdot A_{c}$. Fazendo essa substituição na equação C.2 temos:

\footnotetext{
${ }^{1} \mathrm{~A}$ área $A_{c}$ e a espessura $t_{\bar{r}}$ são a área e espessura estatística de filme correspondentes à pressão relativa equivalente ao raio médio $\bar{r}_{c}$.
} 


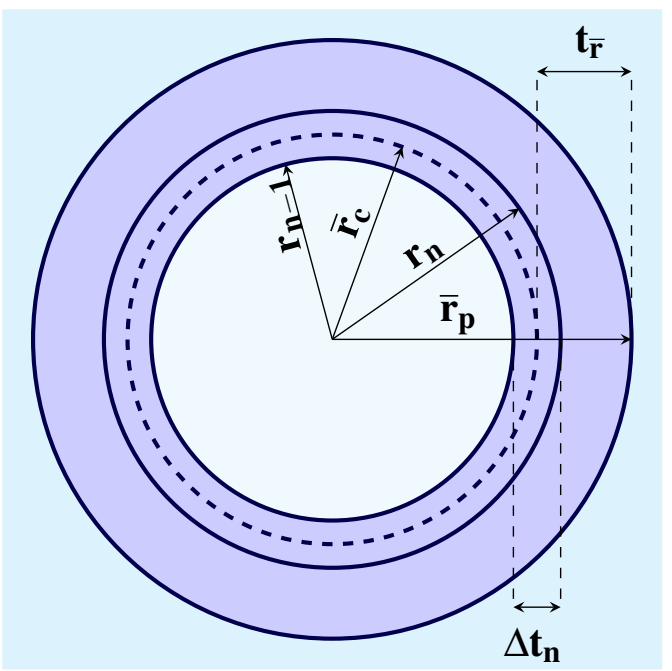

Figura C.1: Diagrama esquemático do processo de dessorção em um poro (BARRETT; JOYNER; HALENDA, 1951).

$$
V_{p 2}=\frac{r_{p 2}^{2}}{\left(r_{k 2}+\Delta t_{2}\right)^{2}}\left(\Delta V_{2}-\Delta t_{2} \cdot A_{p 1} \frac{\left(\bar{r}_{p 1}-t_{\bar{r} 1}\right)}{\bar{r}_{p 1}}\right)
$$

Aplicando esse método aos passos restantes, chega-se á conclusão que:

$$
V_{p n}=\frac{r_{p n}^{2}}{\left(r_{k n}+\Delta t_{n}\right)^{2}}\left(\Delta V_{n}-\Delta t_{n} \cdot \sum_{j=1}^{n-1} A_{p j} c_{j}\right)
$$

Onde $c_{j}=\frac{\left(\bar{r}_{p j}-t_{\overline{r j}}\right)}{\bar{r}_{p j}}$ 


\section{Formulação do método PIXE}

O modelo a seguir é baseado apenas nas emissões características $K$ do espectro.

Considere-se um feixe formado por um número $N_{p}$ de prótons que, ao incidir na amostra, percorre uma distância $d x$ em seu interior, como mostrado na figura D.1. O número de vacâncias $d N$ produzidas por esse feixe de prótons na camada $\mathrm{K}$ dos átomos da amostra é (JOHANSSON; CAMPBELL; MALMQVIST, 1995):

$$
d N=\frac{N_{p} N_{0} C_{Z} \sigma_{Z}(E) d E}{A_{Z} S_{M}(E)}
$$

Onde $N_{0}$ é o número de Avogadro, $C_{Z}$ é a concentração em massa, $A_{Z}$ é a massa atômica e $\sigma_{Z}(E)$ é a seção de choque da produção de vacâncias em função da energia do próton do elemento de número atômico $Z$. O fator $S_{M}(E)$ é o fator de freamento total da amostra e a sua definição $S_{M}=\rho^{-1}(d E / d x)$ relaciona a variação de energia do feixe com a distância percorrida no interior de uma amostra de densidade $\rho$.

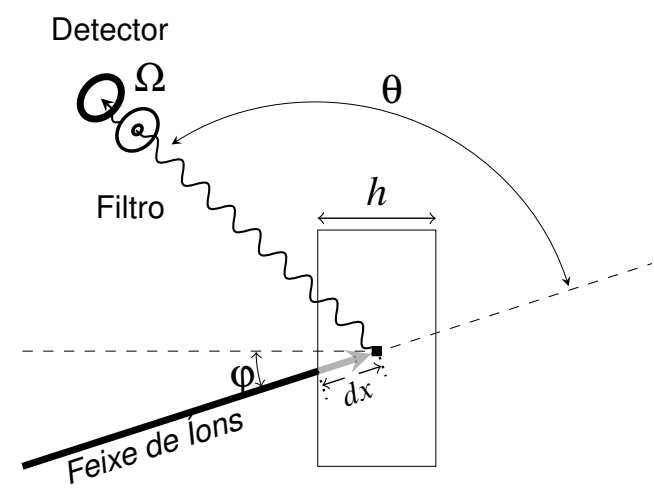

Figura D.1: Diagrama esquemático de um experimento de PIXE.

A intensidade $d Y$ da emissão característica $K$ está relacionada ao número de vacâncias $d N$ por (JOHANSSON; CAMPBELL; MALMQVIST, 1995):

$$
d Y(Z)=\frac{\Omega}{4 \pi} \omega_{Z} \cdot k_{Z} \cdot \varepsilon_{Z}^{i} T_{Z}(E) d N
$$

Onde $\Omega$ é o ângulo sólido, $\omega_{Z}{ }^{1}$ é o rendimento fluorescente, $k_{Z}$ é a probabilidade da linha de emissão $\mathrm{K}, \varepsilon_{Z}^{i}$ é a eficiência do detector e $T_{Z}(E)$ é o fator de transmissão dado pela lei de Lambert.

A energia do feixe varia enquanto atravessa a amostra. Assim, para determinar a intensidade total $Y$ a equação D.2 deve ser integrada entre os valores inicial $\left(E_{0}\right)$ e final $\left(E_{f}\right)$ de

\footnotetext{
${ }^{1}$ Este termo expressa a probabilidade da emissão de um fóton ao invés de um elétron Auger quando uma vacância é preenchida por um elétron de uma camada externa.
} 
energia. Substituindo D.1 na equação D.2, fazendo $N_{p}=Q / q e$ e integrando, a expressão para a intensidade fica:

$$
Y(Z)=\frac{\Omega}{4 \pi} \frac{N_{0} C_{Z}}{A_{Z}} \frac{Q}{q e} \varepsilon_{Z}^{i} \cdot \omega_{Z} \cdot k_{Z} \int_{E_{0}}^{E_{f}} \frac{T_{Z}(E) \cdot \sigma_{Z}(E)}{S_{M}(E)} d E
$$

$Q$ é a carga integrada do feixe, $q$ é o estado da $\operatorname{carga}^{2}, e$ é a carga elementar, $E_{0}$ é a energia de entrada e $E_{f}$ é a energia de saída do feixe de prótons.

\section{D.1 Alvos finos}

Se a amostra utilizada for fina o bastante de modo que os prótons praticamente não percam energia ao atravessá-la, simplificações podem ser realizadas na equação D.3. Nessa condição, o alcance do feixe é máximo, o fator de transmissão $T(E)$ se torna 1 e a seção de choque de produção de vacâncias torna-se uma constante $\sigma_{Z}\left(E_{0}\right)$. O poder de freamento pode ser substituído por:

$$
\int \frac{d E}{S_{M}}=\int d x \rho \cong \frac{h}{\cos \alpha} \rho
$$

Sendo que $h$ é a espessura da amostra e $\varphi$ é o ângulo de incidência.

Fazendo essas substituições na equação D.3 e também $\sigma_{Z}\left(E_{0}\right)=\sigma_{x}\left(E_{0}\right) /\left(\omega_{Z} \cdot k_{Z}\right)$, onde $\sigma_{x}$ é a seção de choque de produção de raios $\mathrm{X}$, obtemos:

$$
Y(Z)=\frac{\Omega}{4 \pi} \varepsilon_{Z}^{i} \frac{N_{0} C_{Z}}{A_{Z}} \frac{Q}{q e \cos \alpha} \sigma_{x}\left(E_{0}\right) \cdot h \cdot \rho
$$

Finalmente, substituindo a concentração em massa $C_{Z}=\rho_{Z} / \rho$, onde $\rho_{Z}$ é a densidade em massa do elemento de número atômico "Z", essa equação pode ser reescrita na forma:

$$
Y(Z)=r_{Z}^{i} \cdot Q \cdot\left(\rho_{Z} \cdot h\right) \text { sendo } r_{Z}^{i}=\frac{\Omega}{4 \pi} \varepsilon_{Z}^{i} \frac{N_{0}}{A_{Z}} \frac{\sigma_{x}\left(E_{0}\right)}{q \cos \alpha}
$$

Onde $r_{Z}^{i}$ é o fator de resposta para alvos finos.

O fator de resposta, também chamado de rendimento efetivo, é um termo que considera o arranjo experimental como a geometria, eletrônica e a eficiência do equipamento utilizado na aquisição dos dados.

\footnotetext{
${ }^{2}$ Para um feixe de prótons, $q=1$.
} 


\section{D.2 Alvos Grossos}

Quando a amostra é espessa a energia do próton incidente não é constante, já que ao atravessá-la ele vai perdendo velocidade. Assim, as simplificações para alvos finos não podem ser aplicadas e a integral da equação D.3 tem que ser resolvida. O fator de resposta para alvos grossos $R_{Z}^{i}$ é definido como:

$$
R_{Z}^{i}=\frac{\Omega}{4 \pi} \frac{N_{0}}{A_{Z} \cdot q \cdot e} \varepsilon_{Z}^{i} \int_{E_{0}}^{E_{f}} \frac{T_{Z}(E) \cdot \sigma_{X}(E)}{S_{M}(E)} d E
$$

O método proposto por Aburaya (2005) permite obter o fator de resposta para alvos espessos a partir do fator de resposta para alvos finos aplicando-se um fator de correção, cuja definição é:

$$
K=\frac{R_{Z}^{i}}{r_{Z}^{i}}
$$

De modo que a intensidade de emissão da linha $\mathrm{K}$ para alvos grossos pode ser escrita:

$$
Y=K \cdot r_{Z}^{i} \cdot C_{Z} \cdot Q
$$

